\title{
Theoretical and Experimental Investigation Into The Machining Performance in Axial Ultrasonic Vibration-Assisted Cutting of Ti6Al4V
}

He Sui ( $\sim$ hsui@cauc.edu.cn )

Civil Aviation University of China

Lifeng Zhang

Civil Aviation University of China

Shuang Wang

Civil Aviation University of China

Zhaojun Gu

Civil Aviation University of China

\section{Research Article}

Keywords: Ti6Al4V alloy, Axial ultrasonic vibration-assisted cutting, Machining performance, Cutting force, Tool life, Surface roughness

Posted Date: April 1st, 2021

DOl: https://doi.org/10.21203/rs.3.rs-362141/v1

License: (9) This work is licensed under a Creative Commons Attribution 4.0 International License. Read Full License 


\title{
Theoretical and experimental investigation into the machining performance in axial ultrasonic vibration-assisted cutting of Ti6Al4 V
}

\author{
He Sui ${ }^{\mathrm{a}, *}$, Lifeng Zhang ${ }^{\mathrm{a}}$, Shuang Wang ${ }^{\mathrm{b}}$, Zhaojun $\mathrm{Gu}^{\mathrm{b}}$ \\ ${ }^{a}$ College of Aeronautical Engineering, Civil Aviation University of China, Tianjin 300300, China \\ ${ }^{\mathrm{b}}$ Information Security Evaluation Center of Civil Aviation, Civil Aviation University of China, Tianjin 300300, China \\ *Corresponding author.Tel. /fax: +86022 24092294. E-mail address: hsui@cauc.edu.cn (H. Sui)
}

\begin{abstract}
Axial ultrasonic vibration-assisted cutting (AUVC) has proved to have better machining performance compared with conventional cutting methods; however, the effect of numerous and complex influencing factors on machining performance has not been clearly revealed and a recommended combination of cutting conditions has not been proposed yet, especially for difficult-to-machine material such as Ti6A14V alloy. This paper focuses on experimental and theoretical investigation into machining performance when cutting Ti6Al4V with the AUVC method. First, a retrospective of the separation characteristics of AUVC is provided and the variable parameter cutting characteristics are demonstrated. We classify the influencing factors on machining performance into four categories: machining parameters, vibration parameters, tool choice, and cooling conditions. The relationship between these factors in terms of their effect on machining performance is established theoretically. Then, it describes experiments to determine the influence of these factors on cutting force, tool life, and surface roughness. For absolute influence, the orders for cutting force, tool life, and surface roughness are respectively cutting depth > amplitude > feed rate > rotation speed, rotation speed $>$ feed rate $>$ amplitude $>$ cutting depth, and feed rate $>$ amplitude $>$ cutting depth $>$ rotation speed. However, for relative influence, the order is unified as: amplitude > feed rate > rotation speed > cutting depth. Finally, it suggests a smaller feed rate, larger amplitude, moderate rotation speed, and smaller cutting depth in addition to a WC tool coated with TiAlN and used under HPC cooling condition for optimal performance of AUVC. This recommendation is based on the theoretical analysis and experimental results of cutting force, surface roughness, and tool life.
\end{abstract}

Key words: Ti6A14V alloy; Axial ultrasonic vibration-assisted cutting; Machining performance; Cutting force;

Tool life; Surface roughness

\section{Introduction}

Saoubi et al. [1] reported that Ti6Al4V alloy has attracted tremendous attention and been extensively applied for structural components in aerospace industries due to its excellent strength to weight ratio, toughness at high temperature, and corrosion resistance. As a mechanical processing technique, cutting has been one of the fastest and most effective operations to provide the final shape of Ti6Al4V alloy components with the required geometric accuracy and performance parameters. However, Amin et al. [2] pointed out about thirteen years ago that the key challenge was the difficulty in efficiently cutting Ti6Al4V alloy, because of its low thermal conductivity. Venugopal 
et al. [3] observed a narrow region adjacent to the cutting edge when high-speed machining Ti6Al4V alloy, where the temperature could be as high as $1,000^{\circ} \mathrm{C}$ due to the low thermal conductivity and high heat capacity. As a result, Zheng et al. [4] and other researchers universally acknowledged that Ti6Al4V was a typical difficult-to-machine material.

The choice of cutting method is very important for Ti6Al4V processing, and ultrasonic vibration cutting (UVC) has been proved to be one of the most effective methods for difficult-tomachine material. Michalski et al. [5] researched the flow stress reduction of metallic materials due to superimposed ultrasonic vibration, and they revealed the correlation between the ultrasonic vibration and earlier material failure, which is attributed to enhanced crack initiation and propagation caused by local stress and strain concentration as well as intermittent high strain rates. Chen et al. [6] developed an ultrasonic vibration helical milling process for machining of Ti6Al4V alloy and reported the axial cutting force reduction up to $64 \%$ and improvement of surface roughness and compressive residual stress. Wang et al. [7] presented a mathematical model for system matching in ultrasonic vibration assisted grinding (UVG) of brittle materials, and revealed the mechanism of grinding force reduction and grinding quality improvement in UAG. Geng et al. [8] revealed the intermittent cutting action of cutting edges in rotary ultrasonic elliptical machining (RUEM) of thick CFRP material, and achieved a better machining performance of temperature reduction, chip adhesion prevention and better microstructures of the machined hole surfaces. The literature above has showed that the UVC method was not only suitable for metallic materials and common alloy materials, but also for hard and brittle materials, and composite materials.

However, conventional UVC is a low-cutting-speed method due to the critical speed, and the advantages gradually disappear as cutting speed increases. For this reason, the author and others [9] proposed a high-speed ultrasonic vibration cutting method which could realize high-speed cutting on a macro level and separation cutting on the micro level, on the order of microseconds. Further studies indicated that its superior performance was not only in the high-speed cutting range but also in the conventional cutting speed range. It is more appropriately called axial ultrasonic vibrationassisted cutting (AUVC), since ultrasonic vibration has always been added in the axial direction of the ultrasonic transducer.

Some studies have been conducted on this method and great progress has been made. Zhang et al. [10] theoretically analyzed and experimentally verified the influence of flank face interference and tool wear on the separation process, with focused analysis of a partial separation state due to flank face interference (in addition to continuous cutting and complete separation). The author and others [11] further analyzed the transient separation characteristic of AUVC and its influence on cutting performance. In addition, Zhang et al. [12] developed an analytical cutting force model taking into account elastic recovery on the flank face and plowing by the round cutting edge, and the experimental results were in agreement with the model. To observe and measure the microcosmic process of AUVC, Zhang et al. [13, 14] also established measurement systems for the ultrasonic-frequency repetitive impulse signal and the thermocouple temperature to measure the impulse cutting force and average cutting temperature. Furthermore, Jiang et al. [15] proposed a 
phase shift control method with closed-loop direct digital synthesis to guarantee more regular surface topography of the machined material.

AUVC was also successfully applied in the machining of Ti6Al4V alloy. Liu et al. [16] found that AUVC had a positive impact on delaying tool wear and extending tool life up to 6.4 times. Moreover, lower cutting force and thinner and shorter chips were achieved with AUVC. They [17] also reported that AUVC resulted in higher compressive residual stresses on the machined surface, greater plastic deformation below it, and moderated surface work-hardening. Lu et al. [18] found that combining the separation cutting of AUVC with the high-pressure coolant method could effectively enhance tool life by up to 6 times at a higher cutting speed of $400 \mathrm{~m} / \mathrm{min}$.

Tools are also one of the most critical factors in machining Ti6Al4V. Coated tungsten carbide (WC) and CBN tools are good choices, and widely used. Zoya and Krishnamurthy [19] studied CBN tool performance in cutting Ti6Al4V very early, and recommended a critical temperature of $700^{\circ} \mathrm{C}$ and a cutting speed range of $185-220 \mathrm{~m} / \mathrm{min}$. Wang et al. [20] developed a binderless cubic boron nitride (BCBN) tool, which achieved a longer tool life. Mao et al. [21] developed a single cBN-WC10Co fiber tool for machining Ti6Al4V, and observed three types of tool wear including wear at the cutting edge, abrasion on the local flank face, and abrasion on the new flank face.

However, coated WC tools, especially with TiAlN coating, have been more widely used for machining Ti6Al4V due to better cost performance. Uddin et al. [22] investigated and analyzed the wear mechanisms of TiAlN-coated carbide tool and discovered that they had an approximately $44 \%$ longer life than uncoated tools. Caliskan and Kucukkose [23] studied the wear behavior of carbide tools with a new CN/TiAlN coating. Abrasion and adhesion were found to be the major wear modes and flank wear, chipping, and build-up edge were the dominant tool failures. Chowdhury et al. [24] also researched the effect of TiAlN coating on the wear performance of cemented carbide, and achieved a longer tool life performance than uncoated cemented carbide tools. Singh et al. [25] reported better tribological behavior and wear performance of TiAlN-coated cutting tools, and a friction reduction of $16 \%$ to $39 \%$ with textured tools. Denkena et al. [26] pointed out that some tool shape modifications such as honed and chamfered cutting edges and cutting edge micro geometry can reduce cutting force and tool wear, in addition to facilitate longer tool life. Kuntoğlu and Sağlam [27] used Taguchi to predict and evaluate progressive tool wear and gave the optimization result of machining parameters during turning process. Toubhans et al. [28] also investigated tool wear and surface integrity in terms of the influence of cutting parameters based on a mechanistic cutting force model. They also validated this original model over a wide range of finishing parameters, which is of great significance to the practical application of this model.

Cooling conditions also play an important role in machining Ti6Al4V. Debnath et al. [29] showed that high-pressure coolant (HPC) supply was an alternative method to conventional flood coolant supply to reduce fluid consumption. Salah et al. [30] also presented a controlled cutting fluid impinging supply system (Cut-list), which reduced cutting fluid consumption by up to $42 \%$, as well as reducing tool flank wear and burr height when machining Ti6Al4V. Klocke et al. [31] and Sadik et al. [32] compared the performance of wet cooling and cryogenic coolant. They reported that wet 
cooling especially HPC could reduce flank wear, however cryogenic coolant gave a better surface finish. Bordin et al. [33] reported that tool life was increased by 9 times and cutting speed could be improved by $30 \%$ for the same tool life with HPC, thus improving productivity dramatically. Mia et al. [34] conducted experiments by turning Ti6Al4V using coated carbide tools with both dry cutting and HPC. The pressurized coolant was directed towards the rake and flank face of the tool, and the applied coolant prolonged tool life by approximately $40 \%$. They $[35,36]$ also presented two studies under dry and HPC conditions. One was focused on prediction of the cutting temperature and chip reduction coefficient; the other concentrated on optimization of the aforementioned quality indices with respect to cutting speed, feed rate, and other conditions.

As an emerging advanced cutting method, AUVC is being widely applied, albeit gradually, for machining Ti6Al4V. However, the influence of the cutting parameters (rotation speed, feed rate, and cutting depth), vibration parameters (frequency and amplitude), tool materials (WC and CBN) and cooling conditions (dry, fluid, and HPC) on cutting performance (cutting force, tool life, and surface roughness) has not been studied systematically and the relationships among the relevant parameters in the machining process also have not been clarified. Therefore, it is impossible to give an explicit parameter selection and optimization path for actual use, which has become a major restriction on the further application of this method.

This paper focuses on further experimental and theoretical investigation into cutting performance in the AUVC process for Ti6Al4V machining, with different cutting parameters, vibration parameters, tool materials, and cooling conditions. And then efforts have been made to assess the complex relationships among these factors and provide an explicit selection and recommendation for the sake of comprehensively improving the cutting performance of AUVC.

\section{Theoretical Analysis}

\subsection{Separation characteristic}

Unlike the traditional UVC process, the vibration in AUVC is applied along the axial direction (which is the feed direction in this paper). As shown in Fig. 1(a), in a typical cylindrical coordinate system, vibration occurs along the z-axis; however cutting is performed along the circumferential tangential direction. Then, the kinematic trajectories of the tool within several adjacent rotations cross each other and form a cutting duration and a separation duration, which is the separation characteristic of AUVC, as exhibited by the extended plane of the workpiece's surface in Fig. 1(b).

It is clear that the two adjacent cutting trajectories intersect each other, and this is the embodiment of the separation characteristic of AUVC. The author and others (2017) has given the critical conditions of the separation characteristic and calculation equation, which is as follows:

$$
\left\{\begin{array}{l}
K_{\mathrm{f}}<2 \\
2 \arcsin \left(\frac{K_{\mathrm{f}}}{2}\right) \leq \varphi \leq 2 \pi-2 \arcsin \left(\frac{K_{\mathrm{f}}}{2}\right)
\end{array}\right.
$$


(a) A typical cylindrical coordiaste system

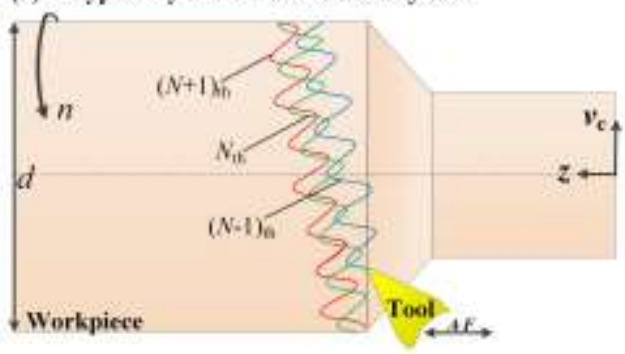

(b) The extended plane of the workpiece to be machined

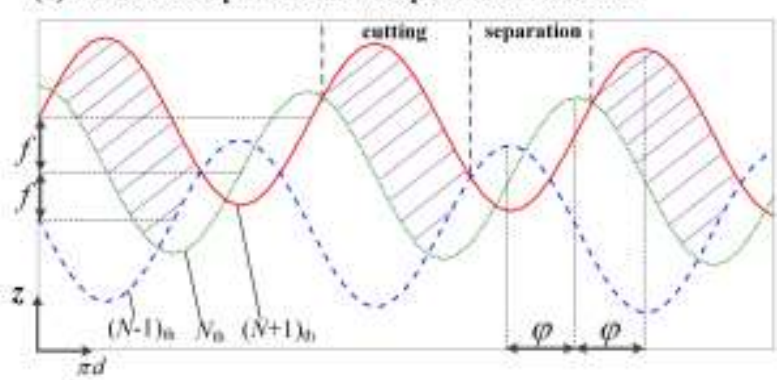

Fig. 1 Schematics of the AUVC process and its separation characteristic

where, $K_{\mathrm{f}}$ is a dimensionless coefficient, namely feed coefficient, which is the ratio of feed rate and ultrasonic vibration amplitude; $\varphi$ is the phase shift between two adjacent tool trajectories, rad. It can be defined as:

$$
\varphi=2 \pi \cdot \lambda=2 \pi \cdot\left[w_{\mathrm{F}}-\mathrm{INT}\left(w_{\mathrm{F}}\right)\right]
$$

where, INT( ) means round down, and $w_{\mathrm{F}}$ is also a dimensionless coefficient, namely cutting frequency ratio, which is the ratio of the vibration frequency and the spindle speed. It is defined as:

$$
w_{\mathrm{F}}=60 \cdot \frac{F}{n}
$$

Then the cutting tool trajectory can be expressed as:

$$
z(\theta)=A \sin \left(w_{F} \theta\right)+\frac{f}{2 \pi} \theta
$$

where, $\theta \in[0,2 \pi]$ is the rotation angle of the machine spindle, rad.

\subsection{Variable parameter cutting characteristics}

According to Eq. (4), the relationship between the tool trajectories and rotation angle in several adjacent rotations for AUVC and conventional cutting (CC) can be easily simulated by MATLAB, as shown in Fig. 2.

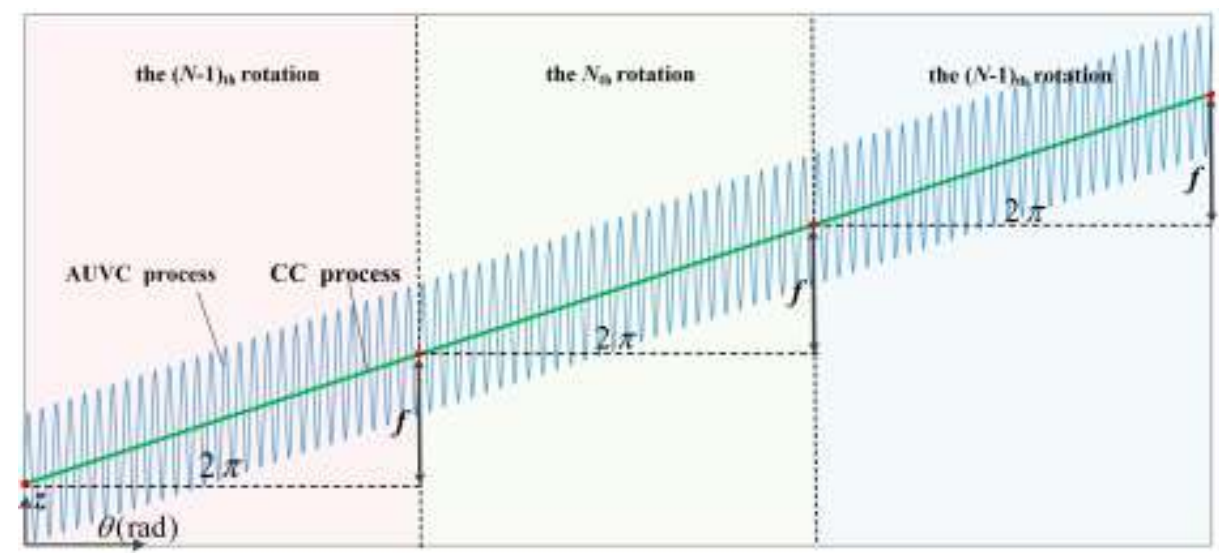

Fig. 2 Relationship of cutting trajectories and rotational angle in several adjacent rotations 
For the $\mathrm{CC}$ process, the relationship between the tool trajectories and rotational angle is a straight line, while it seems to change periodically for AUVC. It is not difficult to see that in the AUVC process, actual feed cutting speed is always changing as a result of the vibration occurring along the feed direction. This also means that the cutting layer changes, because of changes in actual cutting thickness and actual cutting width. Furthermore, the first derivative and the second derivative (i.e. the actual feed cutting speed and actual feed cutting acceleration) of the tool trajectory can be given as:

$$
\left\{\begin{array}{l}
v_{z}(\theta)=2 \pi A F \cos \left(w_{F} \theta\right)+\frac{n f}{60} \\
a_{z}(\theta)=-4 \pi^{2} A F^{2} \sin \left(w_{F} \theta\right)
\end{array}\right.
$$

where, $\frac{n f}{60}$ is the nominal feed cutting speed, while $2 \pi A F \cos \left(w_{F} \theta\right)$ is the additional value caused by vibration. Similarly, the nominal feed cutting acceleration is 0 for $\mathrm{CC}$, however a value of $-4 \pi^{2} A F^{2} \sin \left(w_{F} \theta\right)$ is added for AUVC.

It can be seen that the actual feed cutting speed and acceleration also change according to a harmonic curve, as shown in Fig.3. The impact effect caused by this periodic change greatly influences material removal. With higher feed cutting acceleration, the impact of a cutting edge with higher kinetic energy on the material can cause stress concentration and local deformation in the cutting area, accelerating the formation of chips and improving the material removal rate. At the same time, the negative velocity and acceleration in the feed direction also make it possible for the tool to separate from the processed material, which is the reuse basis of the separation characteristics of AUVC.
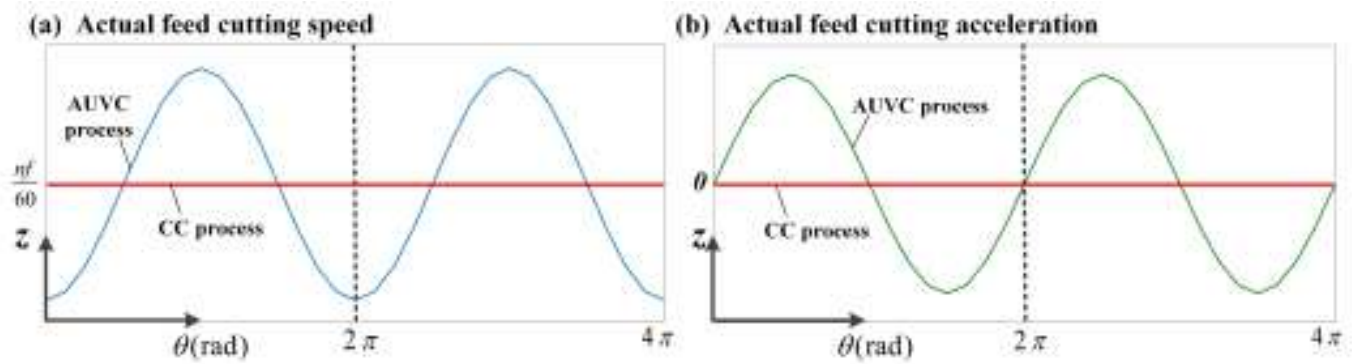

Fig. 3 The actual feed cutting speed and acceleration curve of AUVC

As a result of the harmonic actual feed cutting speed and acceleration, AUVC is a complex cutting process with a curvilinear path. As demonstrated in the above analysis, the actual rake angle and clearance angle in the AUVC process also change as the cutting trajectory develops, which is similar to an elliptical vibration cutting (EVC) process. Fig. 4 shows the evolution process of the actual rake angle and clearance angle in one AUVC cycle.

$M_{1}-M_{2}-M_{3}-M_{4}$ is a typical AUVC cycle, which is divided into three stages: cut-in stage $M_{1}-M_{2}$, cut-out stage $M_{2}-M_{3}$, and separation stage $M_{3}-M_{4}$. In the cut-in stage, the tool begins to contact the workpiece from $M_{l}$, and the cutting thickness gradually increases to the maximum at the deepest cutting point $M_{2}$. In this stage, the actual rake angle is larger than the nominal value, and the actual 
clearance angle is smaller than the nominal value. The actual rake angle reaches its maximum and the actual clearance angle reaches its minimum together in point $M_{2}$.

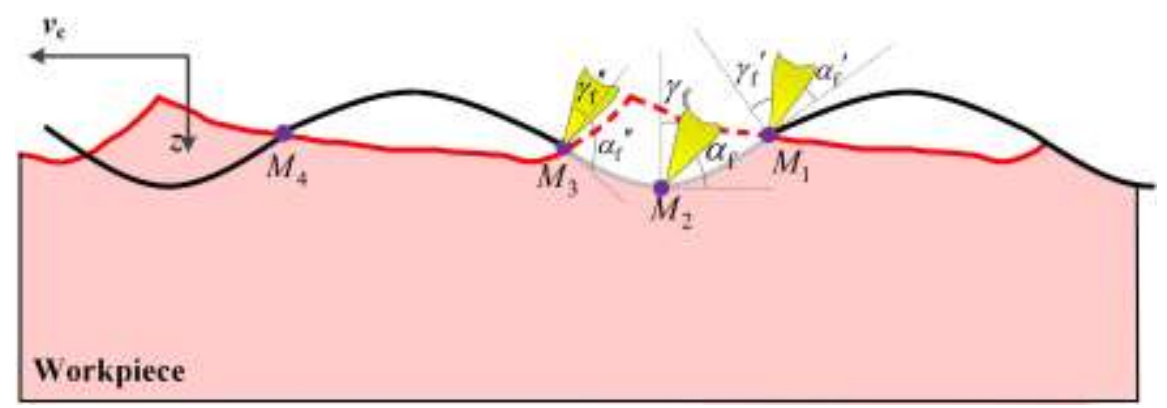

Fig. 4 Evolution process of the actual rake angle and clearance angle change in one AUVC cycle

Then, the cycle moves into the cut-out stage. The cutting thickness decreases gradually, but the cutting speed along the direction of the cutting thickness increases gradually and synchronously. When the speed is greater than the chip flow, the friction between the tool and the chips on the rake face will reverse, thus contributing to the chip discharges. When the tool reaches $M_{3}$, the cutting process for this cycle is over, and the tool separates from the workpiece and chips. In this stage, the actual clearance angle gradually decreases and even appears to have a negative value, while the actual clearance angle gradually increases and may be larger than its nominal value. In point $M_{3}$, the former reaches its minimum and the latter reaches its maximum.

Then, the cycle is in the separation stage until the tool cuts into the workpiece again at point $M_{4}$ and starts to repeat this process in the next cycle. So in a vibration cutting cycle, the actual rake angle and clearance angle change as follows:

$$
\left\{\begin{array}{l}
\gamma=\gamma_{0}-\arctan \frac{2 \pi A F \cos \left(-\frac{60 F}{n} \theta\right)+\frac{n f}{60}}{n \pi d} \\
\alpha=\alpha_{0}+\arctan \frac{2 \pi A F \cos \left(-\frac{60 F}{n} \theta\right)+\frac{n f}{60}}{n \pi d}
\end{array}\right.
$$

where, $\gamma_{0}$ and $\alpha_{0}$ are the nominal rake angle and clearance angle, rad; $d$ is the diameter of the workpiece, $\mathrm{mm}$.

Related research has shown that the frequency and range of the actual rake angle change has great influence on the stability of a cutting system. Compared with a fixed rake angle, the periodic variation of the rake angle can effectively improve the stability of the cutting process and suppress chatter. At the same time, the increase of rake angle in the cut-in stage and the tool's pull effect on chips in the cut-out stage are both conducive to the reduction of cutting force, so as to improve cutting accuracy.

\subsection{Influencing factors in machining performance}

Based on the above analysis and combined with the author's previous research, there are numerous and complex factors influencing the machining performance of AUVC. In general, if the 
workpiece is determined, then these factors can be classified into four categories: machining parameters (rotation speed, feed rate, and cutting depth), vibration parameters (frequency and amplitude), tool choice (nominal angles, tool nose radius, and tool material and coating) and cooling conditions (dry, wet, and advanced methods). The relationships among these factors and their influence on the machining performance of AUVC is summarized in Fig. 5.

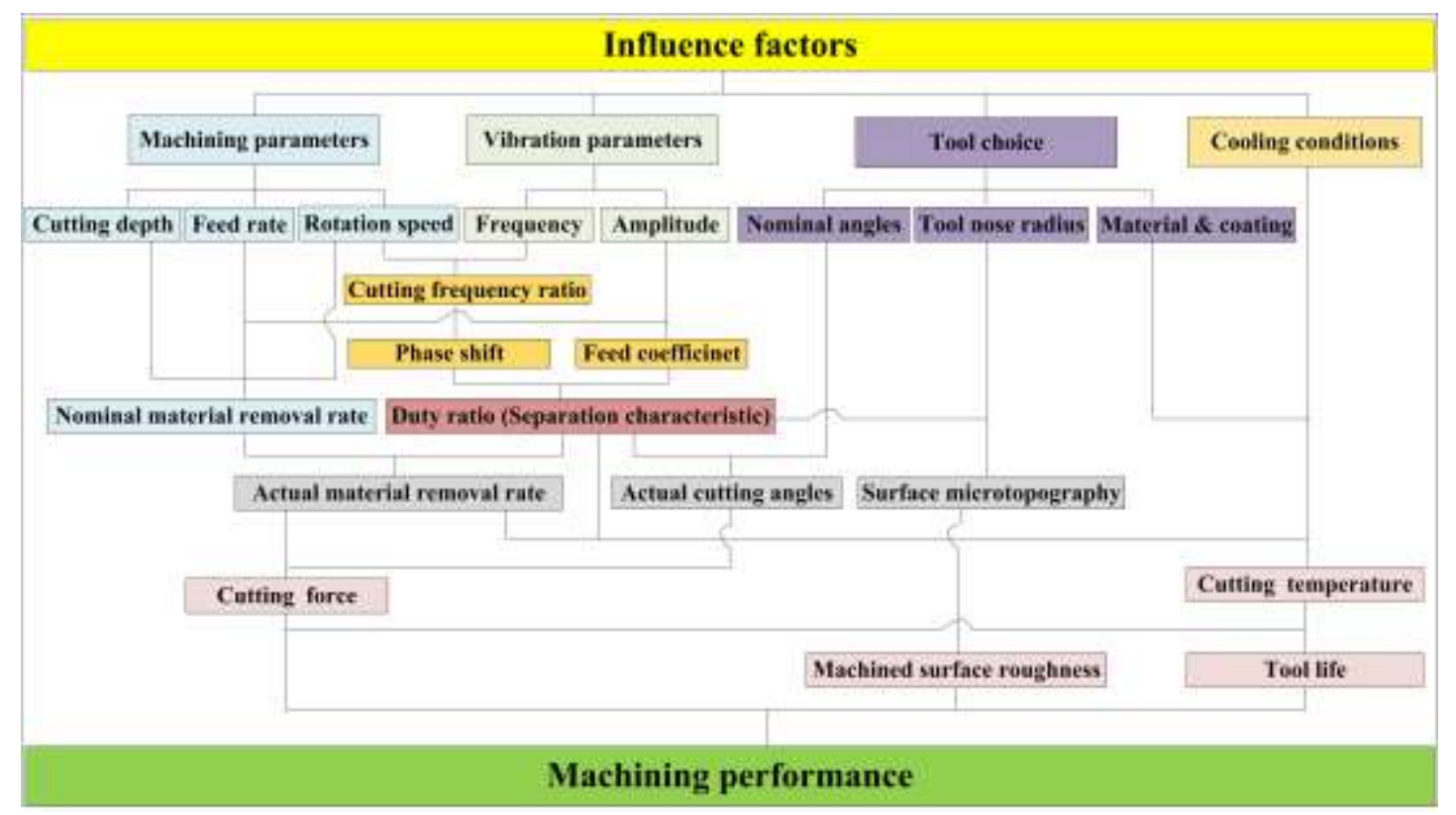

Fig. 5 Relationship among the influencing factors on the machining performance of AUVC

Each factor has a different influence on the final machining performance. Machining parameters of rotation speed, feed rate, and cutting depth jointly determine the nominal material removal rate. Rotation speed and feed rate also indirectly determine the duty ratio, together with vibration parameters (frequency and amplitude) via phase shift and feed coefficient. Duty ratio is the core parameter of AUVC, representing its separation cutting ability. On one hand, it determines the actual material removal rate and actual cutting angles, which ultimately determine the cutting force. On the other hand, it affects the surface micromorphology combined with the tool nose radius, which is related to the machined surface roughness. Duty ratio, cooling conditions, and tool material and coating also determine the cutting temperature. Cutting force and cutting temperature are the main aspects that should be considered in relation to tool life. Cutting force, machined surface roughness, and tool life always allow direct characterization of cutting performance for a machining method.

To recommend better machining condition choices, one must concentrate on the main influencing factors and parameters that characterize machining performance. It is important to note that each of these factors is more or less responsible for overall cutting force, surface roughness, and tool life. In order to explore a feasible parameter optimization path, only the main influencing factors should be taken into consideration and further researched; secondary factors should be ignored in order to avoid unnecessary interference (see Fig. 5). 


\section{Experimental design}

\subsection{Workpiece material}

The experiments were conducted on Ti6Al4V alloy. The chemical compositions and mechanical properties of the material are presented in Tables 1 and 2 . The material block was cut into a cylinder size of $60 \mathrm{~mm} \times 240 \mathrm{~mm}(d \times l)$ and the end and cylinder surfaces of the workpiece were further rough machined with a very shallow cut. This process used a cylinder blank workpiece of $62 \mathrm{~mm} \times 243 \mathrm{~mm}(d \times l)$ with a feed rate of $0.1 \mathrm{~mm} / \mathrm{r}$ and a cutting speed of $40 \mathrm{~m} / \mathrm{min}$.

Table 1 Chemical compositions of Ti6Al4V alloy (wt. \%)

\begin{tabular}{ccccccccc}
\hline $\mathbf{T i}$ & $\mathbf{A l}$ & $\mathbf{V}$ & $\mathbf{F e}$ & $\mathbf{S i}$ & $\mathbf{C}$ & $\mathbf{N}$ & $\mathbf{H}$ & $\mathbf{O}$ \\
\hline balance & 6.35 & 4.1 & 0.25 & $<0.01$ & 0.06 & 0.04 & 0.011 & 0.18 \\
\hline
\end{tabular}

Table 2 Mechanical properties of Ti6Al4V at $20^{\circ} \mathrm{C}$

\begin{tabular}{ccccc}
\hline $\begin{array}{c}\text { Hardness } \\
(\text { HRC })\end{array}$ & $\begin{array}{c}\text { Elastic modulus } \\
(\mathbf{G P a})\end{array}$ & $\begin{array}{c}\text { Yield strength } \\
(\mathbf{M P a})\end{array}$ & $\begin{array}{c}\text { Tensile strength } \\
(\mathbf{M P a})\end{array}$ & $\begin{array}{c}\text { Density } \\
\left(\mathbf{k g} \cdot \mathbf{m}^{\mathbf{3}}\right)\end{array}$ \\
\hline 36 & 112 & 840 & 985 & 4500 \\
\hline
\end{tabular}

\subsection{Ultrasonic vibration system and cutting tool choice}

Fig. 6 depicts the ultrasonic vibration system, which consisted of an ultrasonic power supply and an ultrasonic transducer. The power supply was self-developed, with phase shift control and power regulation functions. The transducer used in this study was also self-developed. Its resonant frequency was $22183 \mathrm{~Hz}$ and maximum amplitude was $9 \mu \mathrm{m}$. The amplitude could be changed by adjusting the output power.
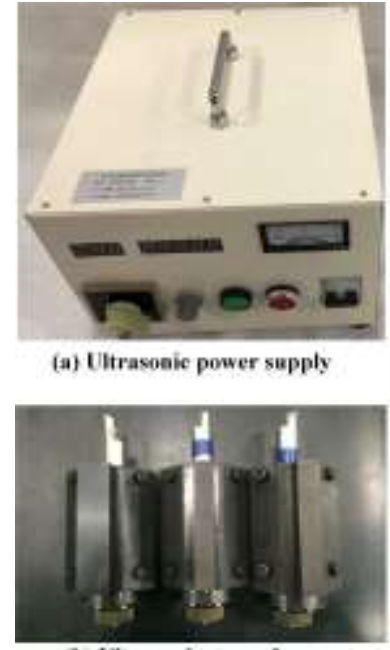

(h) Ultrasonic trunsducer

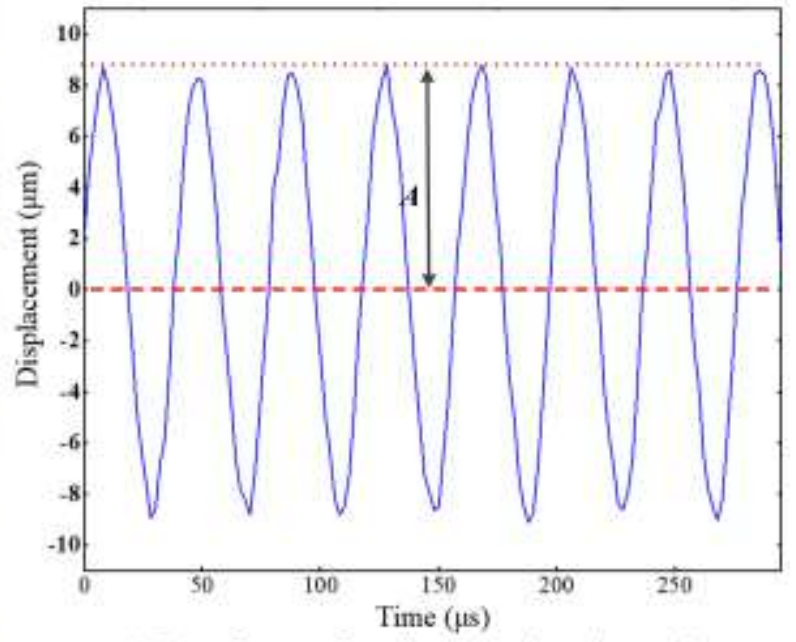

(C) Actaal measured amplitude of th ultrasonic transdacer

Fig. 6 Ultrasonic vibration system and its maximum amplitude

Tungsten carbide (WC) tool inserts coated via physical vapor deposition (PVD) method, made by Zhuzhou Co., Ltd and CBN tool inserts made by Sandvik Co., Ltd have been used in these 
experiments. Both of these tools were triangular inserts with $0^{\circ}$ rake angle, $7^{\circ}$ clearance angle, and $0.2 \mathrm{~mm}$ tool nose radius. The coating of the tungsten carbide (WC) tool was TiAlN, and the hard particles were bonded together by cobalt $(\mathrm{Co})$. The physical and mechanical properties of tungsten carbide (WC) and the TiAlN coating are summarized in Tables 3 and 4. As another common choice for Ti6Al4V machining, a type of PCBN tool was chosen here. The physical and mechanical properties of PCBN tools are summarized in Table 5. Before the actual cutting experiments, the edges of all the inserts were observed to be sharp and clean without any dirt.

Table 3 Physical and mechanical properties of tungsten carbide base (WC)

\begin{tabular}{cccc}
\hline Hardness(HV 10$)$ & Density/(g・m-3) & Elastic modulus/GPa & Particle size/ $\mathbf{\mu m}$ \\
\hline 1510 & 14.7 & 580 & 0.8 \\
\hline
\end{tabular}

Table 4 Physical properties of the TiAIN coating

\begin{tabular}{ccccc}
\hline Type & Material & Thickness $/ \boldsymbol{\mu m}$ & ${\text { Melting point } /{ }^{\circ} \mathbf{C}}$ & Hardness $\left(\mathbf{H V}_{\mathbf{1 0}}\right)$ \\
\hline PVD & TiAlN & 4 & 3070 & 2300 \\
\hline
\end{tabular}

Table 5 Physical and mechanical properties of PCBN

\begin{tabular}{ccccc}
\hline $\begin{array}{c}\text { Hareness } \\
(\mathbf{K n o o p s}) \mathbf{G P a}\end{array}$ & $\begin{array}{c}\text { Density } \\
\left(\mathbf{g} / \mathbf{c m}^{\mathbf{3}}\right)\end{array}$ & $\begin{array}{c}\text { Thermal conductivity at } \\
\mathbf{2 0} \mathbf{C}(\mathbf{W} / \mathbf{m} \cdot \mathbf{K})\end{array}$ & $\begin{array}{c}\text { Substrate grain size } \\
(\boldsymbol{\mu m})\end{array}$ & $\begin{array}{c}\text { Composition } \\
(\mathbf{w t} \%)\end{array}$ \\
\hline \multirow{2}{*}{27.5} & 4.17 & 44 & 2 & $50 \% \mathrm{CBN}, 50 \%$ \\
& & & & $\mathrm{TiC}$ ceramic $(\mathrm{Vol})$ \\
\hline
\end{tabular}

\subsection{Experimental setup}

A CNC-controlled HASS-SL40 machine center has been used in these experiments. For cutting parameters, a range of $1200-2400 \mathrm{r} / \mathrm{min}$ rotation speed and the cutting depth of $0.025-0.1 \mathrm{~mm}$ are selected. In consideration of the separation criteria of AUVC, feed rate should not exceed the maximum peak-valley amplitude. Therefore, the feed rates among $0.005-0.014 \mathrm{~mm} / \mathrm{r}$ are chosen. All cutting parameters and ultrasonic vibration parameters are listed in Table 6.

Table 6 Ultrasonic vibration and cutting parameters

\begin{tabular}{ccccc}
\hline $\begin{array}{c}\text { Frequency } \\
(\mathbf{H z})\end{array}$ & $\begin{array}{c}\text { Peak-valley amplitude } \\
(\boldsymbol{\mu m})\end{array}$ & $\begin{array}{c}\text { Depth of cut } \\
(\mathbf{m m})\end{array}$ & $\begin{array}{c}\text { Rotation speed } \\
(\mathbf{r} / \mathbf{m i n})\end{array}$ & $\begin{array}{c}\text { Feed rate } \\
(\mathbf{m m} / \mathbf{r})\end{array}$ \\
\hline \multirow{2}{*}{22183} & 18 & $0.025-0.01$ & $1200-2400$ & $0.005-0.014$ \\
\hline
\end{tabular}

Three kinds of cooling conditions are taken into account for these experiments: dry, conventional coolant and high pressure coolant (HPC). The fluid used here was water soluble oil emulsion of $6 \%$ concentration, and it is applied by means of either high-pressure cooling with 15Mpa pressure or flood cooling. Table 7 shows the detailed cooling conditions. 
Table 7 Detailed cooling conditions

\begin{tabular}{cccc}
\hline Cooling method & $\begin{array}{c}\text { Coolant pressure } \\
(\mathbf{M p a})\end{array}$ & Flow rate $(\boldsymbol{L} / \mathbf{m i n})$ & $\begin{array}{c}\text { Distance of coolant application } \\
(\boldsymbol{m m})\end{array}$ \\
\hline $\begin{array}{c}\text { Conventional coolant } \\
\text { High pressure coolant } \\
(\text { HPC })\end{array}$ & - & 2.7 & 10 \\
\hline
\end{tabular}

The average cutting force was measured with a 3-component Kistler 9254 dynamometer. Tool wear was observed and measured with an Olympus OLS4100 microscope with a maximum magnification of 1000x. A HITACHI SU8000 scanning electron microscope was also used to take SEM photographs and to conduct EDX analysis on the cutting tools. As ISO standard 3685, tool rejection or failure was determined based on the following criteria: 1) Average flank wear $\mathrm{VB}=0.2 \mathrm{~mm}$; 2) Maximum flank wear $\mathrm{VB}_{\max }=0.3 \mathrm{~mm}$; 3) Excessive chipping/flaking or catastrophic fracture of the cutting edge.

Roughness of the machined surface was measured by a Tylor Hobson Rough-meter with a measurement accuracy of $0.001 \mu \mathrm{m}$. To ensure the accuracy of experiments, they were all carried out more than 3 times under the same conditions; the experiment platform is shown in Fig. 7.

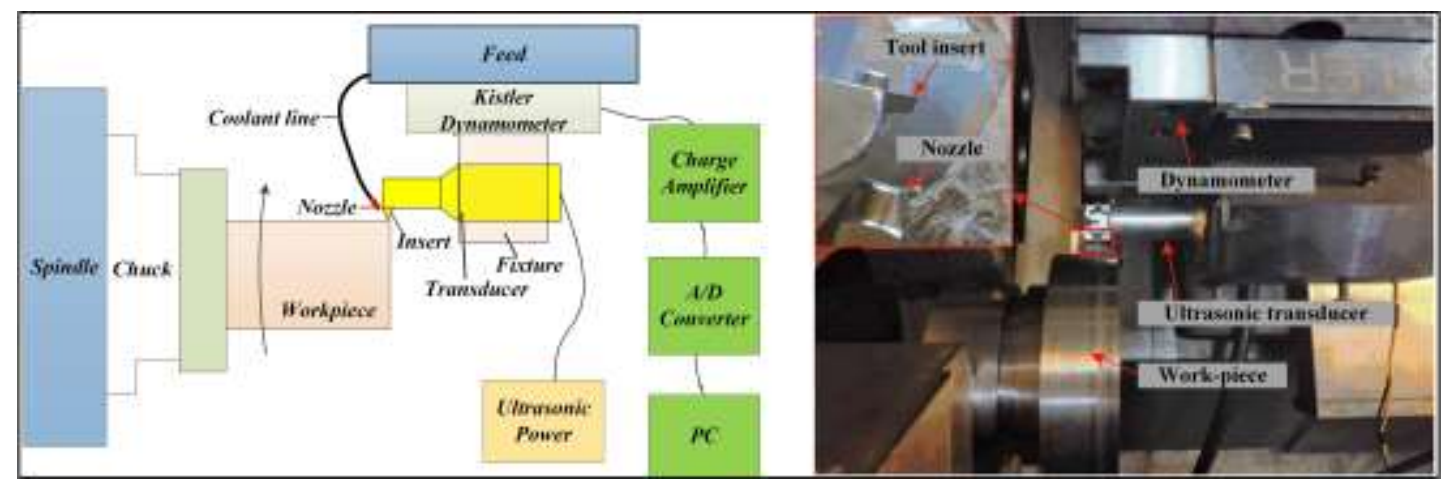

Fig. 7 The experiment platform

As described above, nominal tool angles, tool nose radius, and ultrasonic vibration frequency were determined in advance, so when the experiments were conducted, we looked for other factors. However, each factor has a different influence on different machining performance in dices. For cutting force, the main influence factors were cutting parameters, ultrasonic vibration amplitude, and tool material. However, coolant impact on the transducer caused an error in the measurement results, so, we measured cutting force under dry cutting conditions. Then we added cooling conditions when tool life experiments are conducted. As for the machined surface, in order to avoid interference from tool failure, all the experiments were conducted under either coolant conditions or HPC conditions. Different factors which we considered for different characterizations of machining performance in AUVC were:

- Cutting force: cutting depth $\mathrm{a}_{\mathrm{p}}$, rotation speed $n$, feed rate $f$, amplitude $A$ and tool material; 
- Tool life: cutting depth $\mathrm{a}_{\mathrm{p}}$, rotation speed $n$, feed rate $f$, amplitude $A$, tool material and cooling conditions;

- Surface roughness: cutting depth $\mathrm{a}_{\mathrm{p}}$, rotation speed $n$, feed rate $f$, amplitude $A$ and tool material.

First, we conducted experiments to determine the influence of different factors on cutting force, tool life, and surface roughness. Then, we designed and conducted mixed Taguchi experiments in order to analyze the influencing order of each factor on the machining performance by range analysis. This was revealing because the bigger the range was, the greater the influence was. The range analysis was undertaken both for absolute machining performance of AUVC and for relative machining performance of AUVC compared with CC.

\section{Results and discussion}

\subsection{Measurement of average cutting force}

The experimental results of main cutting force $F_{c}$ and feed resistance force $F_{f}$ with different rotation speed are shown in Fig. 8. It can be seen that when the rotation speed increased within a range of 12002400r/min, the main cutting force and feed resistance force for both AUVC and CC did not change significantly. Less than $1 \mathrm{~N}$ increase in main cutting force and $0.7 \mathrm{~N}$ increase in feed resistance force were observed despite the rotation speed doubling from $1200 \mathrm{r} / \mathrm{min}$ to $2400 \mathrm{r} / \mathrm{min}$. It seemed that rotation speed had little influence on cutting force for both AUVC and CC. Nevertheless, the main cutting force and feed resistance force of AUVC were obviously smaller than those of CC under the same rotation speed, and the ratio between them basically did not change as rotation speed increased.
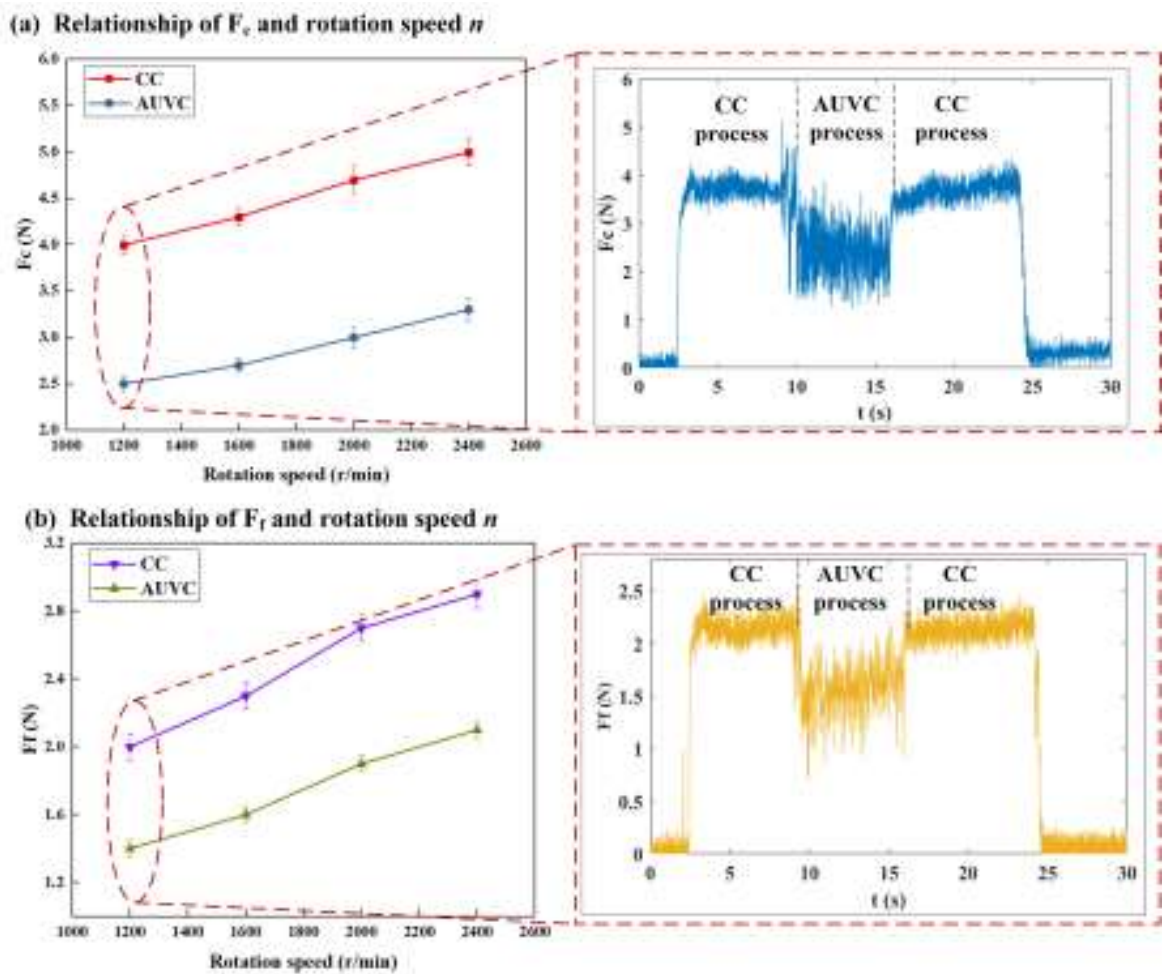

Fig. 8 Results of main cutting force $F_{c}$ and feed resistance force $F_{f}$ with different rotation speed $\left(a_{p}=0.025 \mathrm{~mm}\right.$, $\mathbf{f}=0.005 \mathrm{~mm} / \mathrm{r}, \mathrm{A}=9 \mu \mathrm{m}$, Dry cutting) 
In addition, real-time signals for the main cutting force and feed resistance force were added under $1200 \mathrm{r} / \mathrm{min}$ cutting conditions. To reduce experimental error, in each experiment the cutting process started when the measurement signals were stable. In addition, the force signals for $\mathrm{CC}$ were measured first, and then the ultrasonic power was turned on and the force signals for AUVC were measured. After obtaining a period of stable signals, the ultrasonic power was turned off and other force signals of $\mathrm{CC}$ were measured again. After about 25 seconds, the cutting process was stopped until the dynamometer was shut down. It can be seen more clearly from the real-time signals that the DC component of the cutting force for AUVC was significantly lower than that for CC, which mean the average cutting force of AUVC was smaller than that of CC.

The cutting force signals of AUVC changed more strongly compared to $\mathrm{CC}$ was because of the sine wave transient cutting force of AUVC in one period. This resulted from a transient process with a fluctuating cutting thickness for AUVC, and led to a larger maximum cutting thickness and greater instantaneous cutting force fluctuation.

Cutting depth is one of the most important factors affecting the cutting force in the $\mathrm{CC}$ process. We measured the main cutting force and feed resistance for both CC and AUVC when the cutting depth was changed and other parameters remained unchanged (Fig. 9).

(a) Relationship of $\mathrm{F}_{\mathrm{c}}$ and cutting depth $\mathrm{a}_{\mathrm{p}}$

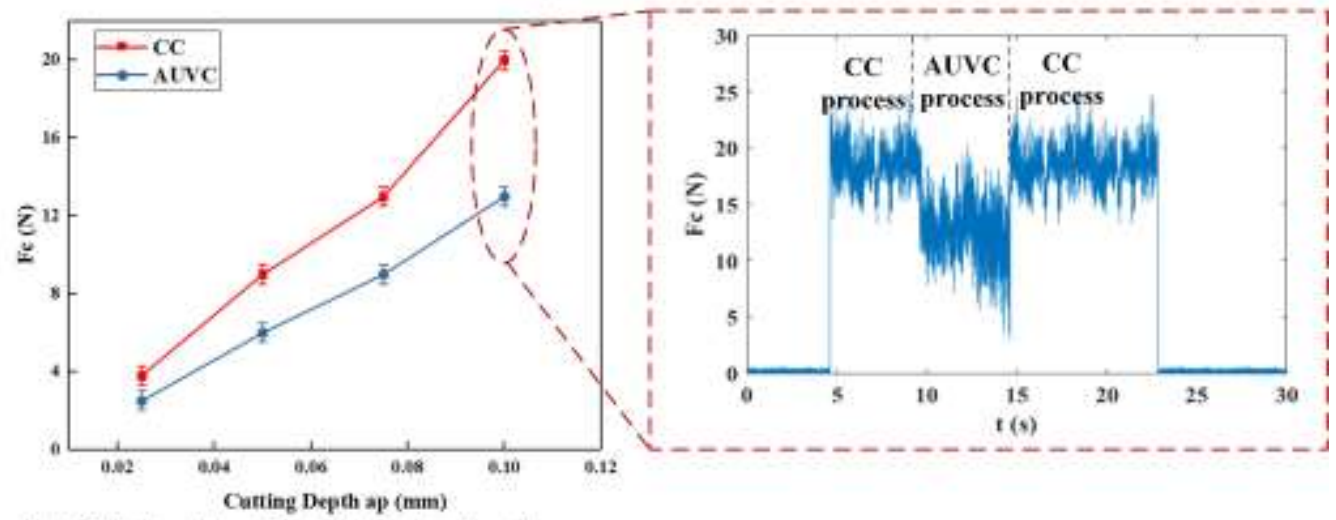

(b) Relationship of $\mathrm{F}_{\mathrm{r}}$ and cutting depth $\mathrm{a}_{\mathrm{p}}$

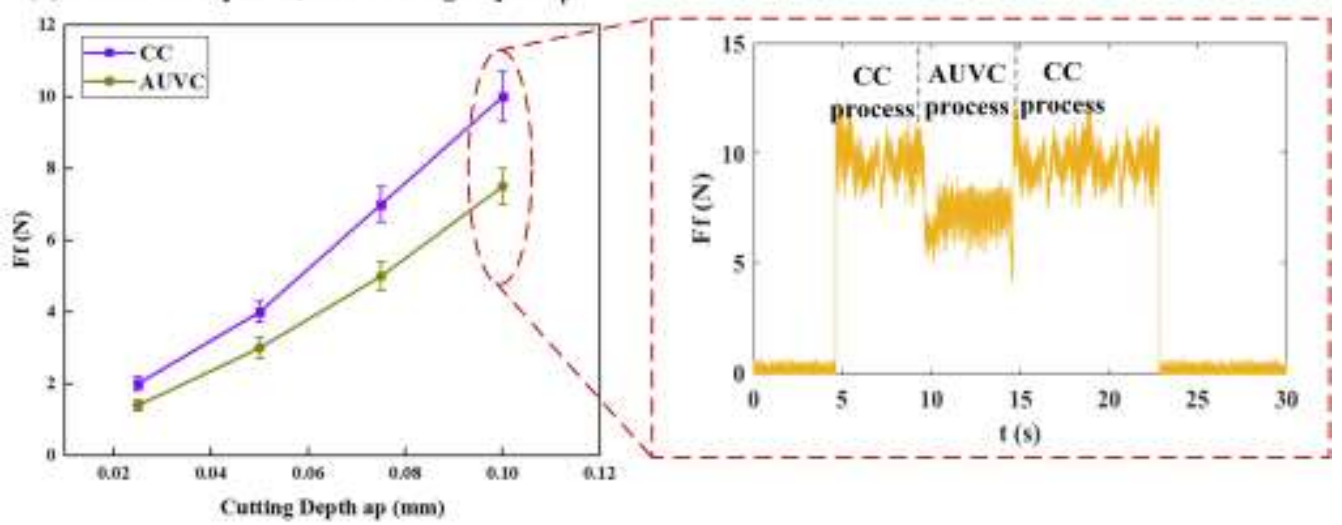

Fig. 9 Results of main cutting force $F_{c}$ and feed resistance force $F_{f}$ with different cutting depth (n=1200r/min, $f=0.005 \mathrm{~mm} / \mathrm{r}, A=9 \mu \mathrm{m}$, Dry cutting) 
It can be seen that when the cutting depth was within the range of $0.025-0.1 \mathrm{~mm}$, the main cutting force and feed resistance force of both AUVC and CC increased distinctly with increased cutting depth. The main cutting force increased from $2.5 \mathrm{~N}$ and $4 \mathrm{~N}$ to about $12 \mathrm{~N}$ and $20 \mathrm{~N}$ for AUVC and $\mathrm{CC}$, respectively. Feed resistance force also changed from $1.4 \mathrm{~N}$ and $2.0 \mathrm{~N}$ to $7 \mathrm{~N}$ and $10 \mathrm{~N}$. The growth rate of the main cutting force and feed resistance force for $\mathrm{CC}$ was obviously greater than that for AUVC. When the cutting depth was larger, the force of CC increased with a larger nonlinear growth; however for AUVC it still maintained relatively good linear growth. The main reason for this difference is that when the cutting depth is larger, the $\mathrm{CC}$ process easily generates a lot of heat, resulting in built-up edge or tool wear, so that the force greatly increases. In AUVC, it is more difficult for this to happen because of the separation process. Also, under the same cutting depth condition, the force of AUVC is obviously smaller than that of CC, as the real-time force signals showed. Thus, compared with rotation speed, cutting depth may have more influence on cutting force.

Feed rate is also a non-negligible parameter affecting cutting force, not only because it determines the material removal rate, but also because of its influence on the separation process of AUVC. When the feed rate was within the range of $0.005-0.014 \mathrm{~mm} / \mathrm{r}$, the main cutting force and feed resistance force for both CC and AUVC increased with the increase of feed rate, as demonstrated in Fig. 10.

(a) Relationship of $\mathrm{F}_{\mathrm{c}}$ and feed rate $f$

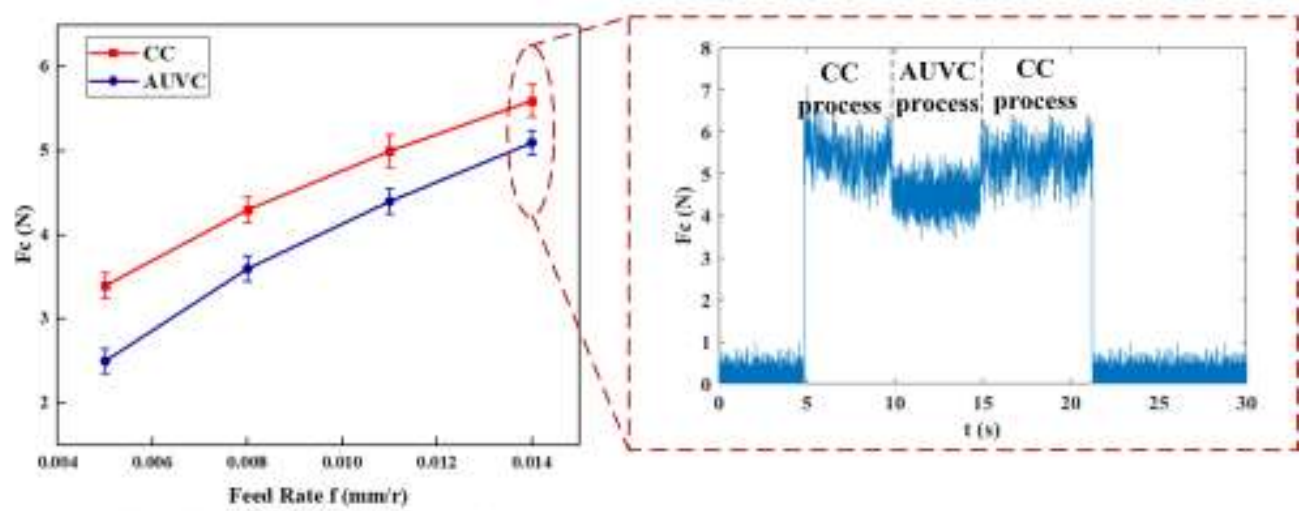

(b) Relationship of $\mathrm{F}_{f}$ and feed rate $f$

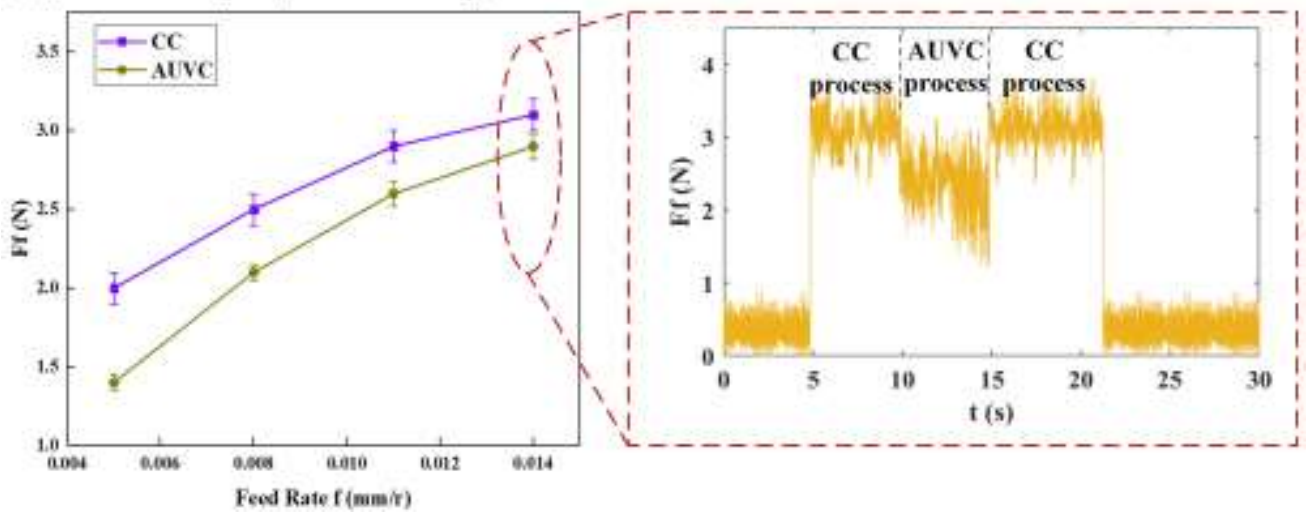

Fig. 10 Results of main cutting force $F_{c}$ and feed resistance force $F_{f}$ with different feed rate (n=1200r/min, $a_{p}=0.025 \mathrm{~mm} / \mathrm{r}, A=9 \mu \mathrm{m}$, Dry cutting) 
In general, the main cutting force and feed resistance force of AUVC was lower than that of $\mathrm{CC}$, however with the increase of feed rate, the two values moved closer and closer. The growth rate of AUVC was higher than that of CC. With increasing feed rate, the feed coefficient $K_{\mathrm{f}}$ decreased clearly, so that the duty ratio of AUVC decreased and the cutting force increased more significantly. Until the feed rate reached the critical value as defined by Eq. (2), the cutting process converted to a continuous one, so that the force for AUVC was the same as that for CC or perhaps a little higher because of the impact effect. We deduced that the feed rate played a more important role in the AUVC process, while it made very little difference in the $\mathrm{CC}$ process.

The results with different tools under different amplitude values are shown in Fig. 11. The cutting force decreased as amplitude increased in AUVC, and the reason is similar to the relationship illustrated in Fig. 10, as feed rate and amplitude are the two direct influencing factors on the duty ratio of AUVC. Because the CC process is not affected by amplitude, the cutting force curve of CC seems smooth. As for tool material, the cutting force with the PCBN tool was a little lower than that with the TiAlN-coated WC tool, whether for AUVC or CC.

In the dry cutting process, the tool and workpiece were softened as the cutting temperature increased, and the cutting force was mainly a function of the relative hardness between them. The hardness of the PCBN changed little with the increase of temperature, in stark contrast to the WC tool. As a result, the relative hardness of PCBN and Ti6Al4V was higher than that of WC and Ti6Al4V, and the cutting force was a little lower with PCBN. However, for AUVC the cutting force was reduced by the separation process, so the effect of PCBN did not seem to be so significant.

(a) Relationship of $\mathrm{F}_{\mathrm{c}}$ and amplitude $A$

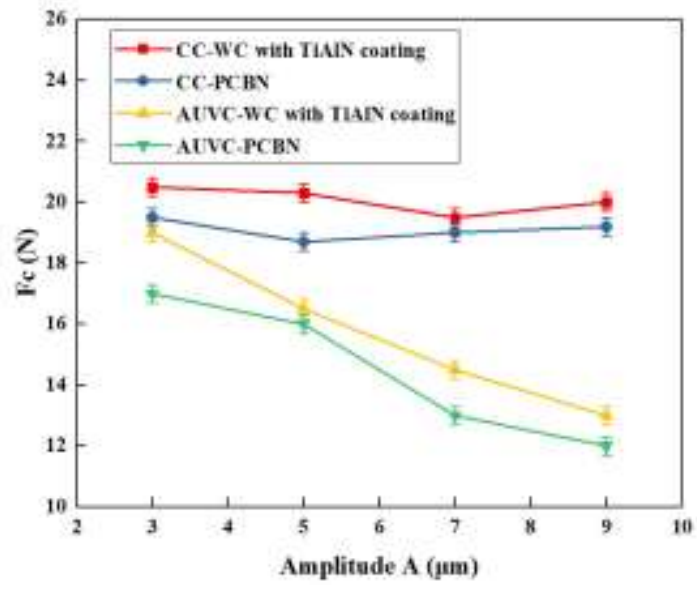

(b) Relationship of $\mathrm{F}_{\mathrm{r}}$ and amplitude $A$

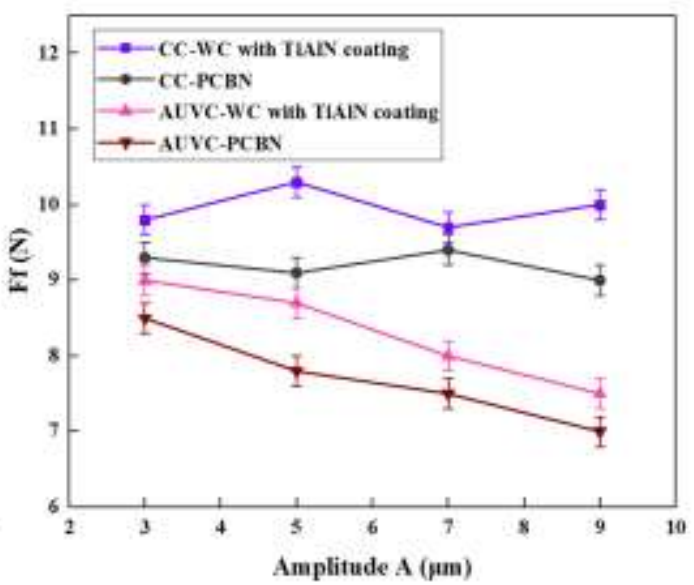

Fig. 11 Results of main cutting force $F_{c}$ and feed resistance force $F_{f}$ with different tools under different amplitude values $\left(\mathrm{n}=1200 \mathrm{r} / \mathrm{min}, \mathrm{a}_{\mathrm{p}}=0.025 \mathrm{~mm} / \mathrm{r}\right.$, Dry cutting)

\subsection{Assessment of tool life}

In this study, we used cutting distance to assess tool life. It is well known that for the CC process, rotation speed is the most important influencing factor for tool life and cutting depth is the secondary factor. However, the feed rate has little effect. Our results for the AUVC process were 
different. On one hand, feed rate was closely correlated with the volume of material removed and the smoothness of the machined surface, both of which are related to tool life; on the other hand, feed rate is also a determinant of duty ratio for HUVC. Thus, the rest and cooling times for tools are important to consider. The influence of cutting parameters and amplitude on tool life is illustrated in Fig. 12.
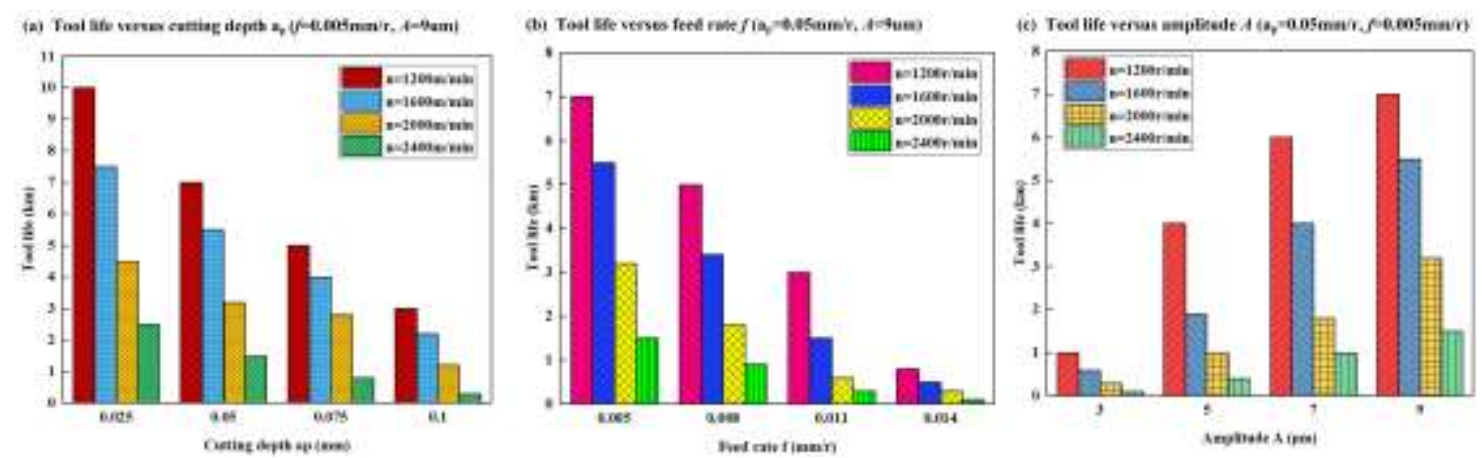

Fig.12 The influence of cutting parameters and amplitude on tool life (Dry cutting)

Rotation speed was clearly the main factor affecting tool life in AUVC. As it increased, tool life decreased dramatically. The influence of cutting depth and feed rate on tool life was the same as that of rotation speed. However, amplitude had the opposite effect. The maximum tool life was about $10 \mathrm{~km}$ under dry conditions with parameters of $0.025 \mathrm{~mm}$ cutting depth, $1200 \mathrm{r} / \mathrm{min}$ rotation speed, $0.005 \mathrm{~mm} / \mathrm{r}$ feed rate, and $9 \mu \mathrm{m}$ amplitude. Both feed rate and amplitude had more influence on tool life in AUVC than in CC, because of their role in determining the duty ratio. It makes sense that tool life was more sensitive to the increase of feed rate and the decrease of amplitude in AUVC process.

With the increase of feed rate, both machined surface roughness and cutting force increased, leading to a decrease in tool life. More importantly, the duty ratio of AUVC increased accordingly, so there was less time for the tool to cool, and a large amount of cutting heat accumulated in the tool within a shorter time. AUVC reflected better tool performance mainly due to its separation process. When the feed rate was $0.014 \mathrm{~mm} / \mathrm{r}$, the duty ratio was close to 1 ; and AUVC is basically a continuous cutting process, so tool life decreased dramatically. It is clear that the slower the feed rate, the longer the tool life.

In order to evaluate the machining performance of the cutting tool, an understanding of the underlying wear mechanism was essential. The wear mechanism varied with the combination and interaction of the tool and workpiece, in addition to the environment.

As titanium alloy is a difficult-to-machine material, the wear mechanism that influenced the failure of the tool may be different from those involved in machining other materials. Abrasive wear, adhesion wear, and oxidation wear are always the main wear mechanisms when machining Ti6Al4V. The SEM pictures and EDX analysis from the flank wear region after $3 \mathrm{~km}$ cutting are shown in Fig. 13. 
(a) Rake face

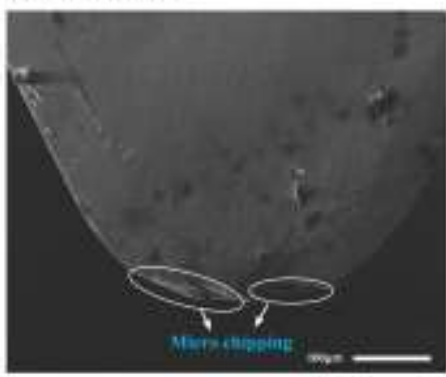

(b) Flank face

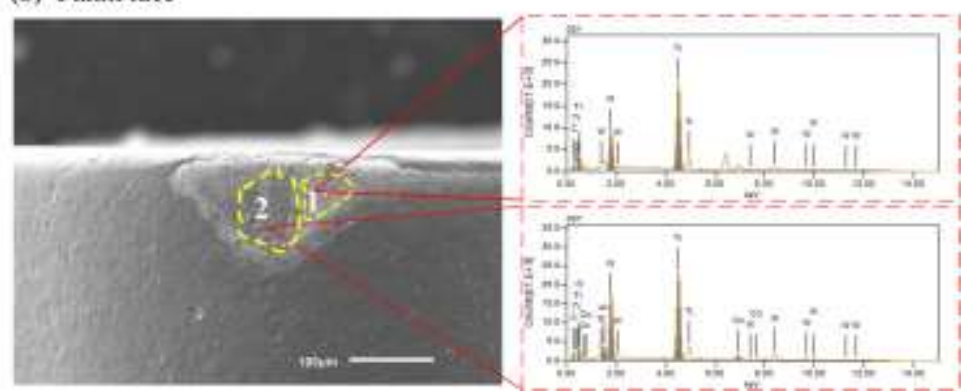

Fig. 13 SEM pictures and EDX analysis on the flank face of WC tool after $3 \mathrm{~km}$ cutting distance of AUVC $(\mathrm{n}=1200 \mathrm{r} / \mathrm{min}, \mathrm{ap}=0.025 \mathrm{~mm} / \mathrm{r}, \mathrm{f}=0.005 \mathrm{~mm} / \mathrm{r}, A=9 \mu \mathrm{m}$, Dry cutting $)$

The wear in the rake face was micro-chipping and the wear in the flank face was complex. As can be seen, region 1 is the area where the coating wore through and an adhesion layer was formed, but region 2 is near the base, so it was worse than region 1. EDX analysis of region 1 showed that there was a large amount of $\mathrm{Ti}$, which proved the occurrence and severity of adhesion wear. At the same time, there was no oxygen $(\mathrm{O})$, so no oxidation had occurred. We were able to deduce that after the coating was worn out mechanically, adhesion wear occurred first, primarily because of the high cutting temperature.

Further, the EDX analysis result for region 2 showed the presence of a large number of $\mathrm{O}$ and Co components other than $\mathrm{Ti}$, indicating that the cutting temperature was relatively high and an oxidation reaction occurred between the tool material and the base material. For the WC tool, surface oxidation was mainly due to the reaction of $\mathrm{W}$ and $\mathrm{C}$ elements with $\mathrm{O}$ elements at high temperature. The final oxidation products of $\mathrm{WC}$ are $\mathrm{WO}_{3}$ and $\mathrm{CO}_{2}$, and the final oxidation products of $\mathrm{Co}$ are $\mathrm{Co}_{3} \mathrm{O}_{4}$ and $\mathrm{Co}_{2}$. Due to the high hardness of these reactants, tools may undergo plastic deformation under high temperature and pressure.

In addition, Ti6A14V has high chemical activity at a relatively high temperature. It can react with gas mediums such as oxygen $(\mathrm{O})$, nitrogen $(\mathrm{N})$, and water vapor, and the absorption of these gases is irreversible. The gas medium and Ti6Al4V may react in two places, namely on the machined surface and the tool surface adhesion layer. Oxidation occurs on the machined surface, which forms an oxide layer in the area, reducing the surface plasticity and thus intensifying tool wear. Oxidation occurring in the tool adhesion layer will form some particles of higher hardness, accompanied by the loss of the adhesion layer and chip outflow.

The above wear mechanisms are not independent of each other. Adhesion will produce oxidation and diffusion, and oxidation will form abrasive wear provides a hard point. Based on the above analysis, the failure of the WC tool in the AUVC process when machining Ti6Al4V at high speed was the result of thermal and mechanical coupling of various wear mechanisms under high temperature and pressure. Tool material is another important factor for tool life. The comparative results of a WC tool and a PCBN tool with different rotation speeds are given in Fig. 14. 


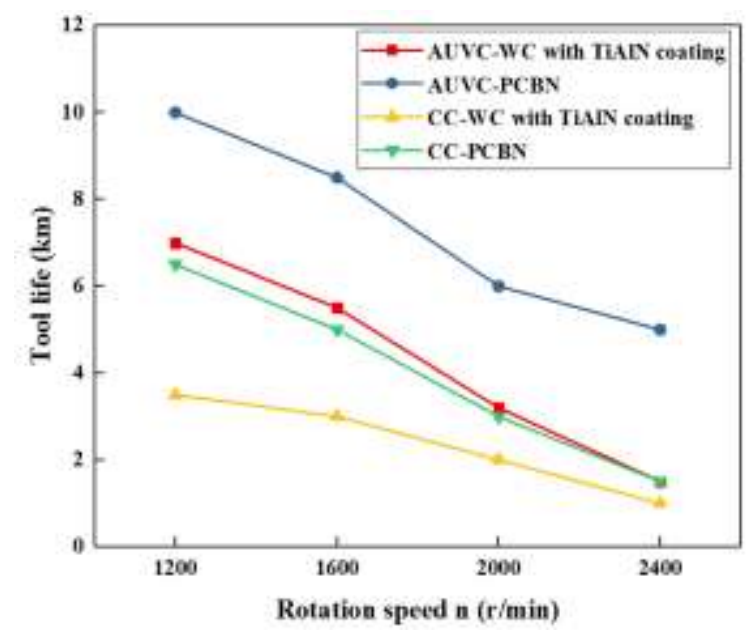

Fig. 14 Comparative results for a WC tool and PCBN tool for cutting distance with different rotation speed (ap $=0.025 \mathrm{~mm} / \mathrm{r}, \mathrm{f}=0.005 \mathrm{~mm} / \mathrm{r}, \mathrm{A}=9 \mu \mathrm{m}$, Dry cutting)

The best result was obtained by using a PCBN tool with the AUVC method. The tool life of the WC tool with AUVC was a little longer than that of a PCBN tool with CC. This indicates that with the AUVC method, better tool performance can be expected with a more cost-effective tool. However, the influence of rotation speed on tool life was essentially the same for WC and PCBN tools. Tool life was extended more than $100 \%$ for CC by replacing the WC tool with a PCBN tool; however this value was only $33 \%$ for AUVC. Thus, the PCBN tool made a bigger difference for CC than for AUVC in a dry cutting process, and replacing WC with PCBN may not be the best choice to extend tool life for AUVC. Nevertheless, cooling conditions have a major impact on tool wear progression, especially in the process of machining titanium alloy, in which the main cause of tool wear is the high cutting temperature. If an appropriate cooling method is adopted, cutting speed can be increased and tool performance prolonged. Experimental results for the influence of cooling conditions on tool life are exhibited in Fig. 15.

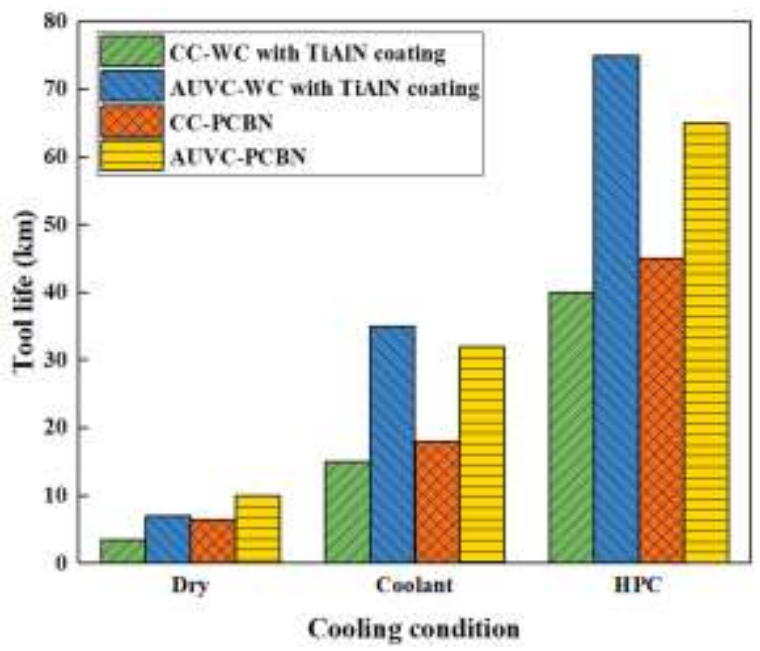

Fig. 15 Experimental results for the influence of cooling conditions on tool life $\left(\mathrm{n}=1200 \mathrm{r} / \mathrm{min}, \mathrm{a}_{\mathrm{p}}=0.025 \mathrm{~mm} / \mathrm{r}\right.$, $\mathbf{f}=0.005 \mathrm{~mm} / \mathrm{r}, \mathrm{A}=9 \mu \mathrm{m})$ 
It can be seen that the influence of cooling conditions is apparent both for AUVC and CC regardless of the tool material. Especially with the HPC method, tool life could be extended by many times. For instance, the life of a WC tool in the AUVC process was extended from about $7 \mathrm{~km}$ to $35 \mathrm{~km}$ (by 5 times) with coolant. However, when the HPC method was applied, the tool life could achieve $70 \mathrm{~km}$ (more than 10 times of the baseline) compared with dry cutting. In addition, if coolant was used, the life of a CBN tool with AUVC was only about $30 \mathrm{~km}$, which seems no different from a WC tool, and thus the advantage disappeared. As for HPC, the life of a CBN tool was less than $70 \mathrm{~km}$, significantly shorter than the WC tool. Better cutting performance was observed when using a WC tool with AUVC in combination with the HPC method. The tool wear process with different cooling methods is shown in Fig. 16. For dry cutting, the tool wear curve was linearized with a large gradient, indicating that the tool would have a short life. When coolant was applied, the gradient of the tool wear curve was smaller and tool wear slowed down. However, the wear curve was also linear. The situation with the HPC method was very different from these two cases. The cutting tool showed three regional wear characteristics leading to failure: initial wear, steady wear, and accelerated wear. As shown in Fig. 16, all of the tool wear progressions showed these characteristics to various degrees, regardless of the tool material. For PCBN tools, the rate of stable regional wear was compressed, resulting in shorter tool life.

(a) WC with TiAIN coating

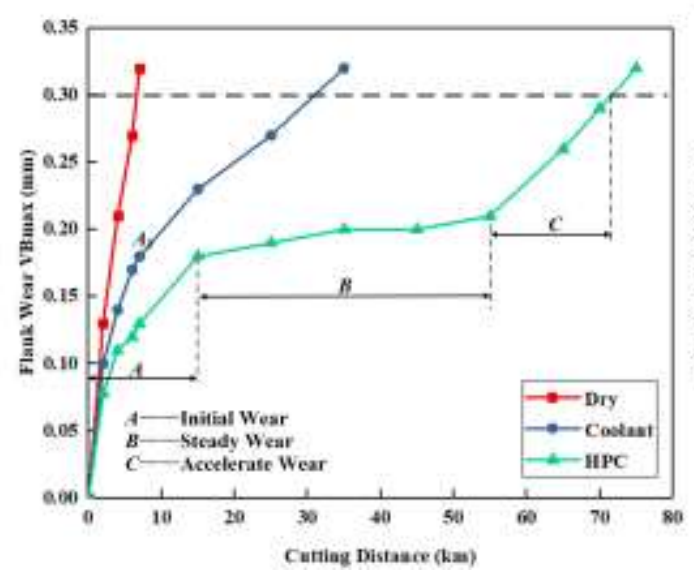

(b) PCBN

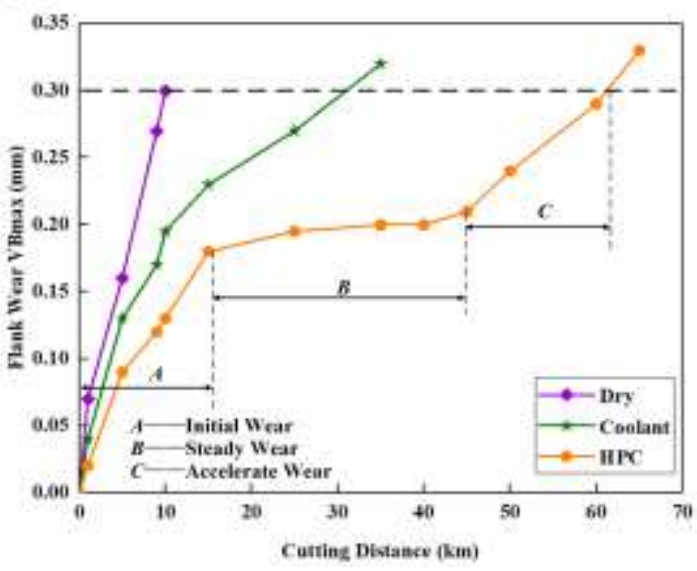

Fig. 16 Tool wear process with different cooling methods $\left(\mathrm{n}=1200 \mathrm{r} / \mathrm{min}, \mathrm{ap}_{\mathrm{p}}=0.025 \mathrm{~mm} / \mathrm{r}, \mathrm{f}=0.005 \mathrm{~mm} / \mathrm{r}, \mathrm{A}=9 \mu \mathrm{m}\right)$

Compared micrographs of flank wear under different cooling conditions (with the AUVC method) are shown in Fig. 17. As well, HPC exhibited better tool wear resistance for a longer cutting distance in AUVC. As a representative example, Fig. 18 shows SEM images of flank wear on the WC tool after cutting distances of $2 \mathrm{~km}$ and $40 \mathrm{~km}$ with the HPC method. A smaller abrasive wear region along the cutting edge was first observed (Fig. 18(a)). This was due to the increased friction wear, which caused thermal stress at the edge and created a wear region. Built-up edges (BUE) from adhesion between the tool and the workpiece were also noticed on the flank region, and were expected to potentially further accelerate abrasion and friction and result in increased wear. Next, 
an apparent enlargement of the wear region was observed (in Fig. 18(b)) as the cutting distance increased. The onset of tool failure was also initiated by micro-chipping.

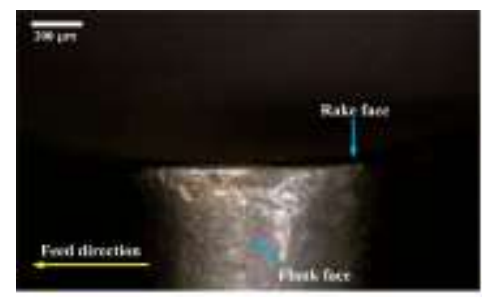

(a) $2 \mathrm{~km}$, Dry

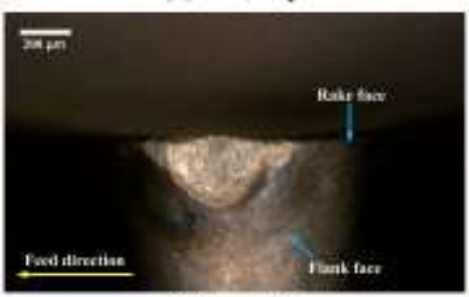

(d) $5 \mathrm{~km}$, Dry

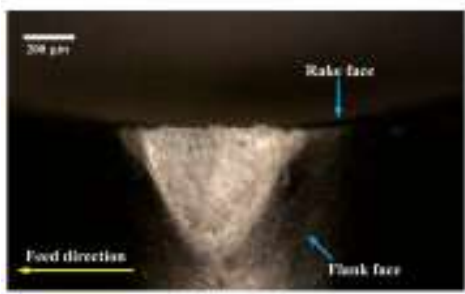

(g) $7 \mathrm{~km}$, Dry

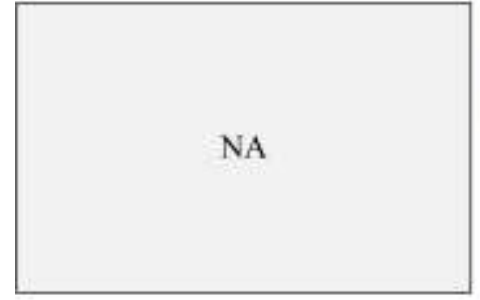

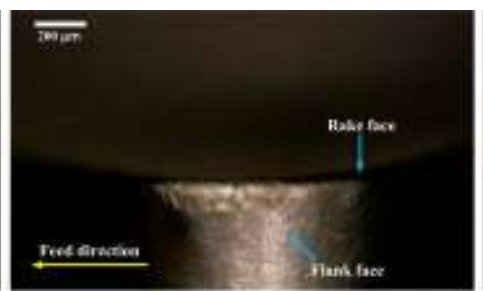

(b) $2 \mathrm{~km}$, Coolant

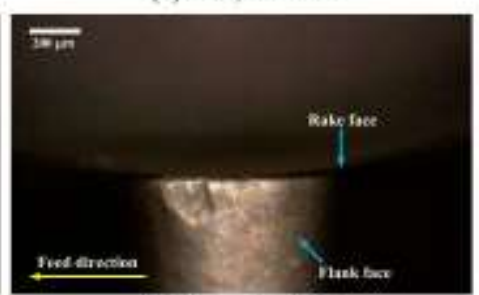

(e) $5 \mathrm{~km}$, Coolant

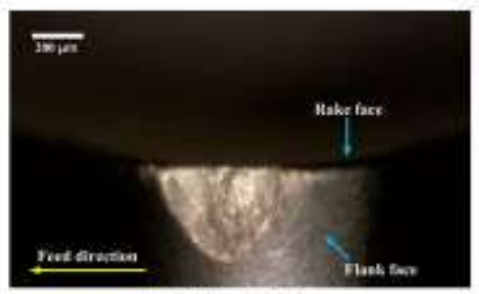

(h) $15 \mathrm{~km}$, Coolant

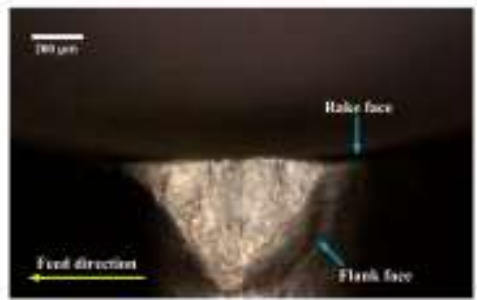

(j) $35 \mathrm{~km}$, Coolant

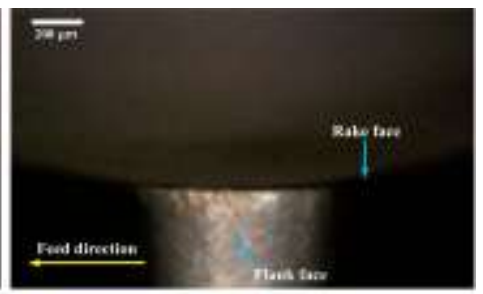

(c) $2 \mathrm{~km}$, HPC

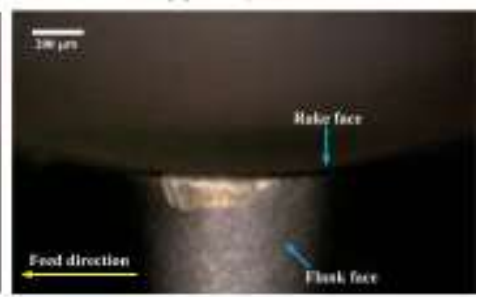

(f) $5 \mathrm{~km}, \mathrm{HPC}$

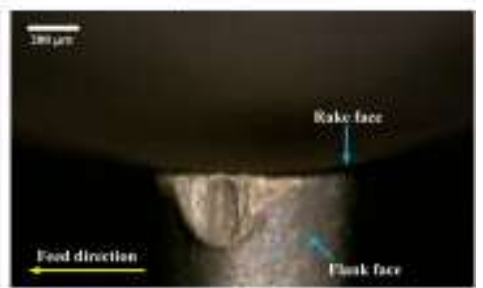

(i) $30 \mathrm{~km}, \mathrm{HPC}$

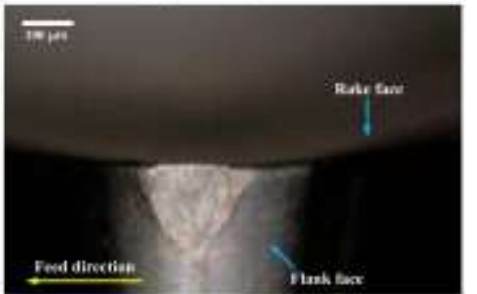

(k) $50 \mathrm{~km}, \mathrm{HPC}$

Fig. 17 Compared micrographs of flank wear under different cooling conditions for AUVC (n=1200r/min, $\left.a_{p}=0.025 \mathrm{~mm} / \mathrm{r}, \mathrm{f}=0.005 \mathrm{~mm} / \mathrm{r}, \mathrm{A}=9 \mu \mathrm{m}\right)$

(a) $2 \mathrm{~km}$

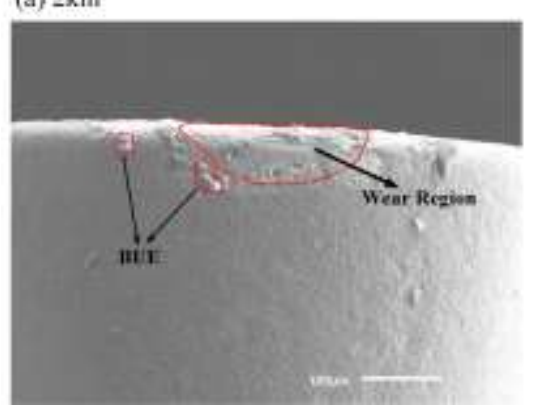

(b) $40 \mathrm{~km}$

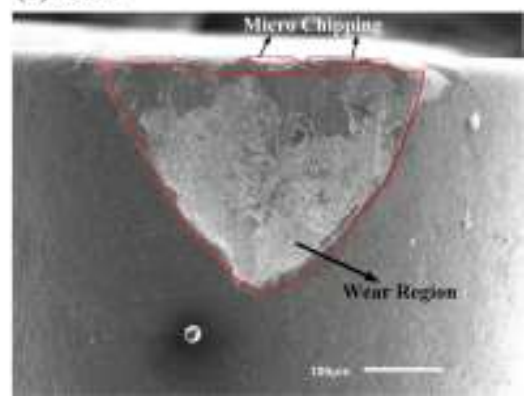

Fig. 18 SEM images of flank wear on a WC tool after $2 \mathrm{~km}$ and $40 \mathrm{~km}$ with HPC

When machining Ti6A14V at a high cutting speed, a narrow region adjacent to the cutting edge is formed and the temperature of this region may be as high as $1,000^{\circ} \mathrm{C}$ because of its low thermal conductivity and high heat capacity. This markedly shortens the cutting distance possible with dry 
cutting. The situation is improved with coolant but the coolant cannot enter into the cutting zone sufficiently, so the effect is fairly limited. As the HPC method is used, a sufficient amount of coolant can enter the cutting zone. Cooperating with the separation process of AUVC, a sufficient flood can cool down the cutting edge, which has accumulated a large amount of cutting heat in the cutting stage. Then, the tool is in better condition for the next cycle, and as a result, the cutting distance is prolonged by several times.

\subsection{Investigation of machined surface roughness}

Machining is a successive process until the tool reaches the wear criteria. Therefore, attention should be focused on tool performance in a successive process. Also, after a certain cutting distance, the primary factor which affects surface roughness becomes the physical factor rather than the geometrical factor. Thus, it is more representative to evaluate the surface roughness after a certain cutting distance. The influence of different parameters on surface roughness after $5 \mathrm{~km}$ with coolant is illustrated in Fig. 19.

It is evident that the machined surface roughness was almost independent of the cutting depth; with the change of cutting depth, the surface roughness curve almost maintained a horizontal line. Rotation speed had little influence on surface roughness. Surface roughness increased with rotation speed, however the range of this change was modest. Feed rate and amplitude appeared to be the main factors influencing surface roughness.
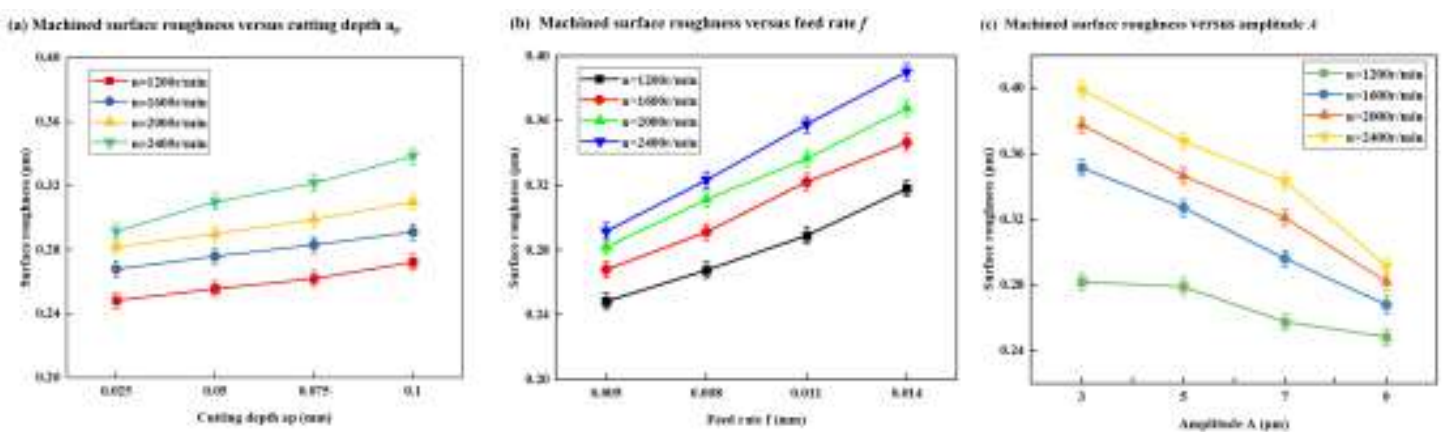

Fig. 19 Influence on surface roughness of WC tool for AUVC after 10km with coolant

In addition, with the increase of feed rate and the decrease of amplitude, surface roughness significantly increased from $\mathrm{Ra} 0.25 \mu \mathrm{m}$ to $\mathrm{Ra} 0.4 \mu \mathrm{m}$ (about $60 \%$ ). It is an established fact that feed rate is always the main factor affecting surface roughness. A slower feed rate always means smaller grooves in the surface micro topography. As a new factor, we found that amplitude determined the duty ratio together with the feed rate, which had a significant effect on surface micro topography. Machined surface roughness was also influenced by two factors: the geometric factor and the physical factor. At the beginning of the cutting operation, the main factor was the geometric one. However, after a certain cutting distance, the primary factor affecting surface roughness became the physical one. Thus, if the feed rate was slower or the amplitude was larger, the duty ratio was smaller, and physical factors such as cutting force, cutting temperature, and burr height were more advantageous for reducing surface roughness. Different cutting tool materials may also affect machined surface roughness; our experimental results are shown in Fig. 20. 


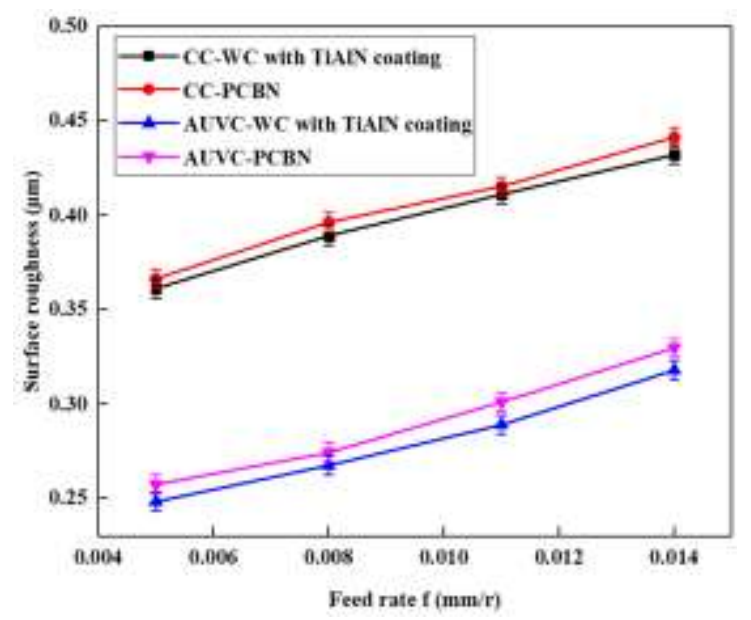

Fig. 20 Influence of tool material on surface roughness for AUVC after $10 \mathrm{~km}$ with coolant (n=1200r/min, $\left.a_{p}=0.025 \mathrm{~mm} / \mathrm{r}, \mathrm{A}=9 \mu \mathrm{m}\right)$

The influence of feed rate on roughness did not change with different tool materials. The surface machined by AUVC was better than that machined with CC after $10 \mathrm{~km}$ of cutting, and the

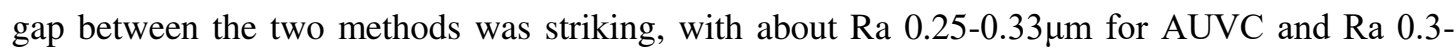
$0.44 \mu \mathrm{m}$ for CC. As for material, the PCBN tool not only failed to improve surface quality, but even led to higher roughness. This may have been due to the ability of the lower grades of $\mathrm{CBN}$ to retain a cutting edge for longer periods. Zoya and Krishnamurthy (2000) observed that surface roughness increased with increasing cutting parameters when machining $\alpha+\beta$ phase-stabilized titanium alloy with a $\mathrm{CBN}$ tool, so $\mathrm{CBN}$ tools may not be the best choice for this task. As cutting is a continuous process, surface roughness changes dynamically with the increase of cutting distance. Fig. 21 illustrates the changes in machined surface roughness with respect to the cutting distance, using one tool in a successive process until the tool reached its wear criteria for both WC and PCBN tools under different cooling conditions. This shows that the results were consistent with Fig. 20 on the whole. After a period of cutting, the surface roughness with AUVC was obviously better than that with CC, while the surface roughness in CC increased sharply.
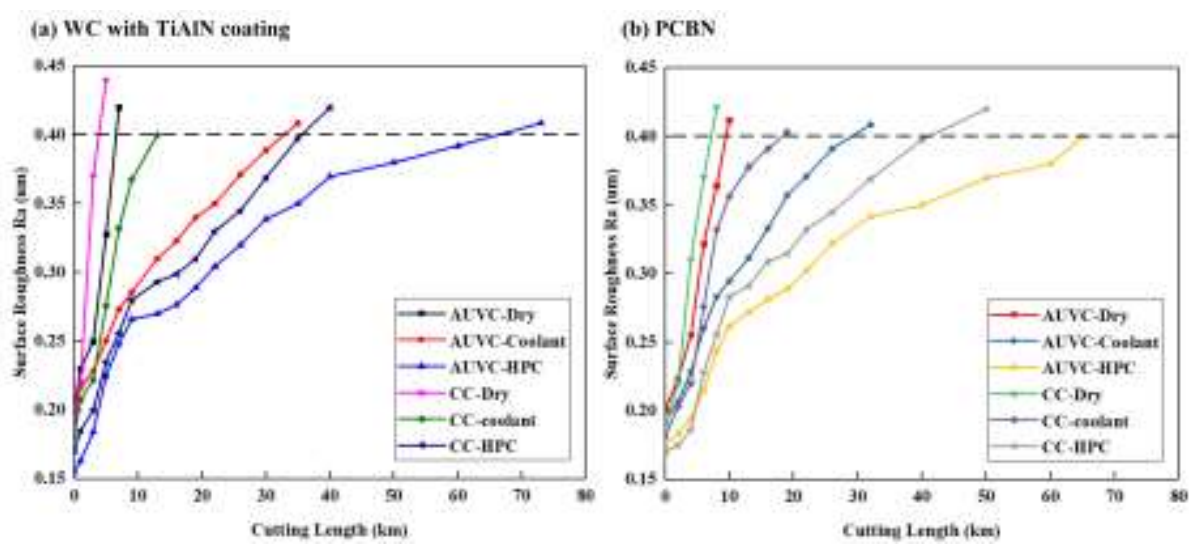

Fig. 21 Machined surface roughness with respect to cutting distance $\left(n=1200 \mathrm{r} / \mathrm{min}, a_{p}=0.025 \mathrm{~mm} / \mathrm{r}\right.$, $\mathbf{f}=0.005 \mathrm{~mm} / \mathrm{r}, \mathbf{A}=9 \mu \mathrm{m})$ 
In addition, cooling conditions had a very significant influence on surface roughness, especially for AUVC. Cooling led to retaining the cutting edge, and interface lubrication prevented the regular surface micro-topography from being destroyed. However, as the process continued, the regular micro-topography changed inevitably, as Fig. 22 demonstrates.

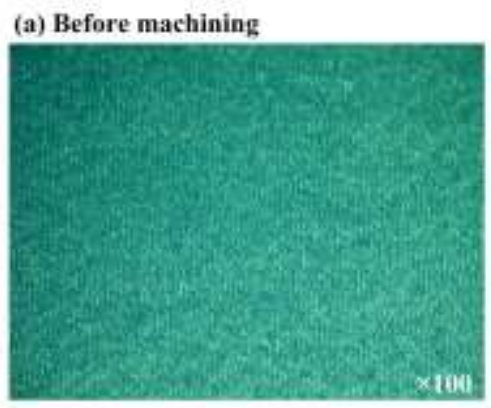

(b) After $5 \mathrm{~km}$
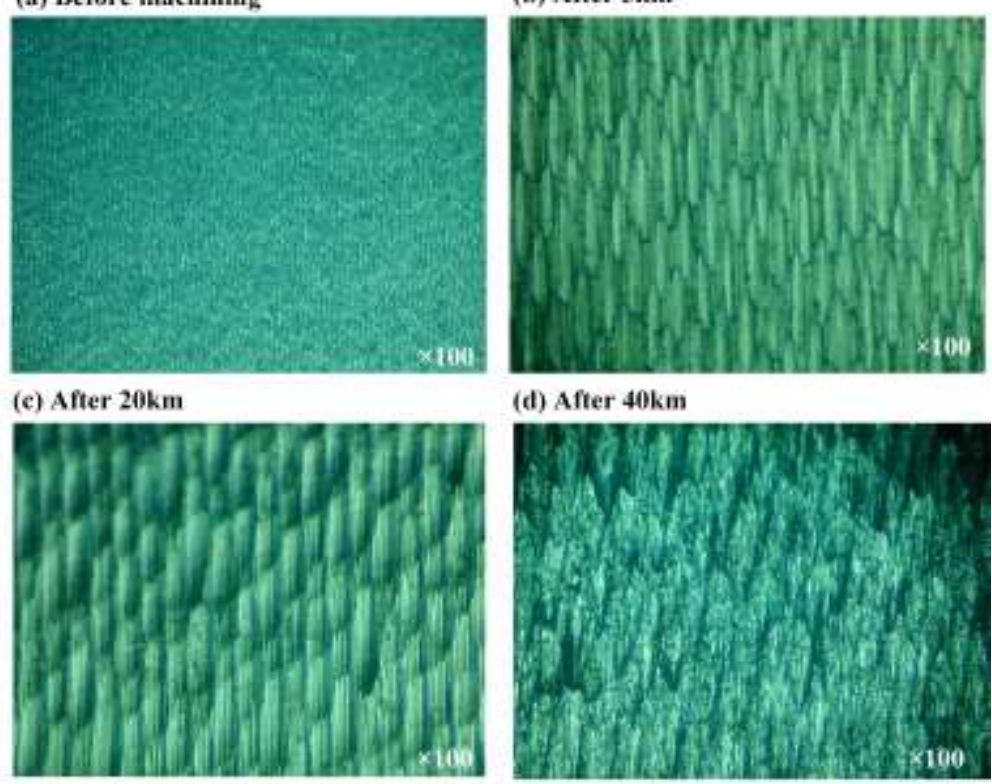

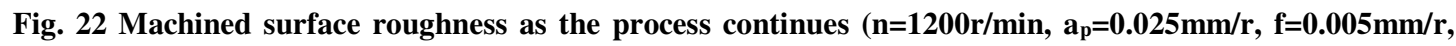
A $=9 \mu \mathrm{m}$, WC tool, HPC)

At the beginning, the micro-topography formed by the sharp cutting edge contained many mounts and grooves and was very regular. After a period of cutting, the boundary of each microtopography unit started to become unclear. Finally, the major structure of each micro-topography unit began to be changed by a blunt tool. Accompanying this process, surface roughness progressively increased.

\subsection{Recommendations for machining conditions}

As explained above, there are many factors affecting the cutting force, tool life, and surface roughness for AUVC. Some preliminary suggestions can be given easily. For instance, HPC is a better choice due to its advantages in extending tool life and reducing surface roughness. WC tools with TiAlN coating are superior to PCBN tools overall. Although the cutting force is lower with $\mathrm{CBN}$, the surface roughness is higher. In addition, the tool life is longer for WC with the HPC method. As a result, we recommend WC tools with TiAlN coating and the HPC cooling method under the conditions used in this study. Except for the vibration frequency which is fixed according to the chosen transducer, other factors have a complex influence on cutting performance. We decided to determine the influence level of each factor so as to find the best combination for AUVC. 
We conducted experiments to determine the influence of parameters on cutting performance and further study their effects. The range analysis results on the main cutting force and its reduction compared with the CC process are given in Fig. 23(a) and (b).
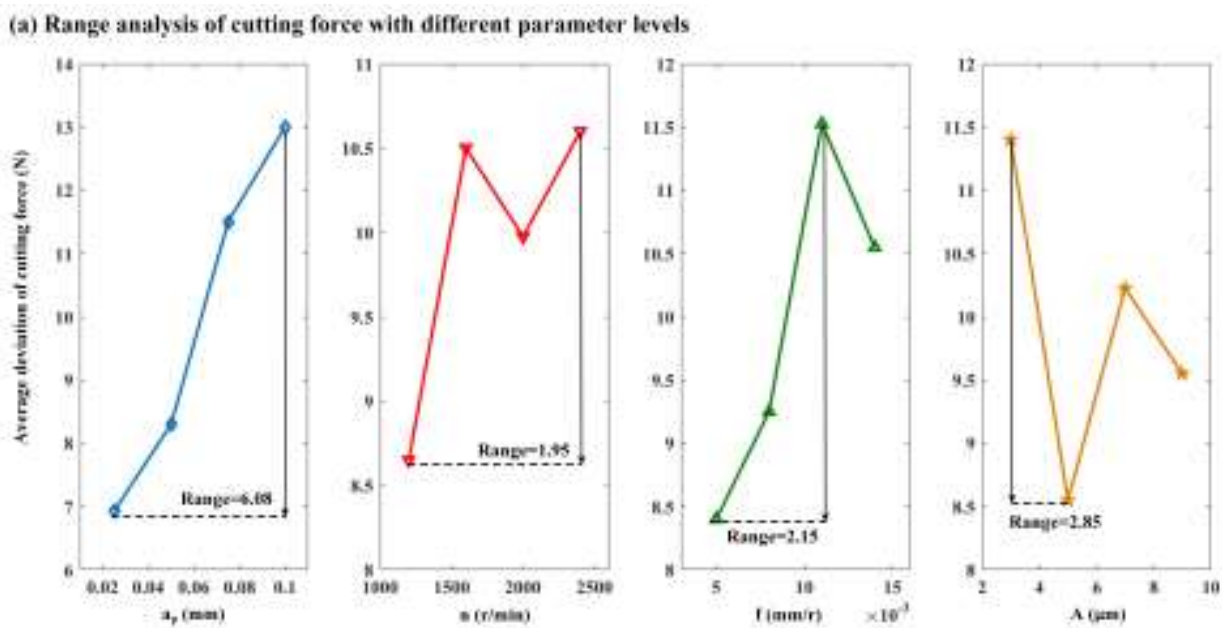

(b) Range analysis of cutting force reduction with different parameter levels
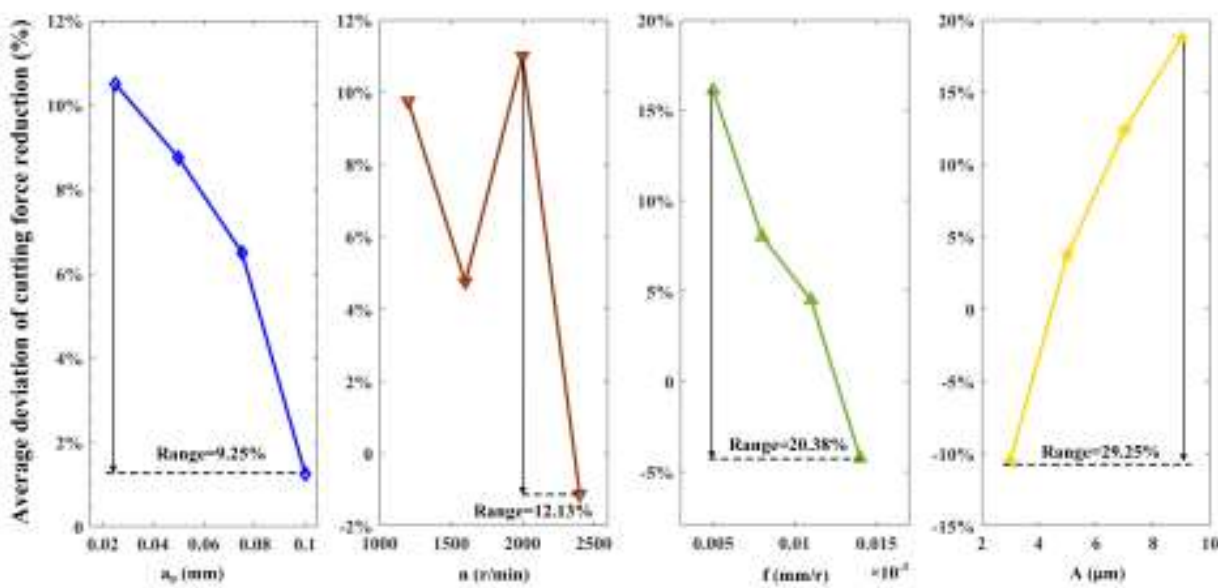

Fig. 23 Range analysis of main cutting force and its reduction with different parameter levels

For the main cutting force, the ranges of cutting depth, rotation speed, feed rate, and amplitude were $6.08 \mathrm{~N}, 1.95 \mathrm{~N}, 2.15 \mathrm{~N}$ and $2.85 \mathrm{~N}$, respectively. The larger the range, the greater the influence was. Thus, cutting depth was the most important parameter, and rotation speed was the least. The order of influence was as follows: cutting depth > amplitude > feed rate > rotation speed. If less cutting force is expected, a smaller cutting depth seems to be necessary.

Main cutting force reduction means a declining percentage of cutting force for AUVC compared with CC under the same conditions. The ranges of cutting depth, rotation speed, feed rate, and amplitude from this point were 9.25\%, 12.13\%, 20.38\% and $29.25 \%$, respectively. As demonstrated, the amplitude was the most important parameter for force reduction and cutting depth was the least. The order of influence was as follows: amplitude > feed rate > rotation speed > cutting depth. This indicated that the parameters that determined duty ratio had a greater effect on cutting force reduction. Feed and amplitude had more unique influence on the main cutting force for AUVC, 
and the effects of cutting depth were more balanced for AUVC and CC. Fig. 24 shows the range analysis of tool life with different parameter levels.
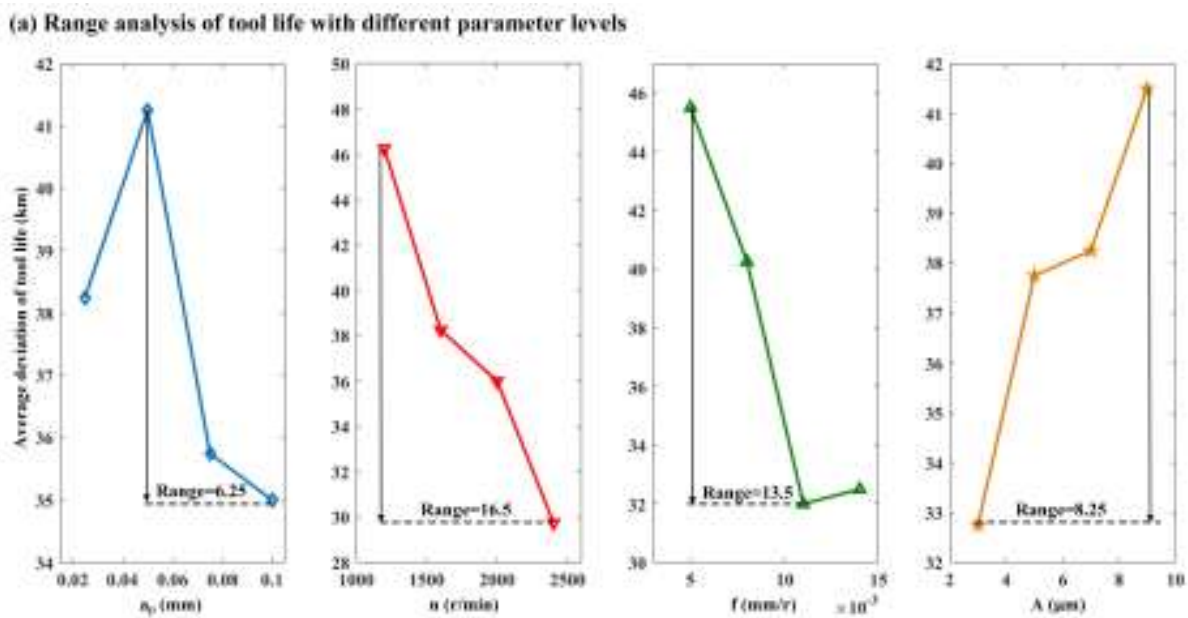

(b) Range analysis of tool life extensien with different parameter levels
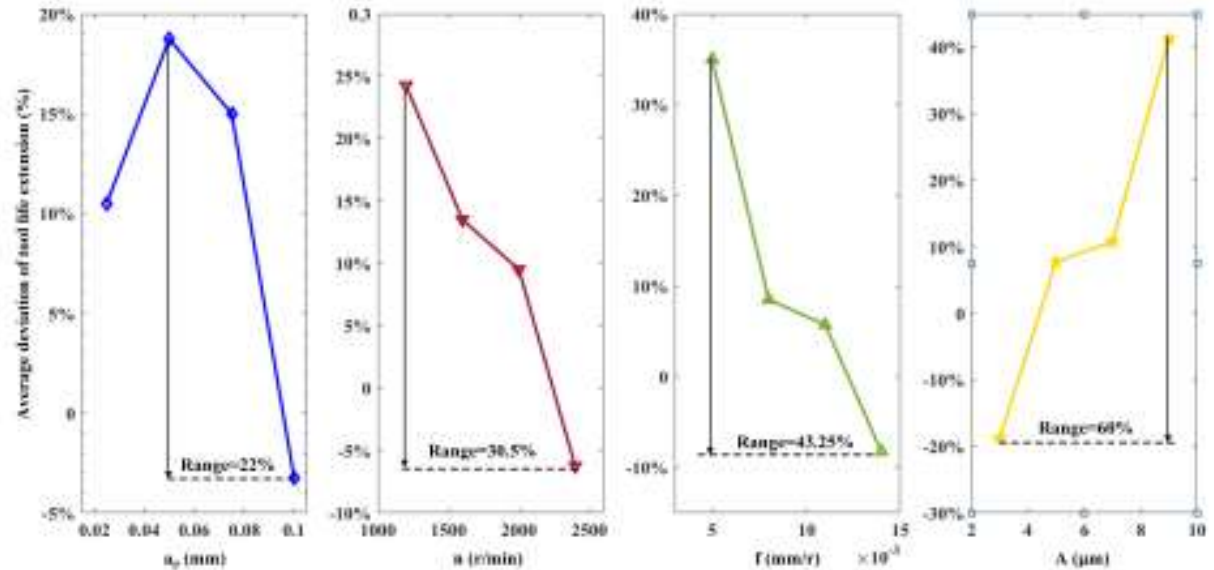

Fig. 24 Range analysis of tool life and its extension with different parameter levels

For tool life, the ranges of cutting depth, rotation speed, feed rate, and amplitude were $6.25 \mathrm{~km}$, $16.5 \mathrm{~km}, 13.5 \mathrm{~km}$ and $8.25 \mathrm{~km}$, respectively. We found that rotation speed was the most important parameter and cutting depth the least. The order of influence was as follows: rotation speed $>$ feed rate > amplitude > cutting depth. Thus, if a longer tool life is desired, a lower rotation speed seems to be necessary. Feed rate and amplitude together affected the duty ratio, which is also very important for tool life.

Tool life extension here means the extended percentage of tool life for AUVC compared with $\mathrm{CC}$ under the same conditions. The ranges of cutting depth, rotation speed, feed rate, and amplitude were $22 \%, 30.5 \%, 43.25 \%$, and $60 \%$, respectively. Clearly, amplitude is the most important parameter for force reduction and cutting depth is the least. The order of influence was as follows: amplitude $>$ feed rate $>$ rotation speed $>$ cutting depth. This indicates that the parameters that determine duty ratio had a larger effect on tool life extension, and thus more unique influence on tool life for AUVC. However, the effects of cutting depth and rotation speed were more balanced 
for AUVC and CC. Fig. 25 shows the range analysis results for the machined surface roughness and its reduction with different parameter levels.

(a) Range analysis of surface roughness with different parameter levets
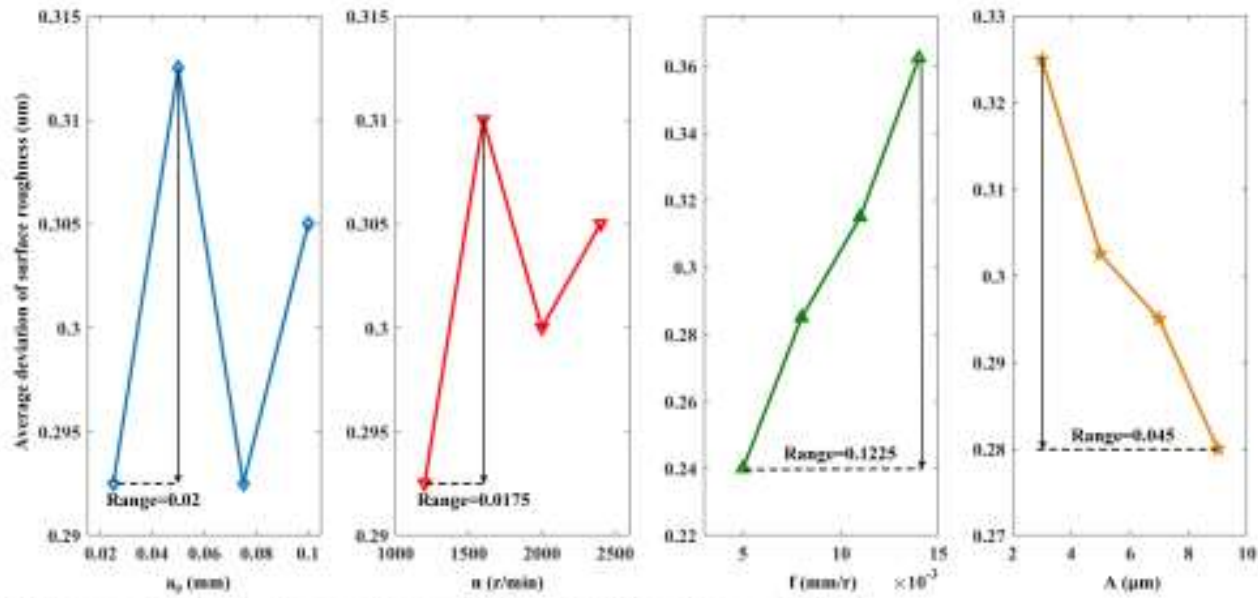

(b) Range analysis of surface roughness reduction with different parameter levels
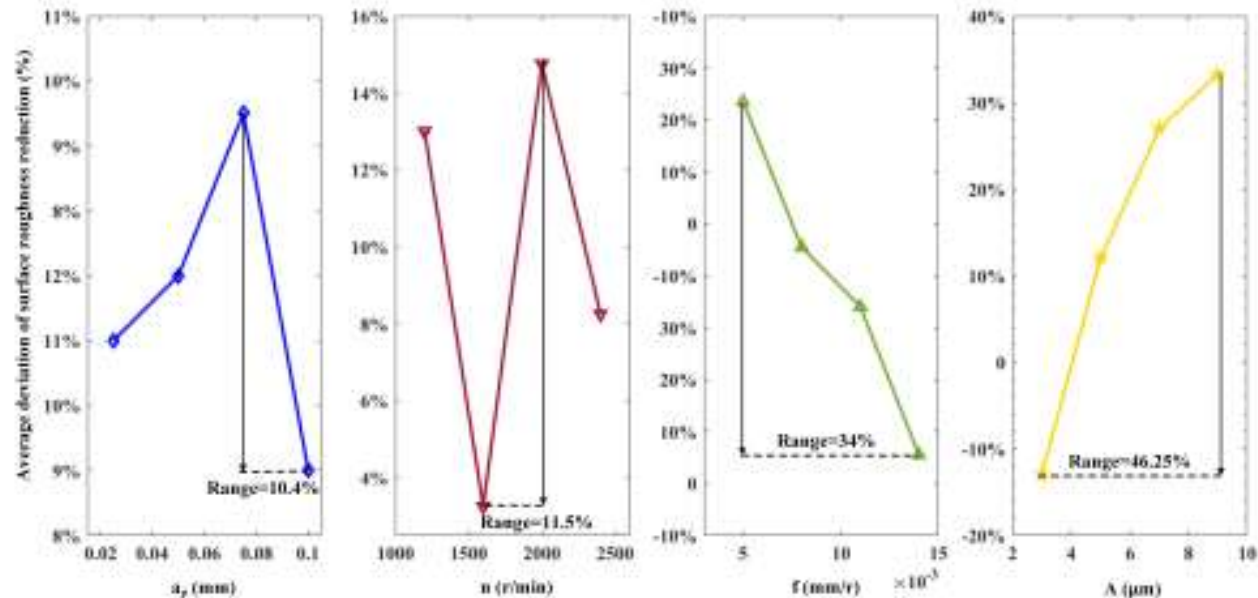

Fig. 25 Range analysis of machined surface roughness and its reduction with different parameter levels

For surface roughness, the ranges of cutting depth, rotation speed, feed rate and amplitude were $\mathrm{Ra} 0.02 \mu \mathrm{m}, \mathrm{Ra} 0.0175 \mu \mathrm{m}, \mathrm{Ra} 0.1225 \mu \mathrm{m}$, and $\mathrm{Ra} 0.045 \mu \mathrm{m}$, respectively. Feed rate was the most important parameter and cutting depth was the least. The order of influence was as follows: feed rate $>$ amplitude $>$ cutting depth > rotation speed. Thus, if a better surface is desired, a lower feed rate seems to be necessary.

Surface roughness reduction here means the reduced percentage of machined surface roughness for AUVC compared with CC under the same conditions. The ranges of cutting depth, rotation speed, feed rate, and amplitude from this perspective were $10.4 \%, 11.5 \%, 34 \%$, and $46.25 \%$, respectively. As shown, the amplitude was the most important parameter for force reduction and cutting depth was the least. The order of influence was as follows: amplitude $>$ feed rate $>$ rotation speed $>$ cutting depth. This indicates that feed rate and amplitude had a larger effect on tool life extension. These two factors had more unique influence on tool life for AUVC as they determined 
the micro-structure of the machined surface. However, the effects of cutting depth and rotation speed were more balanced for AUVC and CC.

Based on the above analysis, we recommend a lower feed rate, a larger amplitude, a moderate spindle rotation speed, and a smaller cutting depth, with a TiAlN-coated WC tool under the HPC cooling method. These conditions seem to be the best option to optimize the cutting performance of AUVC when fully considering cutting force, surface roughness, and tool life.

\section{Conclusions}

This study involved a thorough experimental and theoretical investigation into machining performance for axial ultrasonic vibration-assisted cutting of Ti6Al4V. First, we provided a retrospective of the separation process of AUVC and analyzed and demonstrated the variable parameter cutting aspects. Next, we classified the influencing factors on the machining performance of AUVC into four categories and established the relationships among them theoretically. Finally, we conducted experiments to determine the influence of these factors on cutting force, tool life, and surface roughness, and recommended a specific combination of cutting conditions for better integrated cutting performance of AUVC. The final conclusions are as follows:

- AUVC has variable parameters as the result of the vibration performed along the feed direction.

The actual feed cutting speed and acceleration change according to a harmonic curve, and the actual rake angle and clearance angle also change with the cutting trajectory developed in the AUVC process.

- The influencing factors on AUVC performance can be classified into four categories: machining parameters (rotation speed, feed rate, and cutting depth), vibration parameters (frequency and amplitude), tool choice (nominal angles, tool nose radius, and material and coating) and cooling conditions (dry, wet, and advanced methods). All these factors affect the cutting force, tool life, and surface roughness to a greater or lesser degree.

- The influence of the above factors on AUVC performance should be considered in two ways: absolute influence and relative influence. The former is a direct effect on the performance of AUVC, and the latter is an effect on the performance improvement in AUVC compared with CC. For absolute influence, the order of influence on cutting force is: cutting depth > amplitude > feed rate $>$ rotation speed. The order for tool life is: rotation speed $>$ feed rate $>$ amplitude $>$ cutting depth. The order for surface roughness is: feed rate > amplitude > cutting depth > rotation speed. However, for relative influence, the order of these three aspects is uniformly: amplitude $>$ feed rate $>$ rotation speed $>$ cutting depth

- We recommend a slower feed rate, a larger amplitude, a moderate spindle rotation speed, and a smaller cutting depth, with a TiAlN-coated WC tool under HPC cooling as a better choice for AUVC machining performance when synthetically considering cutting force, surface roughness, and tool life. 


\section{Ethical Approval}

Not applicable.

\section{Consent to Participate}

Not applicable.

\section{Consent to Publish}

Not applicable.

\section{Authors Contributions}

Author He Sui carried out theoretical and experimental study of this paper, and was a major contributor in writing the manuscript. Author Lifeng Zhang contributed to the conception of the study, and helped perform the theoretical analysis part with constructive discussions. Author Shuang Wang performed the data analyses and wrote the manuscript. Author Zhaojun Gu contributed significantly to analysis and manuscript preparation.

\section{Funding}

This work was supported by Research Start-up Fund of Civil Aviation University of China (grant no. 2020KYQD81).

\section{Competing Interests}

We declare that we have no financial and personal relationships with other people or organizations that can inappropriately influence our work, there is no professional or other personal interest of any nature or kind in any product, service and/or company that could be construed as influencing the position presented in, or the review of, the manuscript entitled.

\section{Availability of data and materials}

All data generated or analyzed during this study are included in this published article, and further request can be contacted with the corresponding author.

\section{References}

1. Saoubi RM, Axinte D, Soo SL, Nobel C, Attia H, Kappmeyer G, Engin S, Sim W (2015) High performance cutting of advanced aerospace alloys and composite materials. CIRP Ann. 64 (2): 557-580. https://10.1016/j.cirp.2015.05.002

2. Amin AKMN, Ismail AF, Khairusshima MKN (2007) Effectiveness of uncoated WC-Co and PCD inserts in end milling of titanium alloy-Ti6-Al-4V. J. Mater. Process. Technol. 192193(1): 147-158. https://doi.org/10.1016/j.jmatprotec.2007.04.095 
3. Venugopal KA, Paul S, Chattopadhyay AB (2007) Growth of tool wear in turning of Ti-6Al4V alloy under cryogenic cooling. Wear. 262(9-10): 1071-1078. https://doi.org/10.1016/j.wear. $\underline{2006.11 .010}$

4. Zheng K, Liao W, Dong Q, Sun L (2018) Friction and wear on titanium alloy surface machined by ultrasonic vibration-assisted milling. J. Braz. Soc. Mech. Sci. Eng. 40: 411. https://doi.org/10.1007/s40430-018-1336-9

5. Michalski M, Lechner M, Gruber M, Merklein M (2018) Influence of ultrasonic vibration on the shear formability of metallic materials. CIRP Ann. 67: 277-280. https://doi.org/10.1016/j.cirp.2018.04.108

6. Chen G, Ren CZ, Zou YH, Qin XD, Lu LP, Li SP (2019) Mechanism for material removal in ultrasonic vibration helical milling of Ti6Al4V alloy. Int. J. Mach. Tool Manufact. 138: 1-13. https://doi.org/10.1016/j.ijmachtools.2018.11.001

7. Wang Y, Lin B, Wang SL, Cao XY (2014) Study on the system matching of ultrasonic vibration assisted grinding for hard and brittle materials processing. Int. J. Mach. Tool Manufact. 77: 66-73. https://doi.org/10.1016/j.ijmachtools.2013.11.003

8. Geng DX, Lu ZH, Yao G, Liu JJ, Li Z, Zhang DY (2017) Cutting temperature and resulting influence on machining performance in rotary ultrasonic elliptical machining of thick CFRP, Int. J. Mach. Tool Manufact. 123: 160-170. https://doi.org/10.1016/j.ijmachtools.2017.08.008

9. Sui H, Zhang XY, Zhang DY, Jiang XG, Wu RB (2017) Feasibility study of high-speed ultrasonic vibration cutting titanium alloy. J. Mater. Process. Tech. 247: 111-120. https:// doi.org /10.1016/ j. jmatprotec.2017.03.017

10. Zhang XY, Sui H, Zhang DY, Jiang XG (2018a) Study on the separation effect of high-speed ultrasonic vibration cutting. Ultrasonics. 87: 166-181. https://doi.org/10.1016/j.ultras. $\underline{2018.02 .016}$

11. Sui H, Zhang LF, Wang S, Gu ZJ (2020) Transient separation cutting characteristic of axial ultrasonic vibration-assisted cutting. Int. J. Adv. Manuf. Tech. 110: 2407-2425. https://doi.org/10.1007/s00170-020-06020-3

12. Zhang XY, Sui H, Zhang DY, Jiang XG (2018b) An analytical transient cutting force model of high-speed ultrasonic vibration cutting, Int. J. Adv. Manuf. Tech. 95: 3929-3941. https://doi.org/10.1007/s00170-017-1499-Z

13. Zhang XY, Sui H, Zhang DY, Jiang XG (2018) Measurement of ultrasonic-frequency repetitive impulse cutting force signal. Measurement 129: 653-663. https://doi.org/10.1016/j. measurement.2018.06.043

14. Zhang XY, Lu ZH, Peng ZL, Sui H, Zhang DY (2018) Development of a tool-workpiece thermocouple system for comparative study of the cutting temperature when high-speed ultrasonic vibration cutting Ti-6Al-4V alloys with and without cutting fluids, Int. J. Adv. Manuf. Tech. 96: 237-246. https://doi.org/10.1007/s00170-018-1600-2 
15. Jiang X G, Zhang XY, Zhu XB, Sui H, Zhang DY (2018) Study of Phase Shift Control in HighSpeed Ultrasonic Vibration Cutting, IEEE T. Ind. Electron. 65: 2467-2474. $\underline{10.1109 / \text { TIE.2017.2740827 }}$

16. Liu JJ, Jiang XG, Han X, Gao Z, Zhang DY (2019a) Effects of rotary ultrasonic elliptical machining for side milling on the surface integrity of Ti-6Al-4V. Int. J. Adv. Manuf. Tech. 1: 1451-1465. https://doi.org/10.1007/s00170-018-2847-3

17. Liu JJ, Jiang XG, Han X, Zhang DY (2019b) Influence of parameter matching on performance of high-speed rotary ultrasonic elliptical vibration-assisted machining for side milling of titanium alloys. Int. J. Adv. Manuf. Tech. 101: 1333-1348. https://doi.org/10.1007/s00170018-3006-6

18. Lu ZH, Zhang DY, Zhang XY, Peng ZL (2020) Effects of high-pressure coolant on cutting performance of high-speed ultrasonic vibration cutting titanium alloy. J Mater Process Technol. 279: 116584. https://doi.org/10.1016/j.jmatprotec.2019.116584

19. Zoya ZA, Krishnamurthy R (2000) The performance of CBN tools in the machining of titanium alloys. Journal of Materials Processing Technology. 100: 80-86. https://doi.org/10.1016/S0924-0136(99)00464-1

20. Wang ZG, Rahman M, Wong YS (2005) Tool wear characteristics of binderless CBN tools used in high-speed milling of titanium alloys. Wear. 258: 752-758. https://doi.org/10.1016/j.wear.2004.09.066

21. Mao C, Zhang YC, Peng XX, Zhang B, Hua YL, Bi ZM (2018) Wear mechanism of single cBN-WC-10Co fiber cutter in machining of Ti-6Al-4V alloy. Journal of Materials Processing Tech. 259: 45-57. https://doi.org/10.1016/j.jmatprotec.2018.04.015

22. Uddin MS, Pham B, Sarhan A, Basak A, Pramanik A (2017) Comparative study between wear of uncoated and TiAlN-coated carbide tools in milling of Ti6Al4V, Adv. Manuf. 5(1): 83-91. http://www.aim.shu.edu.cn/EN/10.1007/s40436-016-0166-1

23. Caliskan H, Kucukkose M (2015) The effect of aCN/TiAlN coating on tool wear, cutting force, surface finish and chip morphology in face milling of Ti6Al4V superalloy. Int. J. Refract. Met. Hard Mater. 50: 304-312. https://doi.org/10.1016/j.jirmhm.2015.02.012

24. Chowdhury MSI, Bose B, Yamamoto K, Shuster LS, Paiva J, Fox-Rabinovich GS, Veldhuis SC (2020) Wear performance investigation of PVD coated and uncoated carbide tools during high-speed machining of TiAl6V4 aerospace alloy. Wear. 446-447: 203168. https://doi.org/10.1016/j.wear.2019.203168

25. Singh R, Dureja JS, Dogra M, Gupta MK, Mia M, Song QH (2020) Wear behavior of textured tools under graphene-assisted minimum quantity lubrication system in machining Ti-6Al-4V alloy. Tribol Int. 145: 106183. https://doi.org/10.1016/j.triboint.2020.106183

26. Denkena B, Michaelis A, Herrmann M, Pötschke J, Krödel A, Vornberger A, Picker T (2020) Influence of tool material properties on the wear behavior of cemented carbide tools with rounded cutting edges. Wear. 456-457: 203395. https://doi.org/10.1016/j.wear.2020.203395 
27. Kuntoğlu M, Sağlam H (2019) Investigation of progressive tool wear for determining of optimized machining parameters in turning. Measurement. 140: 427-436. https://doi.org/10.1016/j.measurement.2019.04.022

28. Toubhans B, Fromentin G, Viprey F, Karaouni H, Dorlin T (2020) Machinability of inconel 718 during turning: Cutting force model considering tool wear, influence on surface integrity. J Mater Process Technol. 285: 116809. https://doi.org/10.1016/j.jmatprotec.2020.116809

29. Debnath S, Reddy MM, Yi QS (2014) Environmental friendly cutting fluids and cooling techniques in machining: a review. J. Clean. Prod. 83: 33-47. https://doi.org/10.1016/j.jclepro.2014.07.071

30. Salah G, Islam S, Fawad I, Huo DH (2018) Experimental analysis of system parameters for minimum cutting fluid consumption when machining Ti-6Al-4V using a novel supply system. Int. J. Adv. Manuf. Technol. 95: 2795-2809. https://doi.org/10.1007/s00170-017-1216-y

31. Klocke F, Demmer A, Heselhaus M (2004) Material removal mechanisms in ultrasonicassisted diamond turning of brittle materials. Int J Mater Prod Technol 20(4): 231-238. https://doi.org/10.1504/ IJMPT.2004.004249

32. Sadik MI, Isakson S, Malakizadi A, Nyborg L (2016) Influence of coolant flow rate on tool life and wear development in cryogenic and wet milling of Ti-6Al-4V. Procedia CIRP. 46: 9194. https://doi.org/10.1016/j.procir.2016.02.014

33. Bordin A, Bruschi S, Ghiotti A, Bariani PF (2015) Analysis of tool wear in cryogenic machining of additive manufactured Ti6Al4V alloy. Wear. 328-329: 89-99. https://doi.org/10.1016/j.wear.2015.01.030

34. Mia M, Khan MA, Dhar NR (2017) High-pressure coolant on flank and rake surfaces of tool in turning of Ti-6Al-4V: investigations on surface roughness and tool wear. Int. J. Adv. Manuf. Technol. 90: 1825-1834. https://doi.10.1007/s00170-016-9512-5

35. Mia M, Khan MA, Dhar NR (2016a) Performance prediction of high pressure coolant assisted turning of Ti-6Al-4V. Int. J. Adv. Manuf. Technol. 90(5-8): 1433-1445. https://doi:10.1007/s00170-016-9468-5

36. Mia M, Khan MA, Rahman SS, Dhar NR (2016) Mono-objective andmulti-objective optimization of performance parameters in high pressure coolant assisted turning of Ti-6Al4V. Int. J. Adv. Manuf. Technol. 1: 1-10. https://doi:10.1007/s00170-016-9372-z 


\section{Figures}

(a) A typical cylindrical coordinate system

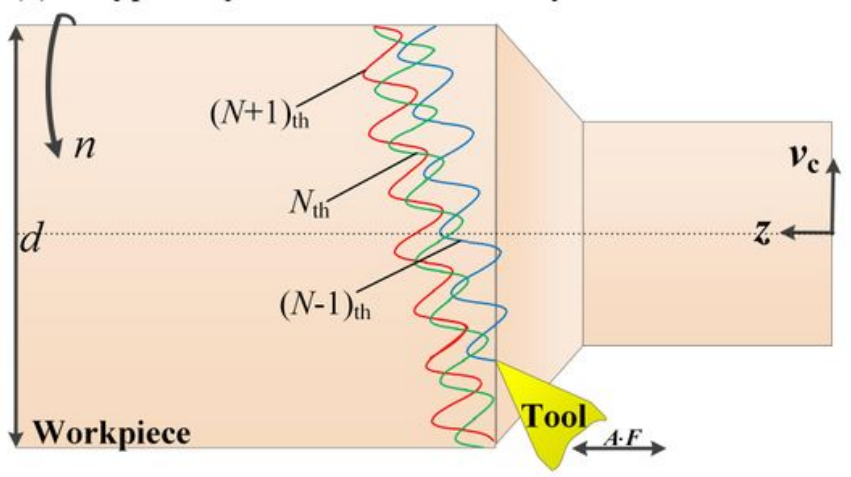

(b) The extended plane of the workpiece to be machined

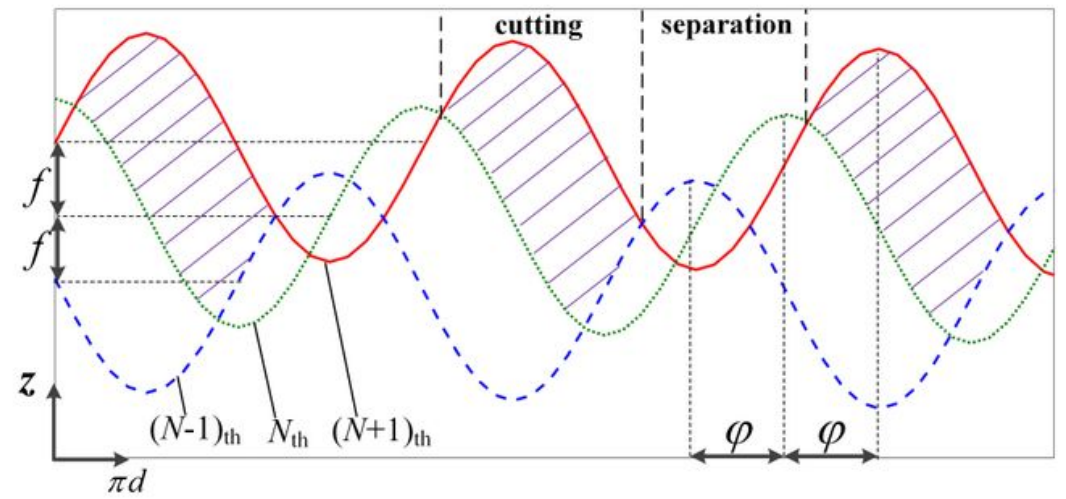

Figure 1

Schematics of the AUVC process and its separation characteristic

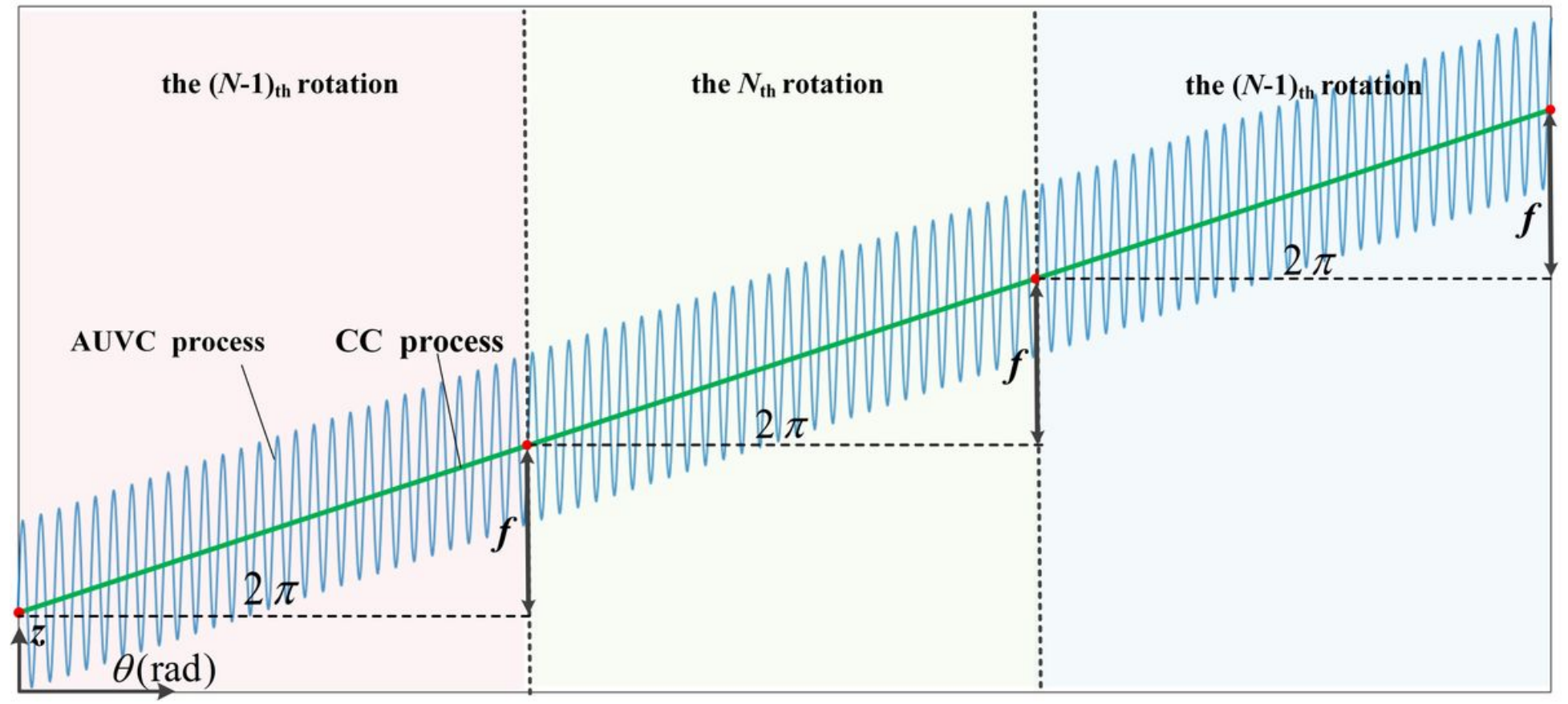

Figure 2

Relationship of cutting trajectories and rotational angle in several adjacent rotations 
(a) Actual feed cutting speed

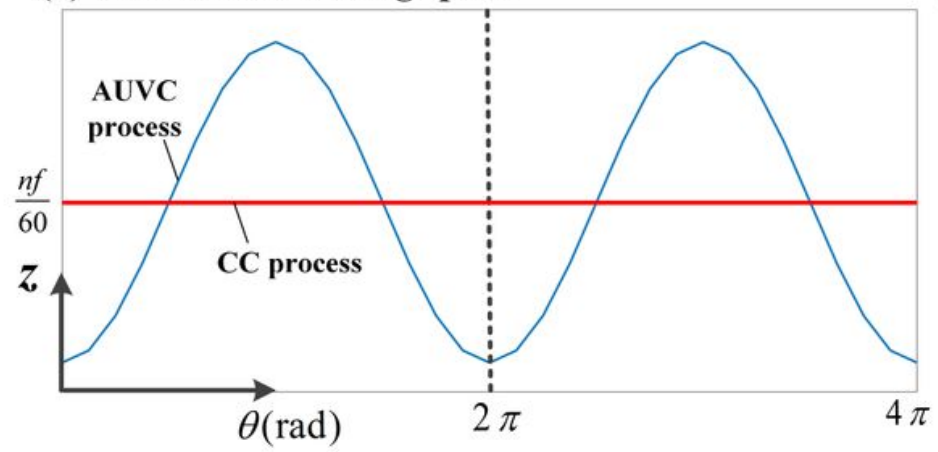

(b) Actual feed cutting acceleration

\section{Figure 3}

The actual feed cutting speed and acceleration curve of AUVC

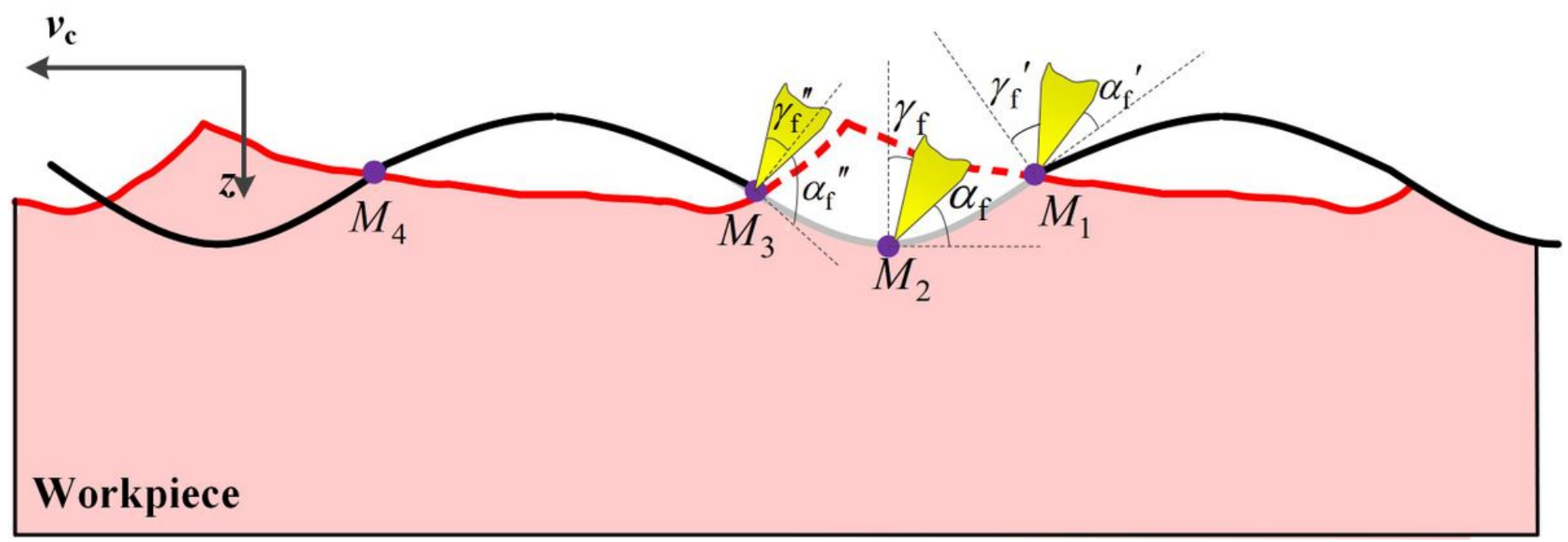

Figure 4

Evolution process of the actual rake angle and clearance angle change in one AUVC cycle 


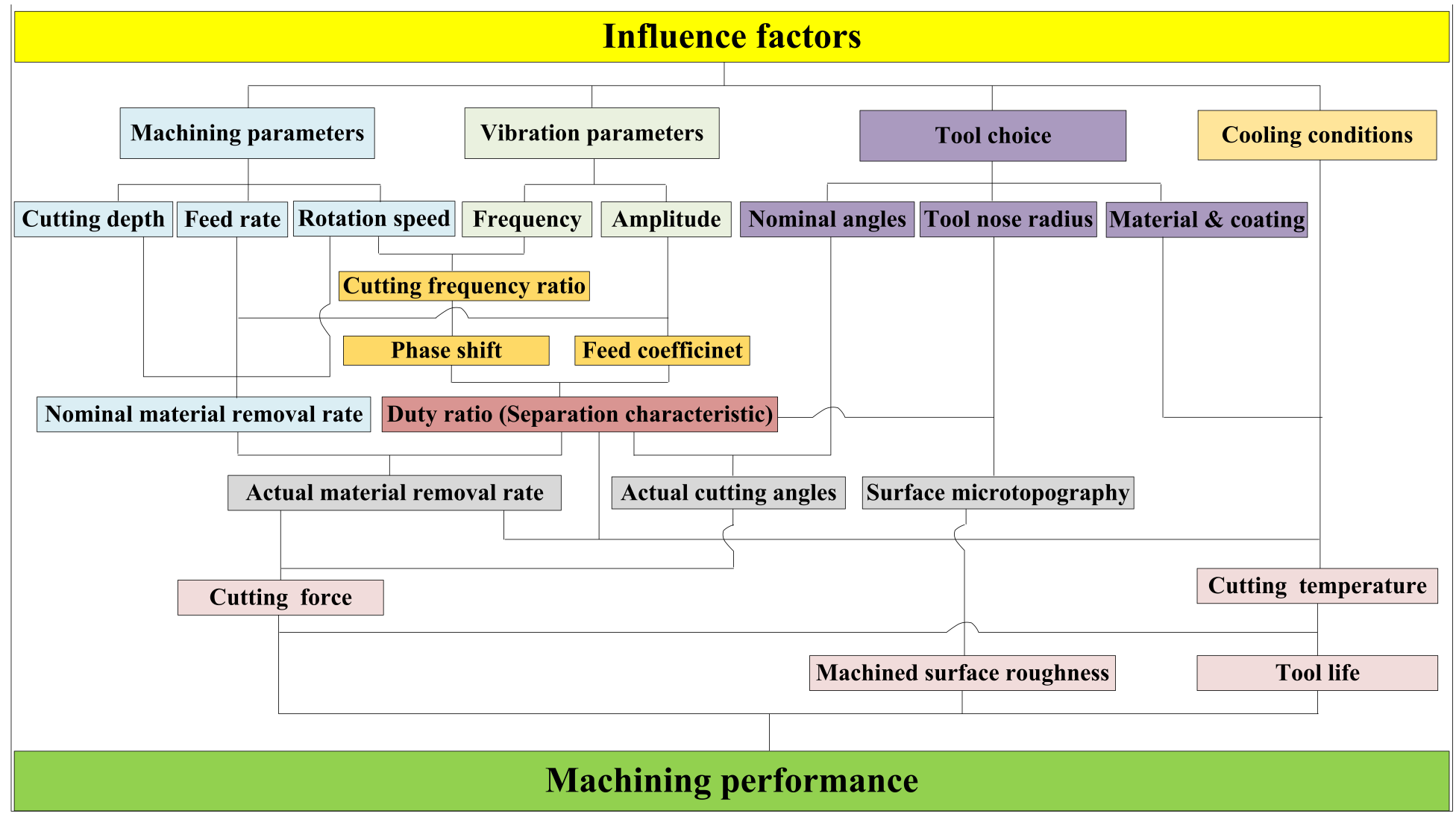

\section{Figure 5}

Relationship among the influencing factors on the machining performance of AUVCRelationship among the influencing factors on the machining performance of AUVC 


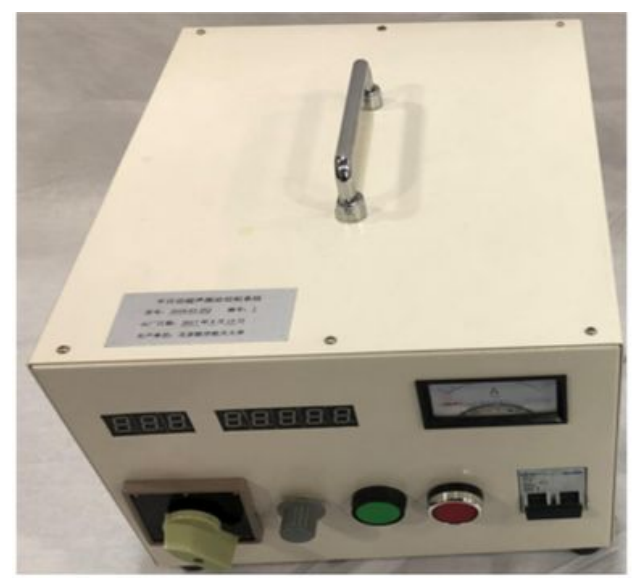

(a) Ultrasonic power supply

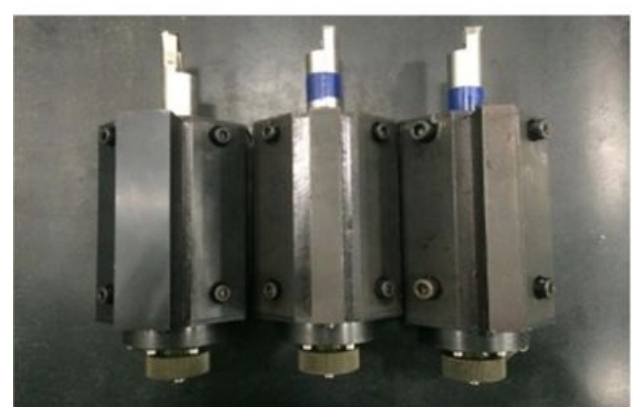

(b) Ultrasonic transducer

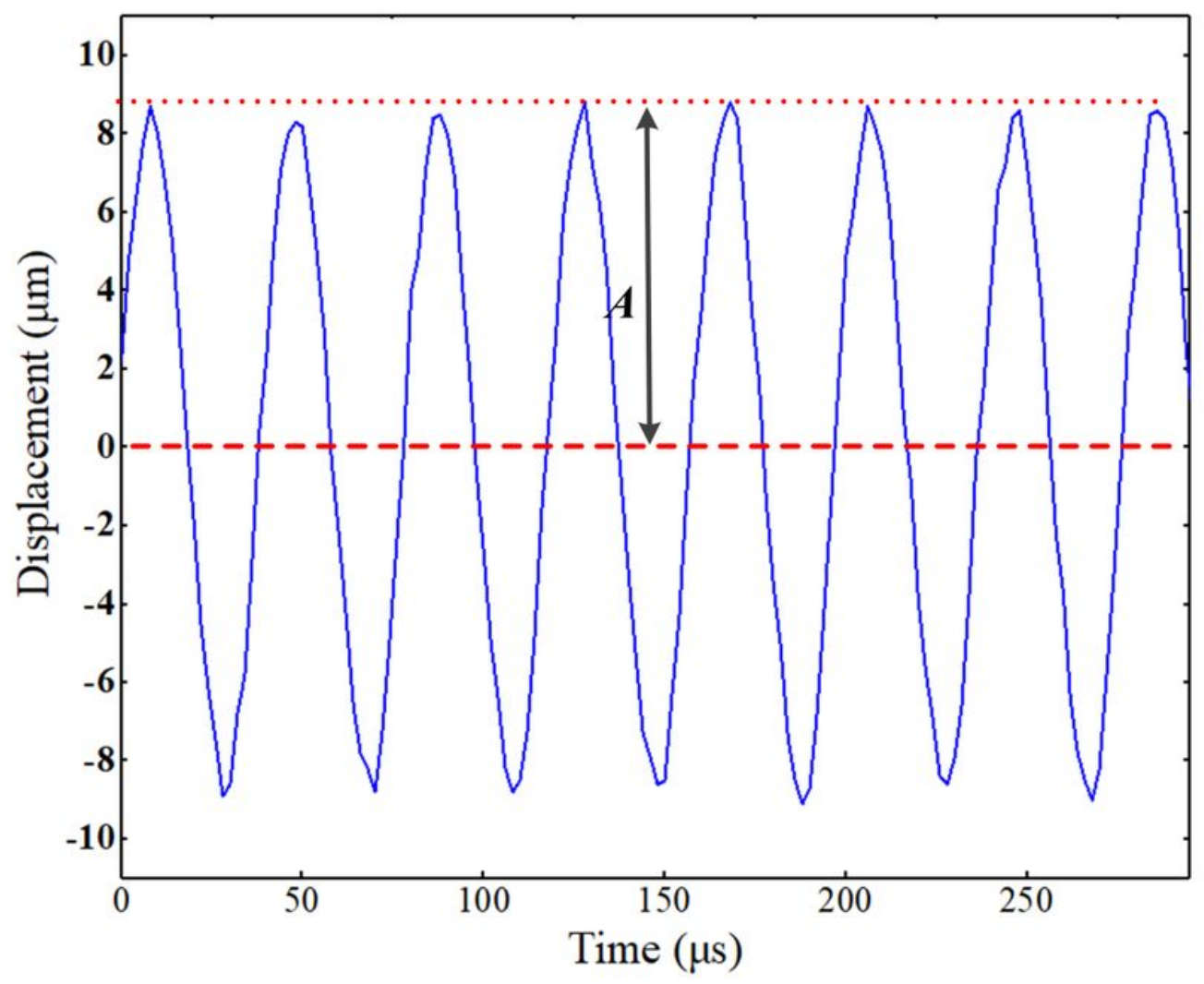

(C) Actual measured amplitude of th ultrasonic transducer

Figure 6

Ultrasonic vibration system and its maximum amplitude

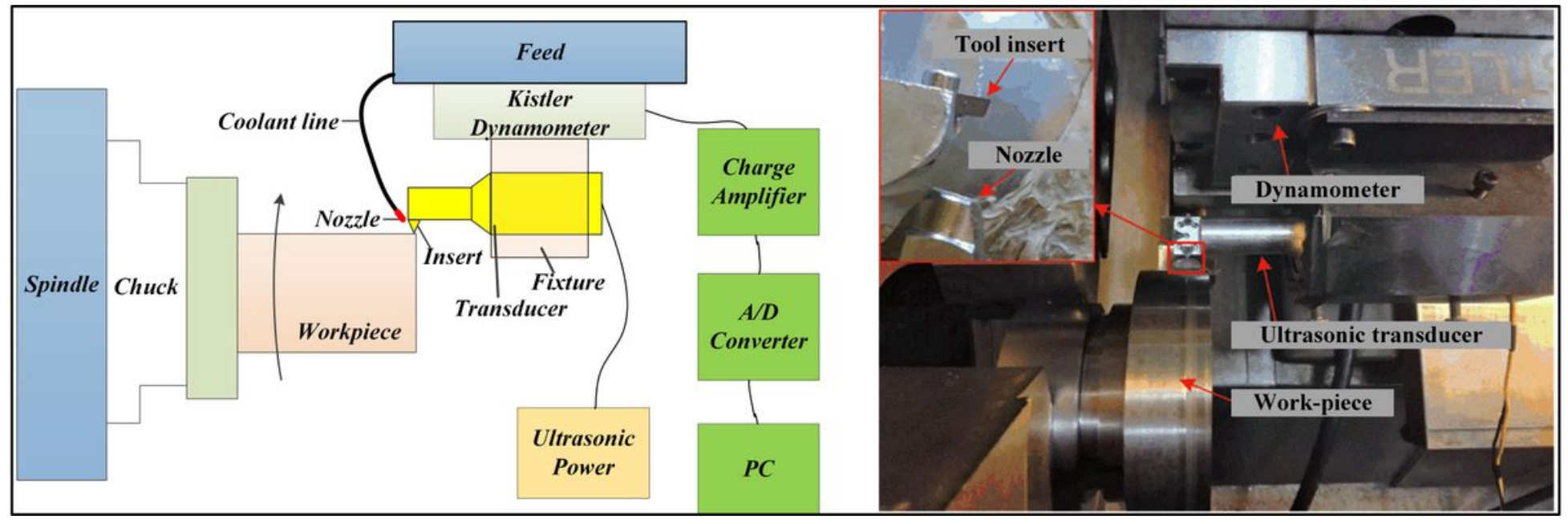

Figure 7

The experiment platform 
(a) Relationship of $F_{c}$ and rotation speed $n$

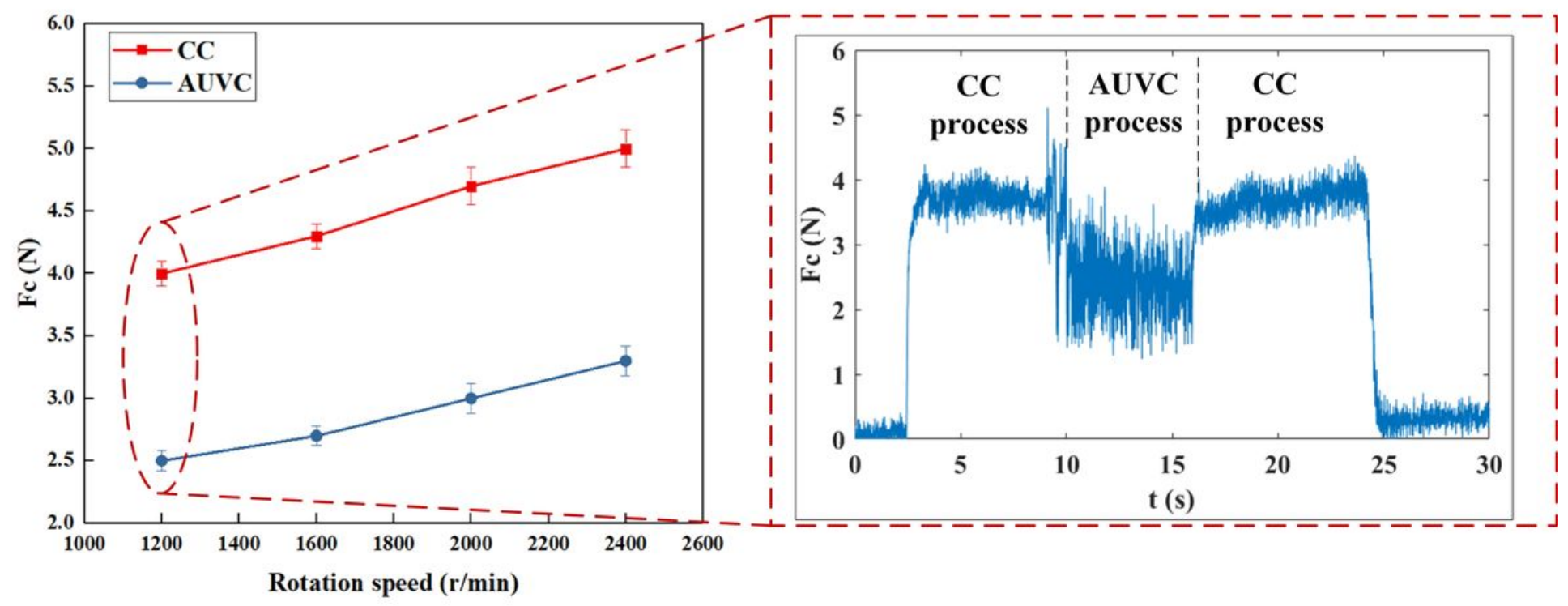

(b) Relationship of $F_{f}$ and rotation speed $n$

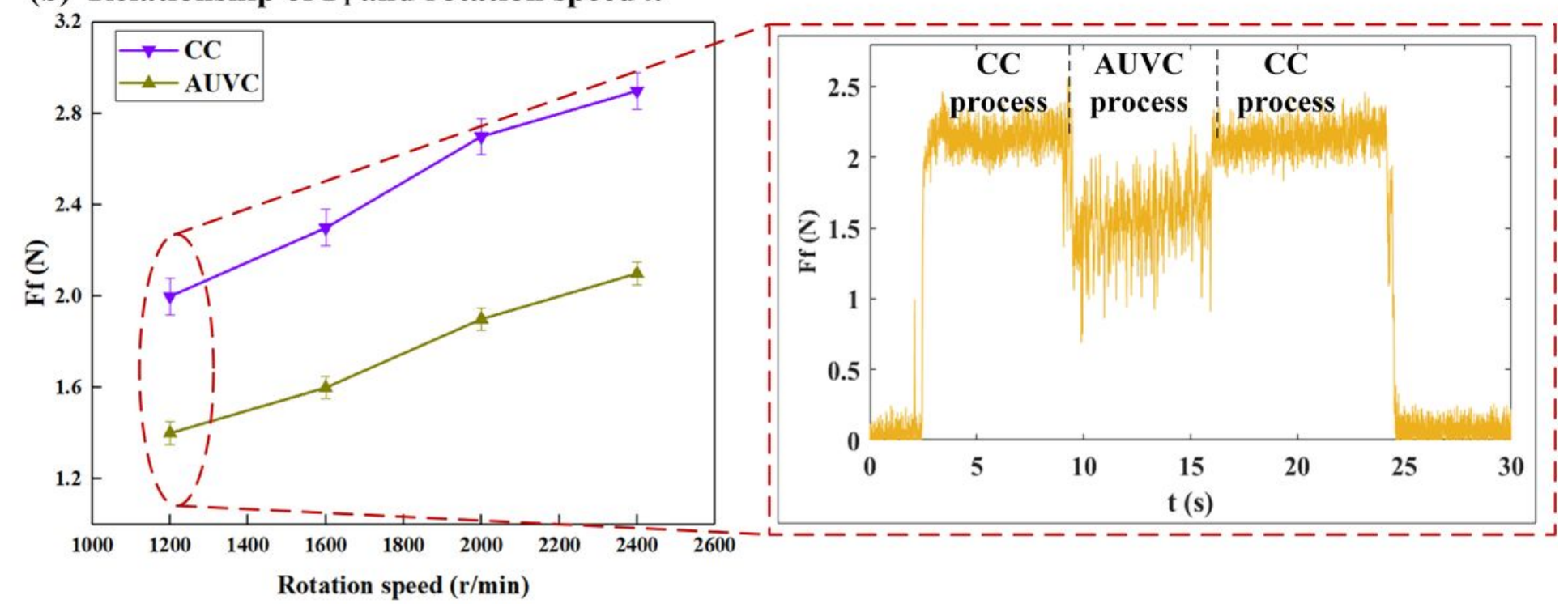

Figure 8

Results of main cutting force Fc and feed resistance force Ff with different rotation speed (ap $=0.025 \mathrm{~mm}$, $f=0.005 \mathrm{~mm} / \mathrm{r}, A=9 \mu \mathrm{m}$, Dry cutting) 
(a) Relationship of $F_{c}$ and cutting depth $a_{p}$

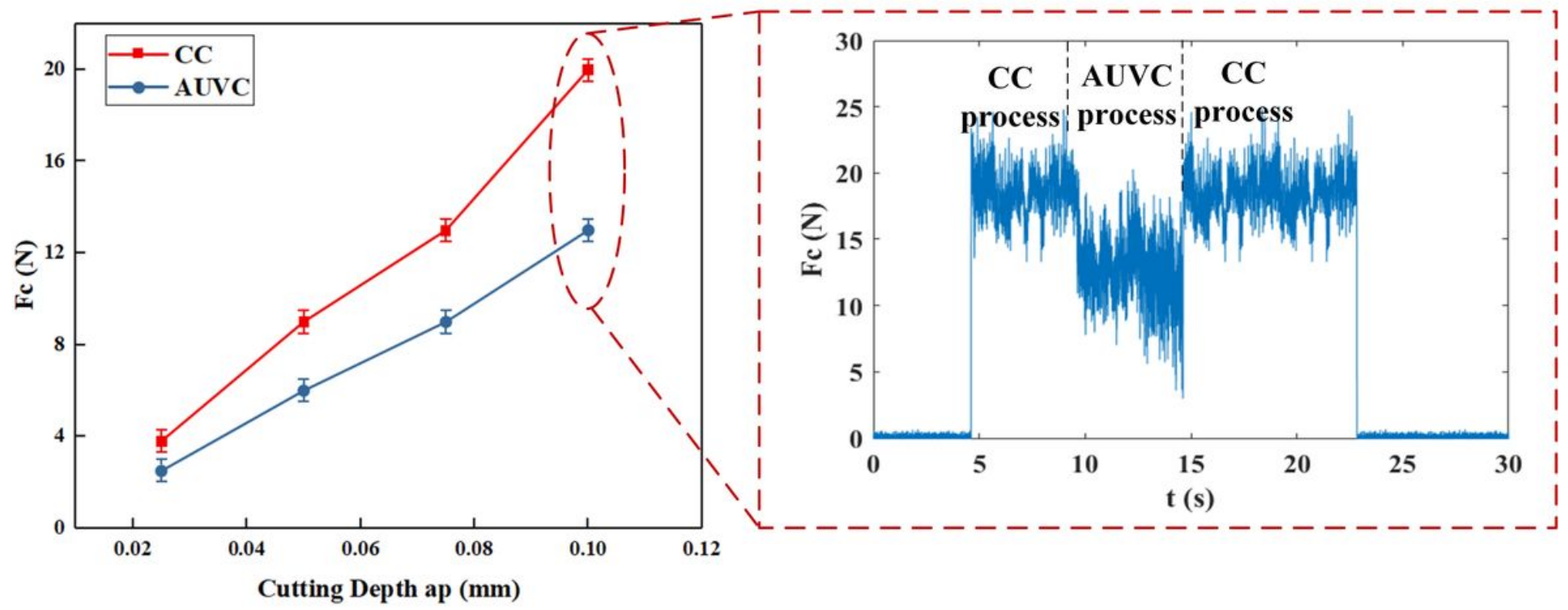

(b) Relationship of $F_{f}$ and cutting depth $a_{p}$

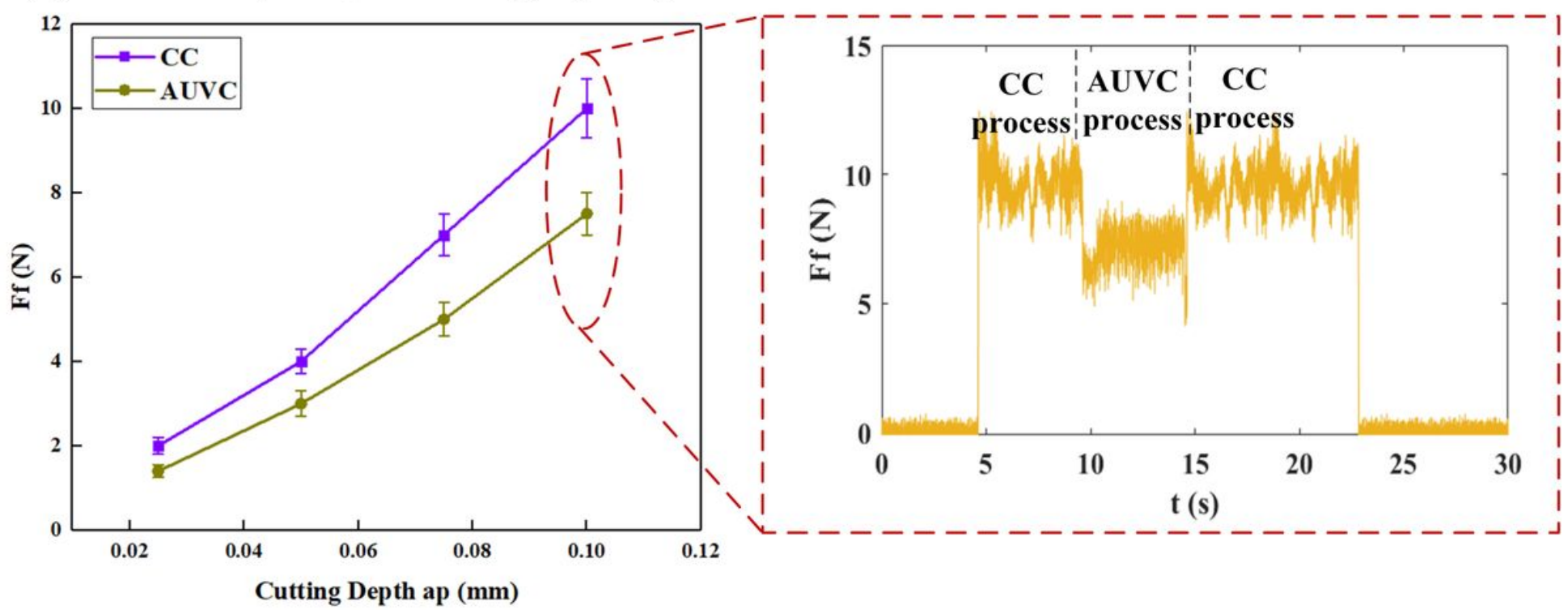

Figure 9

Results of main cutting force Fc and feed resistance force Ff with different cutting depth ( $\mathrm{n}=1200 \mathrm{r} / \mathrm{min}$, $f=0.005 \mathrm{~mm} / \mathrm{r}, A=9 \mu \mathrm{m}$, Dry cutting) 
(a) Relationship of $\mathrm{F}_{\mathrm{c}}$ and feed rate $f$

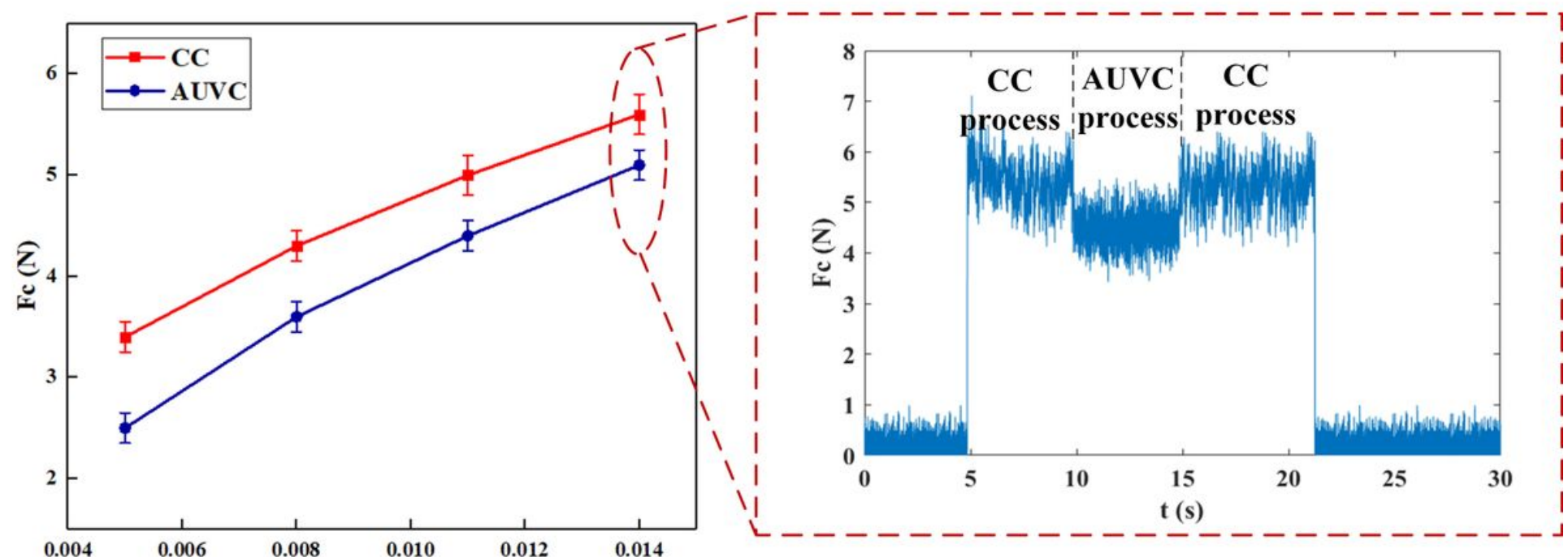

(b) Relationship of $\mathrm{F}_{\mathrm{f}}$ and feed rate $f$

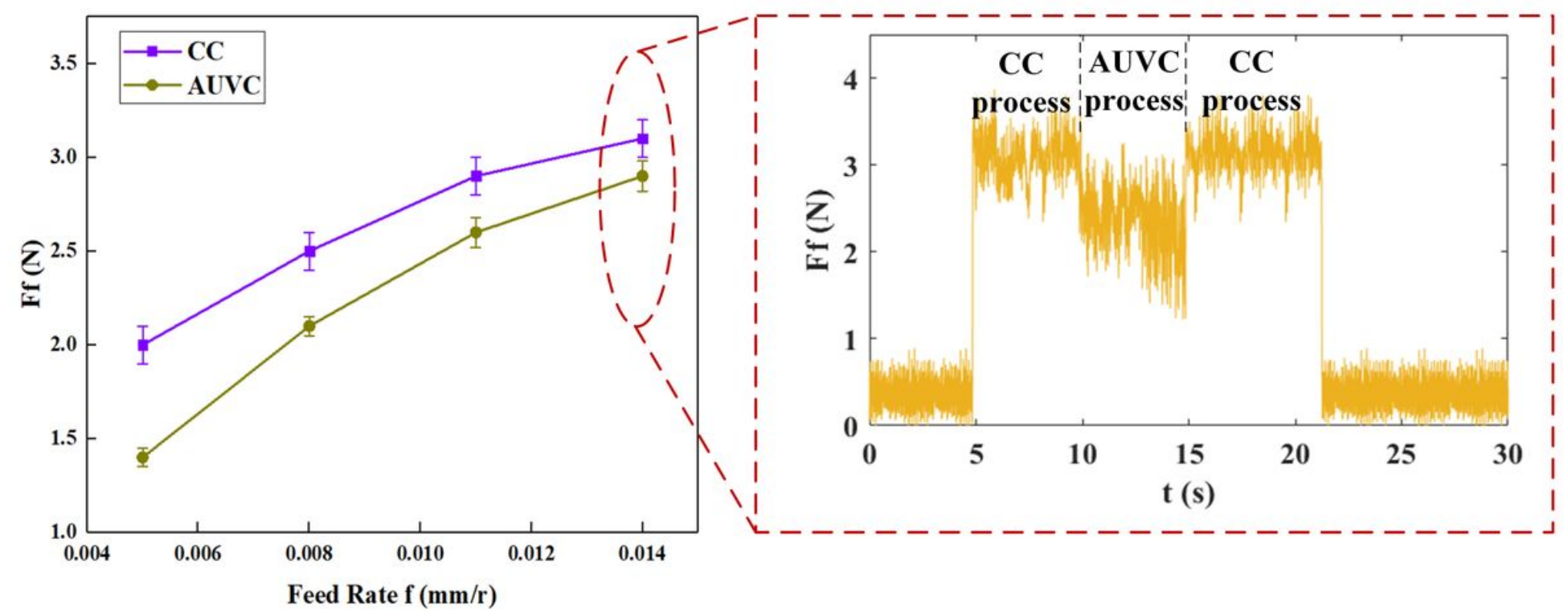

Figure 10

Results of main cutting force Fc and feed resistance force Ff with different feed rate $(n=1200 \mathrm{r} / \mathrm{min}$, $a p=0.025 \mathrm{~mm} / \mathrm{r}, \mathrm{A}=9 \mu \mathrm{m}$, Dry cutting) 
(a) Relationship of $\mathrm{F}_{\mathrm{c}}$ and amplitude $A$

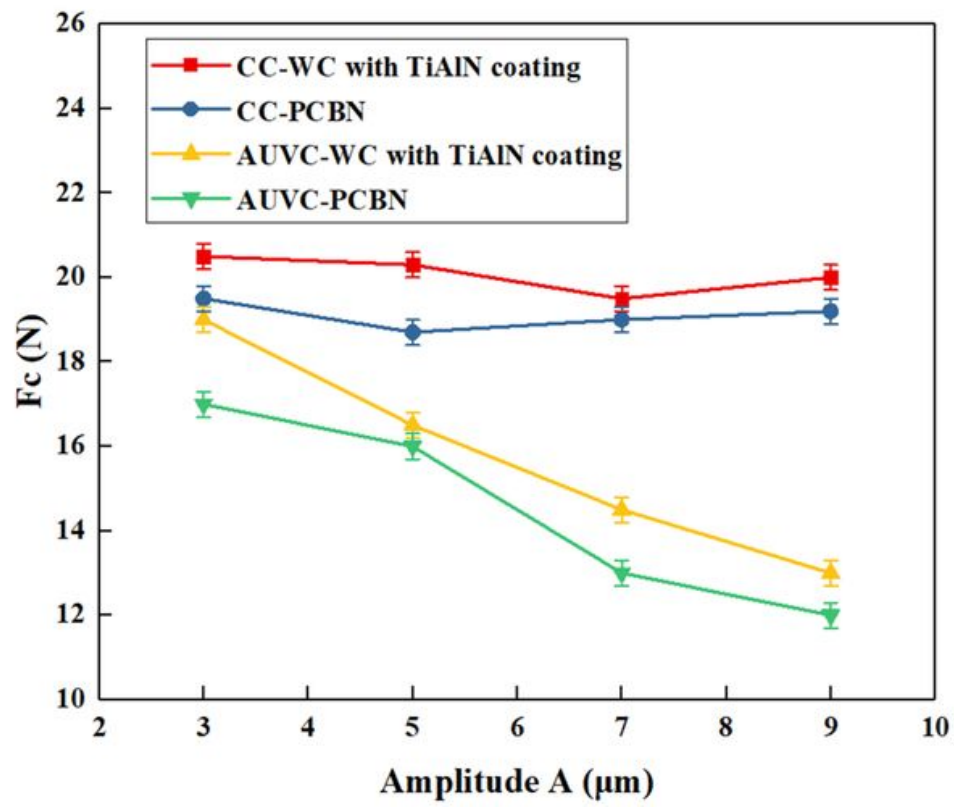

(b) Relationship of $\mathrm{F}_{\mathrm{f}}$ and amplitude $A$

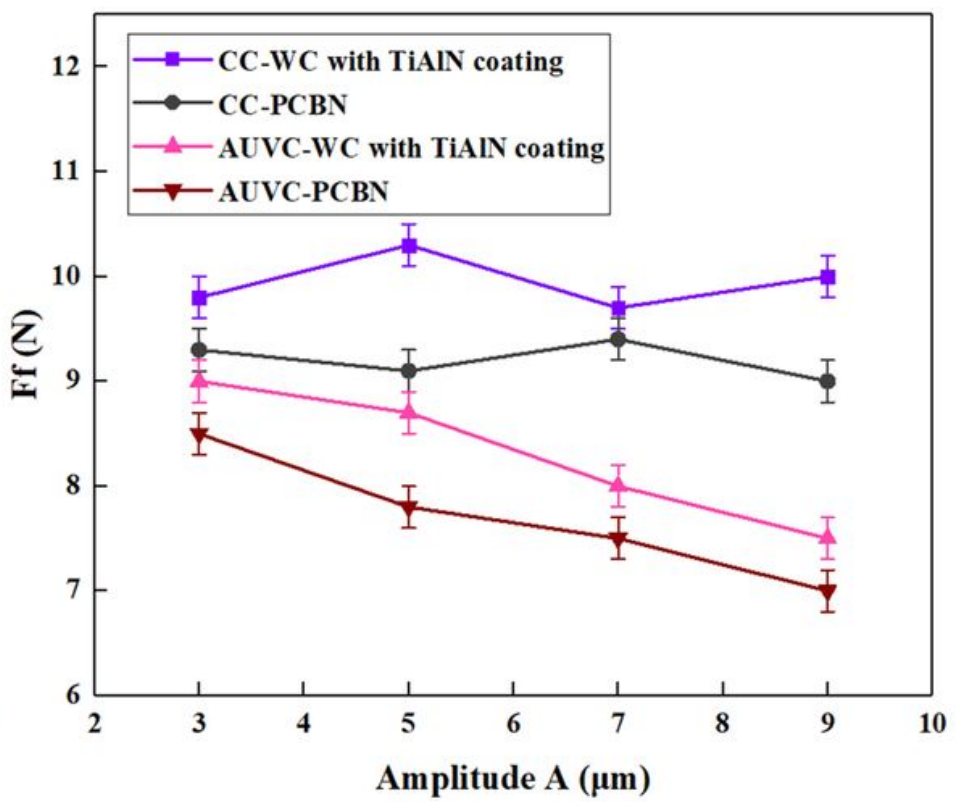

\section{Figure 11}

Results of main cutting force Fc and feed resistance force $\mathrm{Ff}$ with different tools under different amplitude values ( $n=1200 \mathrm{r} / \mathrm{min}, \mathrm{ap}=0.025 \mathrm{~mm} / \mathrm{r}$, Dry cutting)

(a) Tool life versus cutting depth $\mathrm{a}_{\mathrm{p}}(f=0.005 \mathrm{~mm} / \mathrm{r}, A=9 \mathrm{um})$

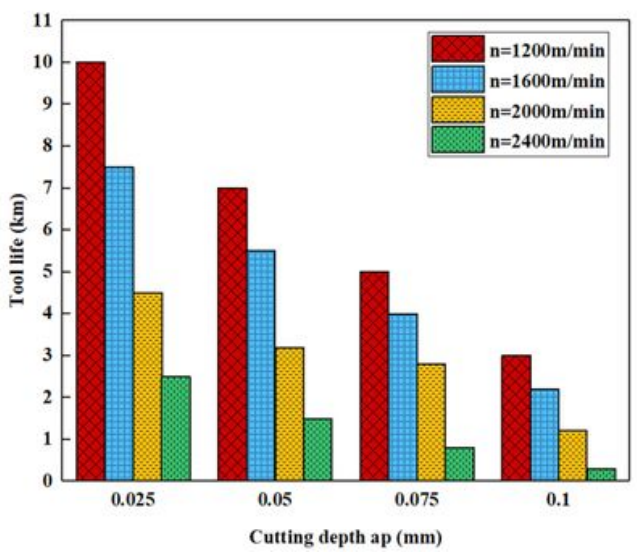

(b) Tool life versus feed rate $f\left(\mathrm{a}_{\mathrm{p}}=0.05 \mathrm{~mm} / \mathrm{r}, A=9 \mathrm{um}\right)$

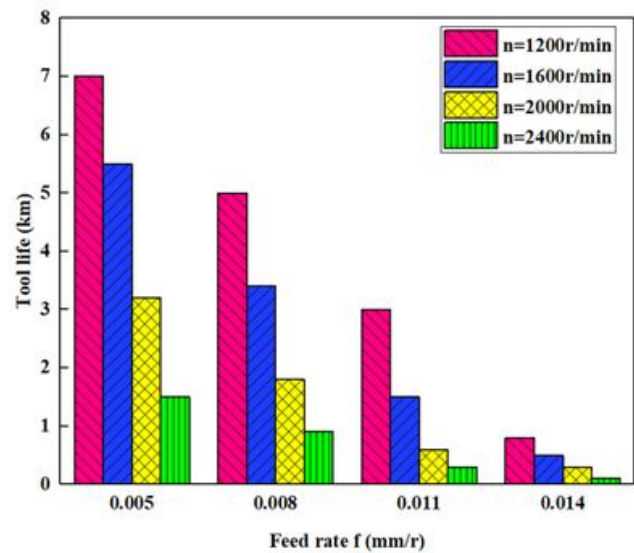

(c) Tool life versus amplitude $A\left(\mathrm{a}_{\mathrm{p}}=0.05 \mathrm{~mm} / \mathrm{r}, f=0.005 \mathrm{~mm} / \mathrm{r}\right)$

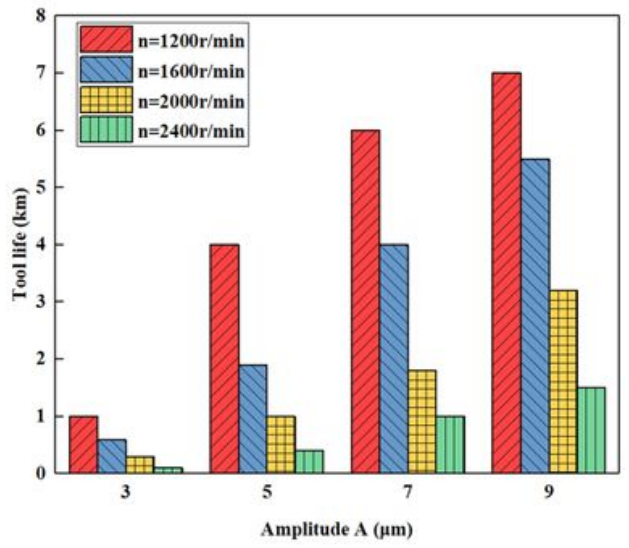

Figure 12

The influence of cutting parameters and amplitude on tool life (Dry cutting) 
(a) Rake face

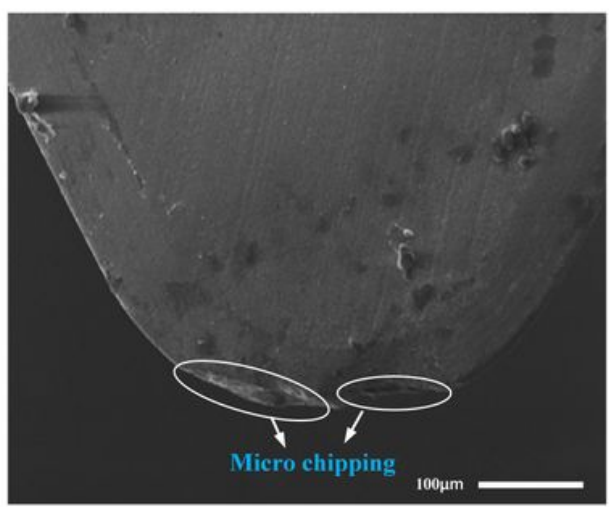

(b) Flank face

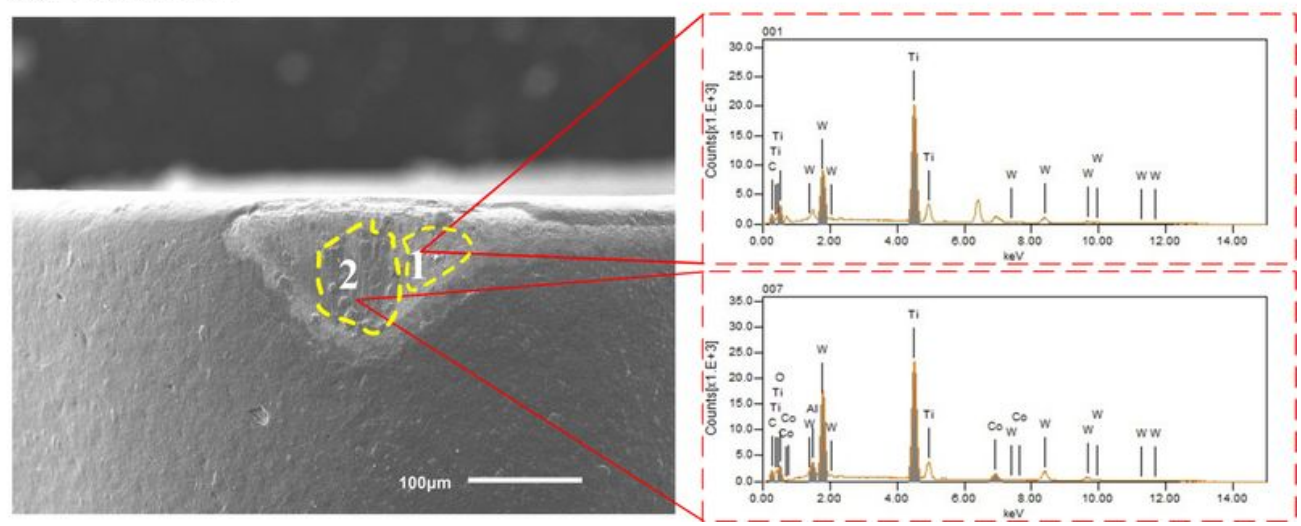

Figure 13

SEM pictures and EDX analysis on the flank face of WC tool after $3 \mathrm{~km}$ cutting distance of AUVC $(\mathrm{n}=1200 \mathrm{r} / \mathrm{min}, \mathrm{ap}=0.025 \mathrm{~mm} / \mathrm{r}, \mathrm{f}=0.005 \mathrm{~mm} / \mathrm{r}, \mathrm{A}=9 \mu \mathrm{m}$, Dry cutting)

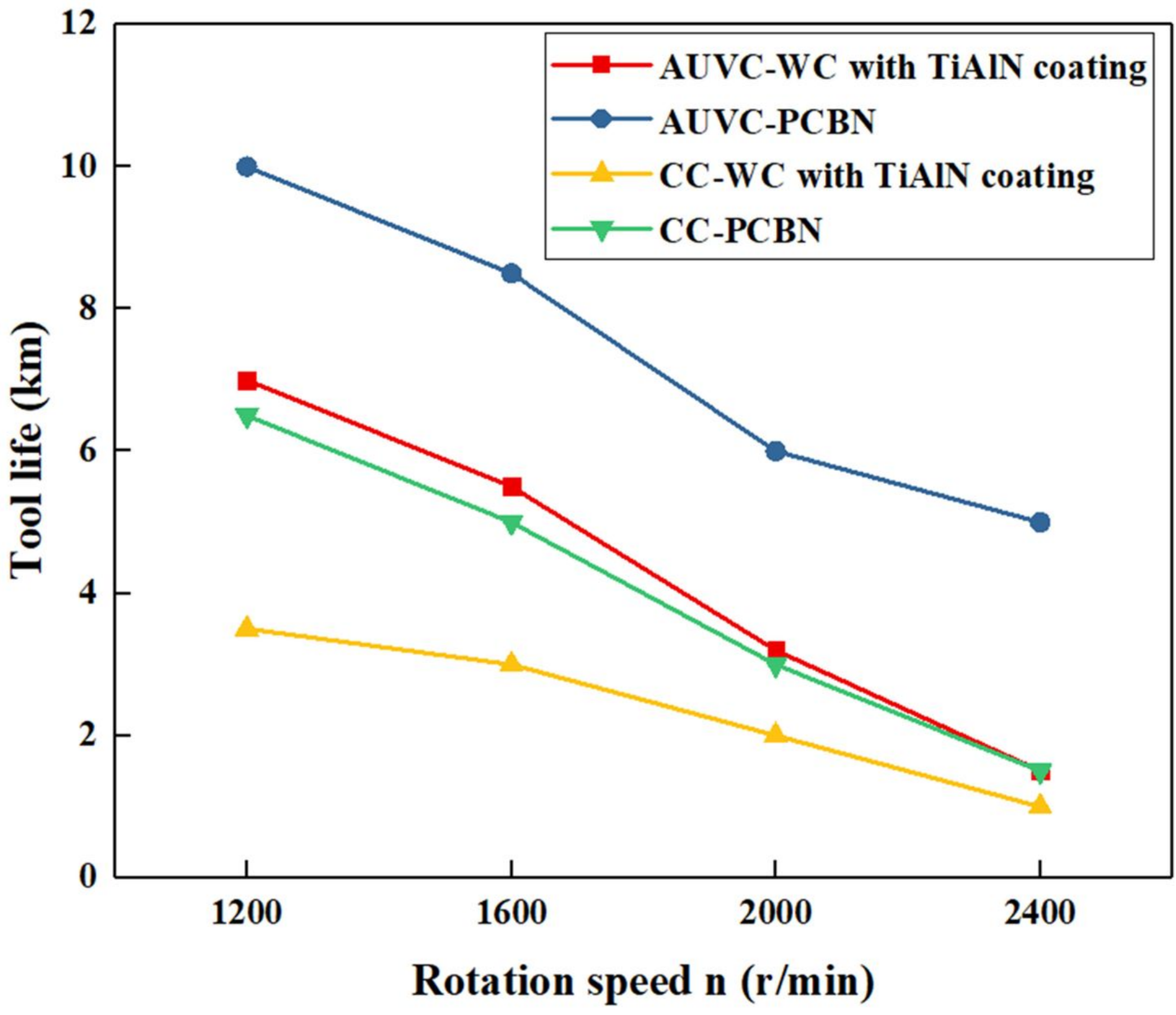


Figure 14

Comparative results for a WC tool and PCBN tool for cutting distance with different rotation speed (ap $=0.025 \mathrm{~mm} / \mathrm{r}, \mathrm{f}=0.005 \mathrm{~mm} / \mathrm{r}, \mathrm{A}=9 \mu \mathrm{m}$, Dry cutting)

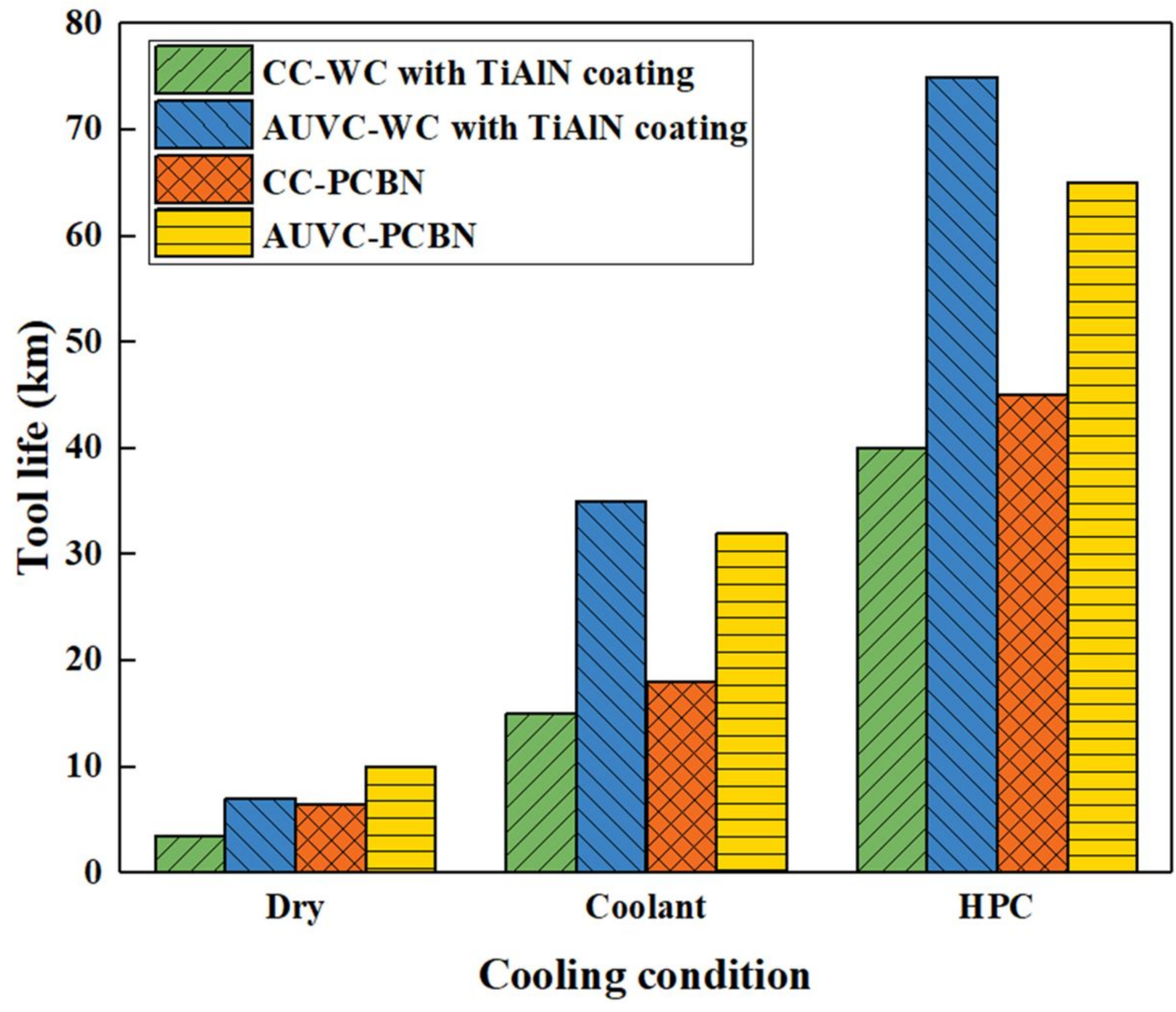

Figure 15

Experimental results for the influence of cooling conditions on tool life $(n=1200 \mathrm{r} / \mathrm{min}$, ap $=0.025 \mathrm{~mm} / \mathrm{r}$, $f=0.005 \mathrm{~mm} / \mathrm{r}, \mathrm{A}=9 \mu \mathrm{m})$ 
(a) WC with TiAIN coating

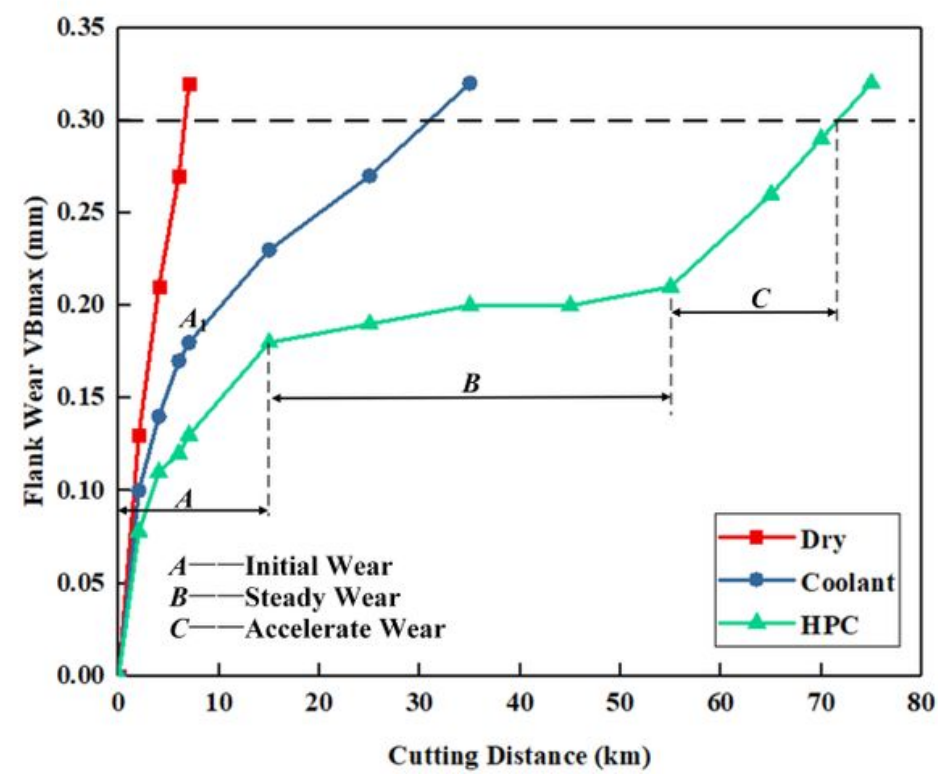

(b) PCBN

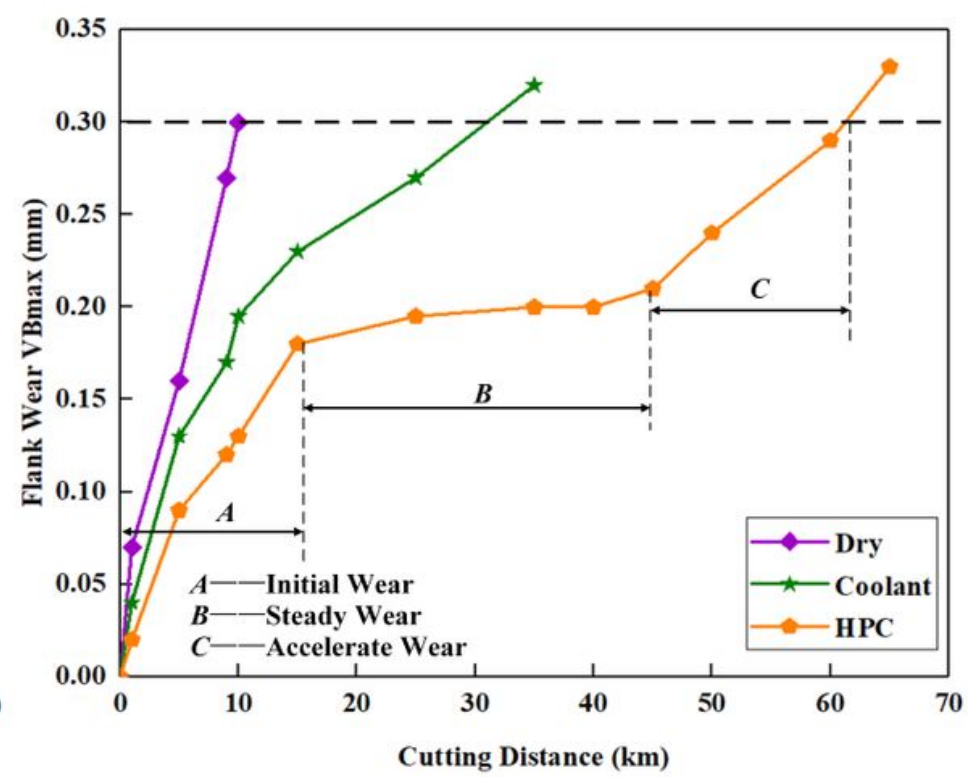

Figure 16

Tool wear process with different cooling methods $(n=1200 \mathrm{r} / \mathrm{min}, a p=0.025 \mathrm{~mm} / r, f=0.005 \mathrm{~mm} / \mathrm{r}, A=9 \mu \mathrm{m})$ 


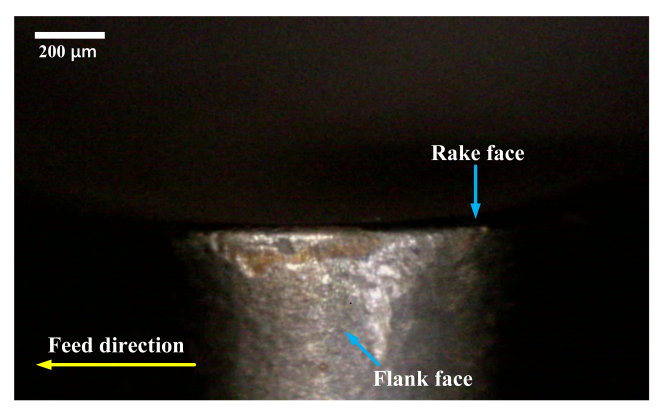

(a) $2 \mathrm{~km}$, Dry

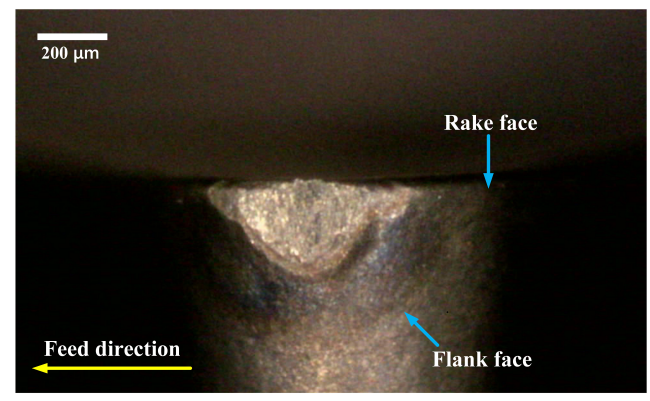

(d) $5 \mathrm{~km}$, Dry

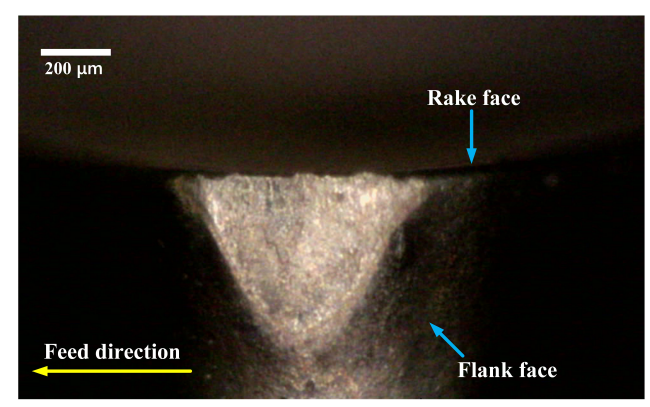

(g) $7 \mathrm{~km}$, Dry
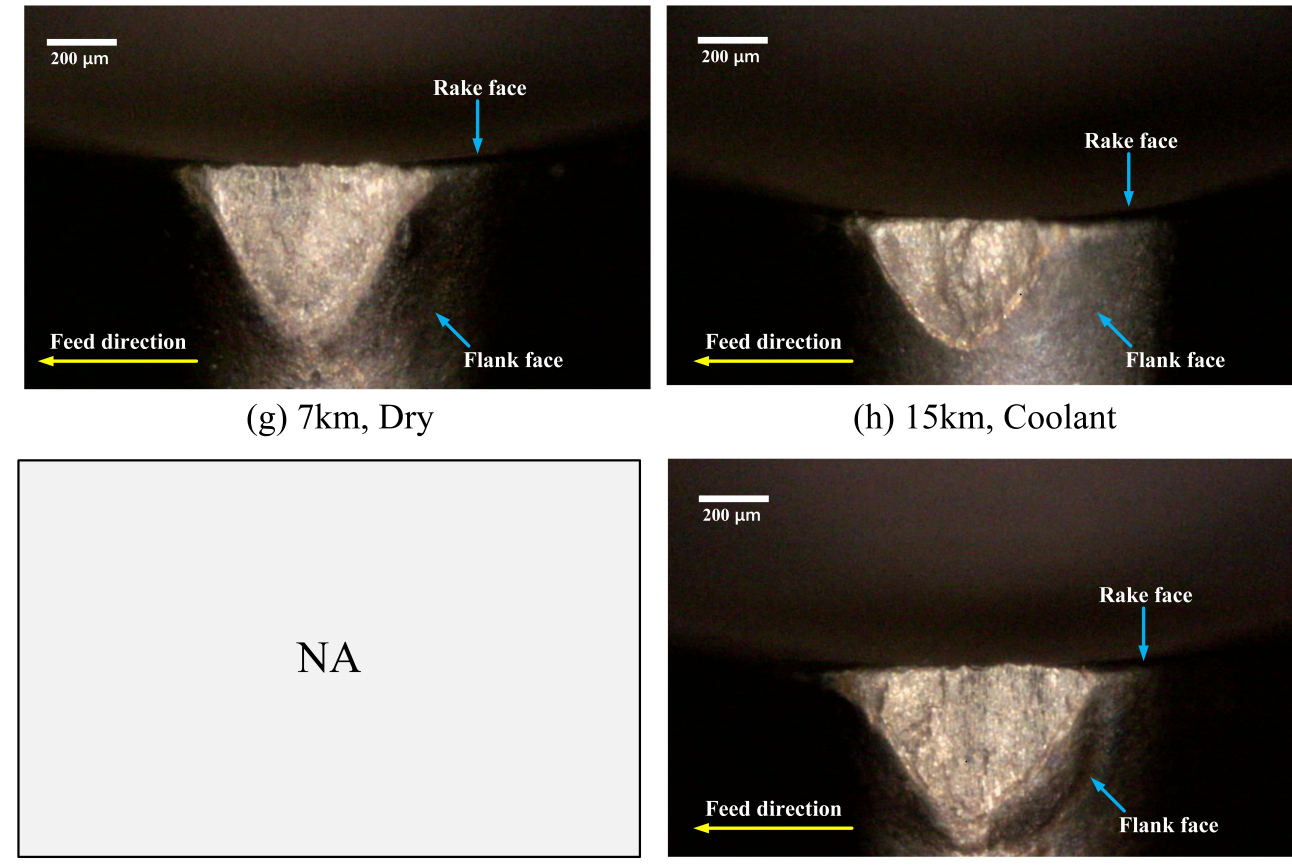

(h) $15 \mathrm{~km}$, Coolant

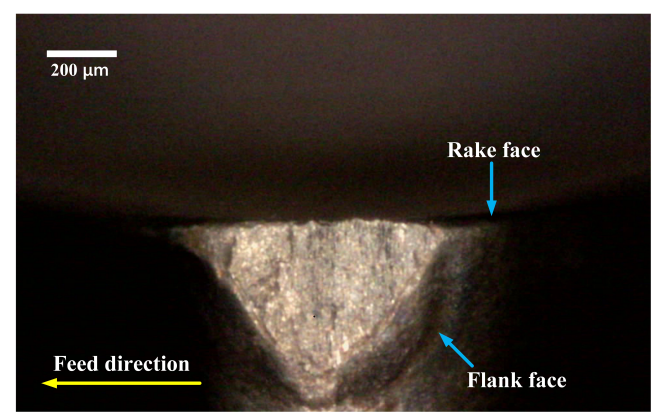

(j) $35 \mathrm{~km}$, Coolant

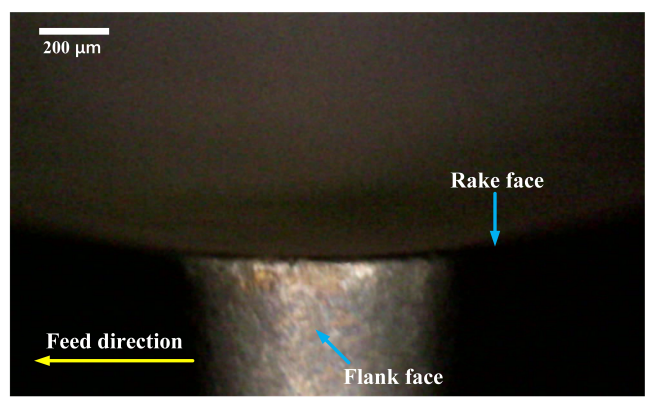

(c) $2 \mathrm{~km}, \mathrm{HPC}$

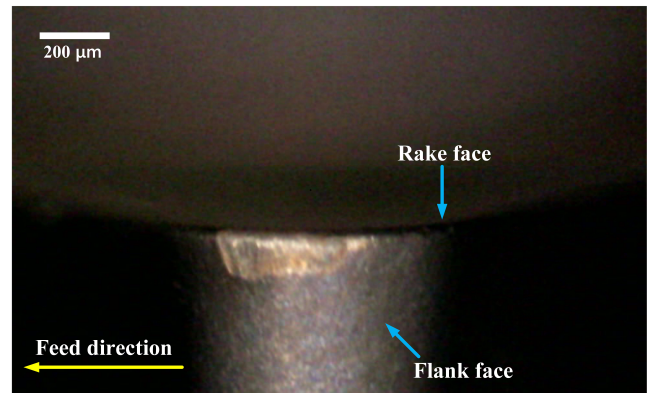

(f) $5 \mathrm{~km}, \mathrm{HPC}$

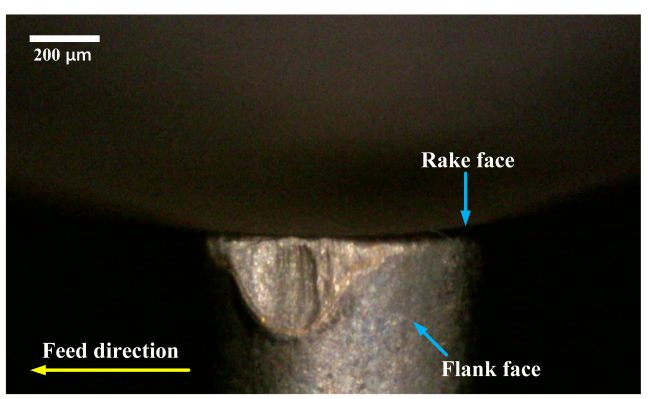

(i) $30 \mathrm{~km}, \mathrm{HPC}$

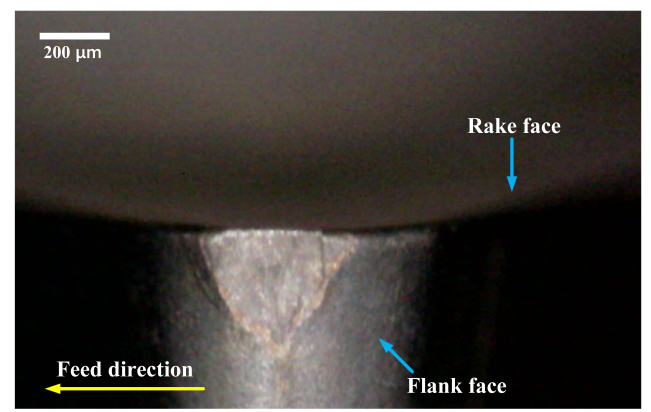

(k) $50 \mathrm{~km}, \mathrm{HPC}$

\section{Figure 17}

Compared micrographs of flank wear under different cooling conditions for AUVC $(n=1200 \mathrm{r} / \mathrm{min}$, $a p=0.025 \mathrm{~mm} / \mathrm{r}, \mathrm{f}=0.005 \mathrm{~mm} / \mathrm{r}, \mathrm{A}=9 \mu \mathrm{m})$ 
(a) $2 \mathrm{~km}$

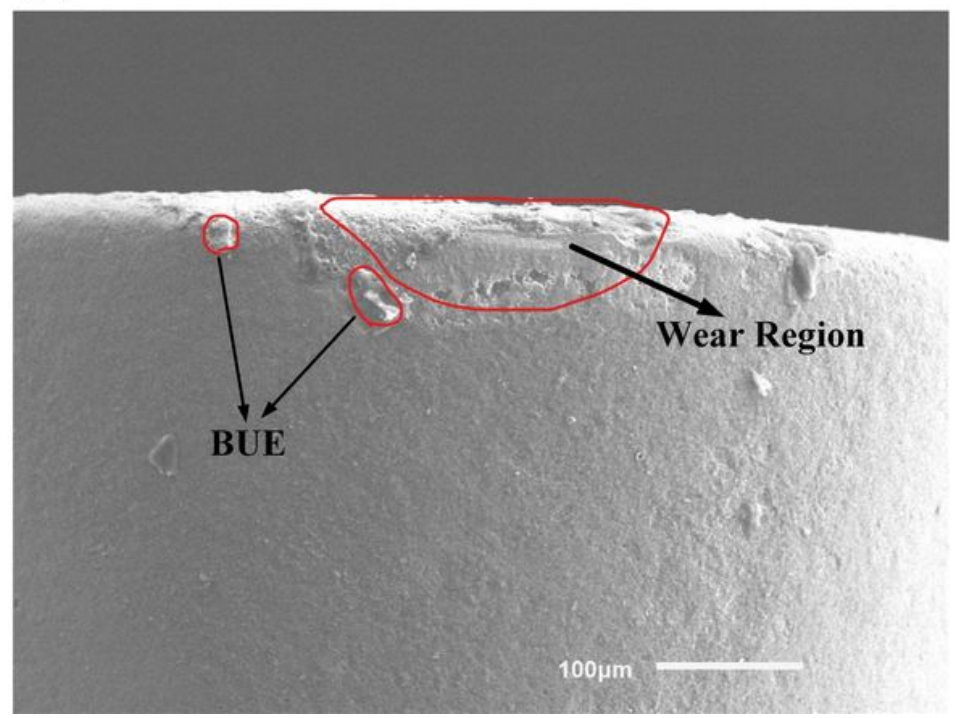

(b) $40 \mathrm{~km}$

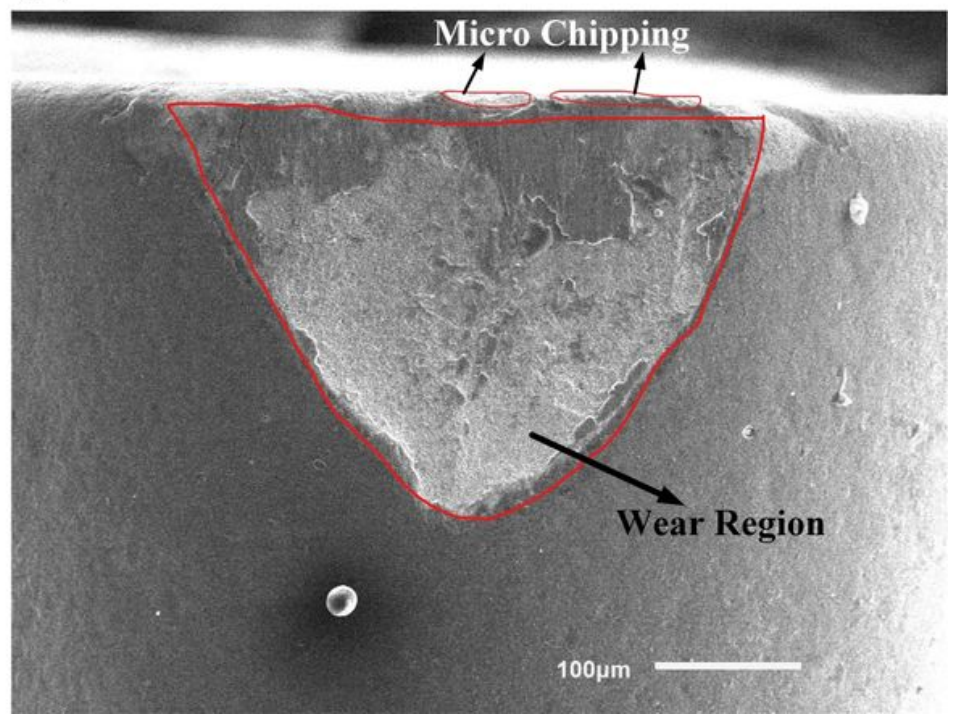

\section{Figure 18}

SEM images of flank wear on a WC tool after $2 \mathrm{~km}$ and $40 \mathrm{~km}$ with HPC

(a) Machined surface roughness versus cutting depth $a_{p}$

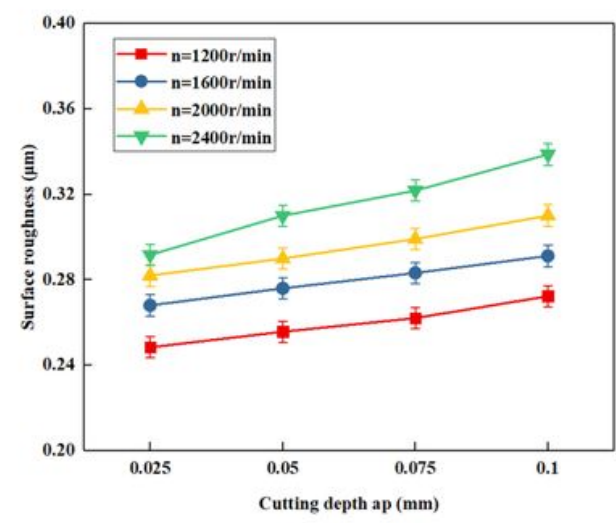

(b) Machined surface roughness versus feed rate $f$

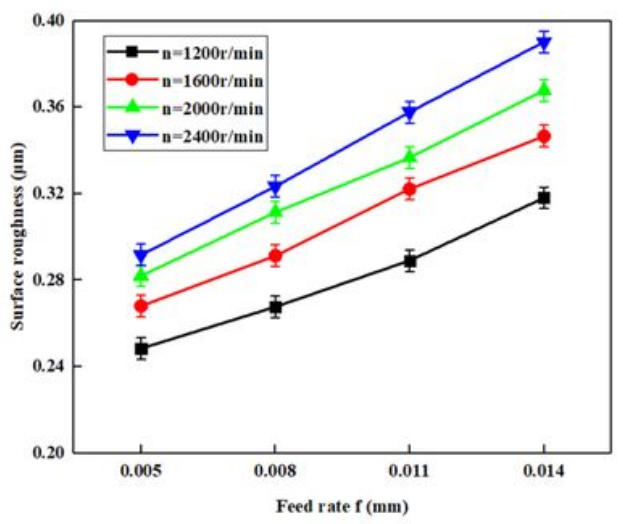

(c) Machined surface roughness versus amplitude $A$

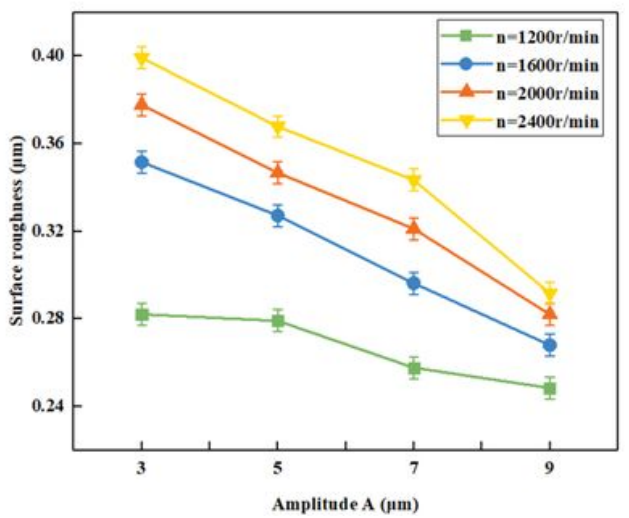

Figure 19

Influence on surface roughness of WC tool for AUVC after $10 \mathrm{~km}$ with coolant 


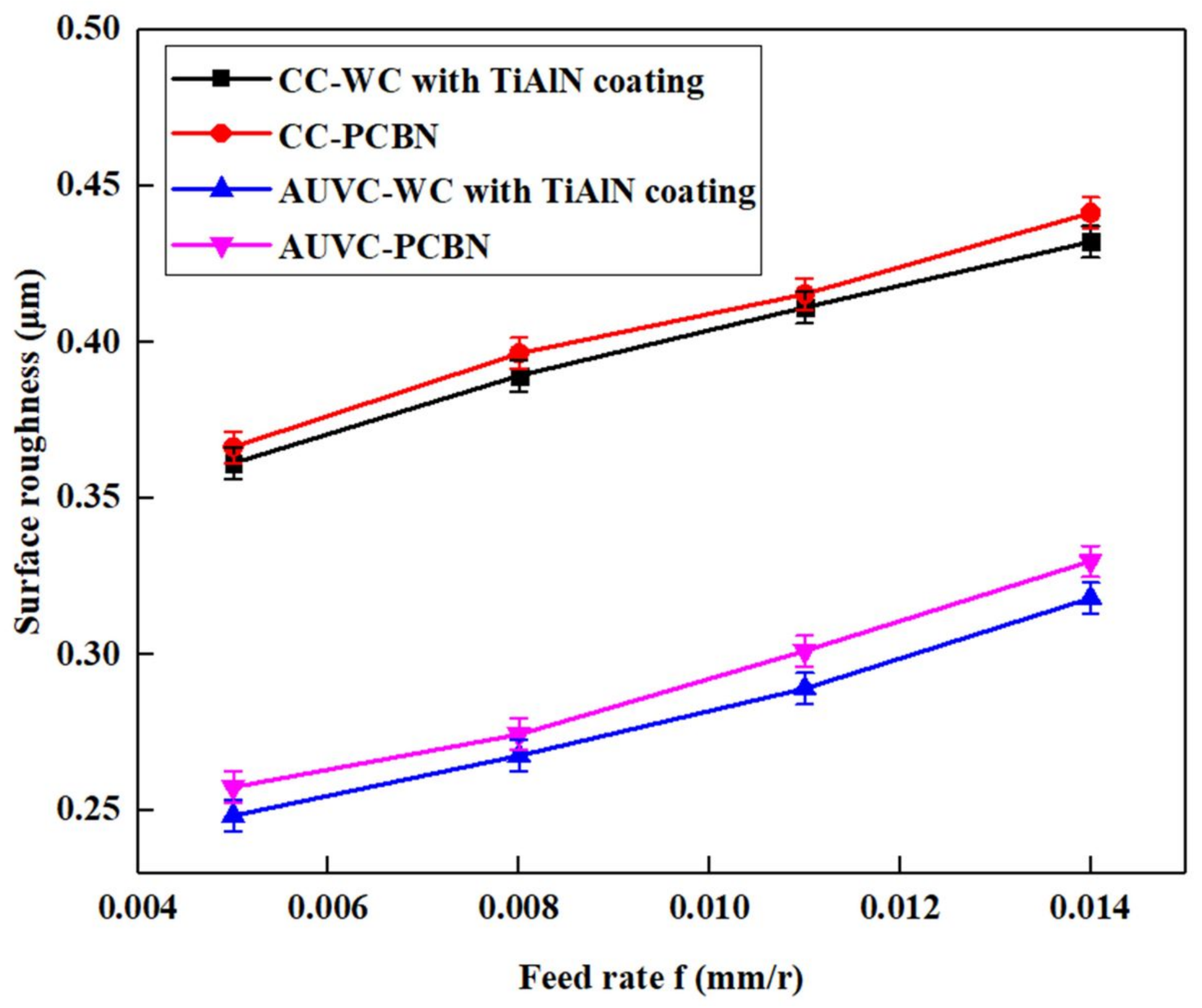

Figure 20

Influence of tool material on surface roughness for AUVC after $10 \mathrm{~km}$ with coolant $(\mathrm{n}=1200 \mathrm{r} / \mathrm{min}$, ap $=0.025 \mathrm{~mm} / \mathrm{r}, \mathrm{A}=9 \mu \mathrm{m})$ 
(a) WC with TiAIN coating

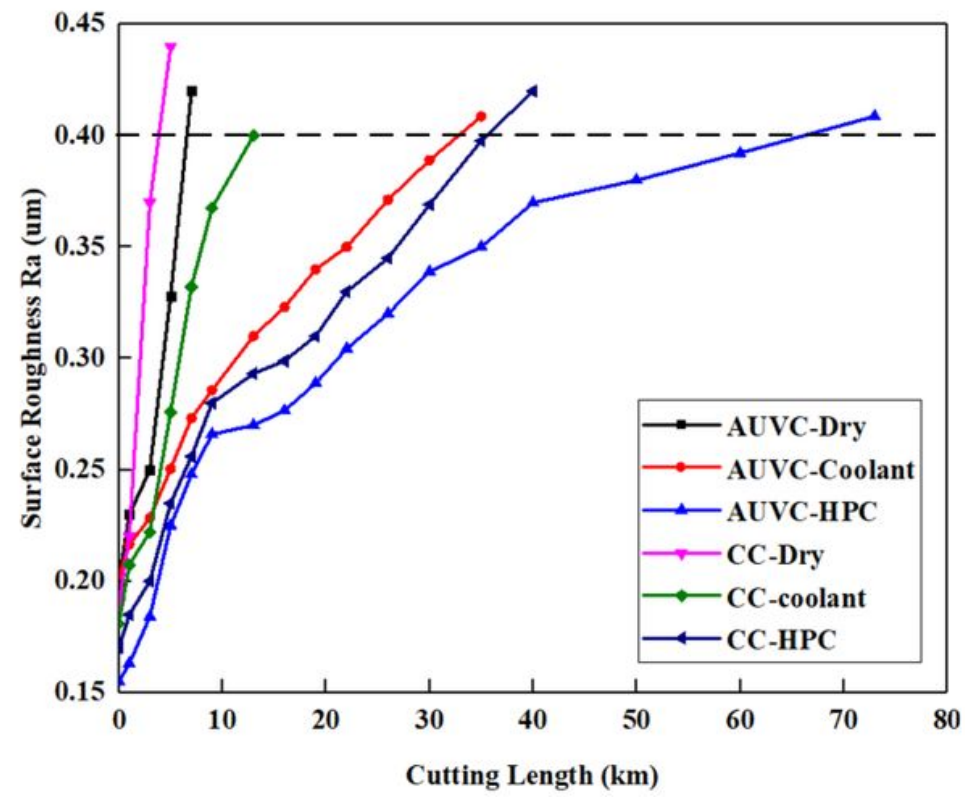

(b) PCBN

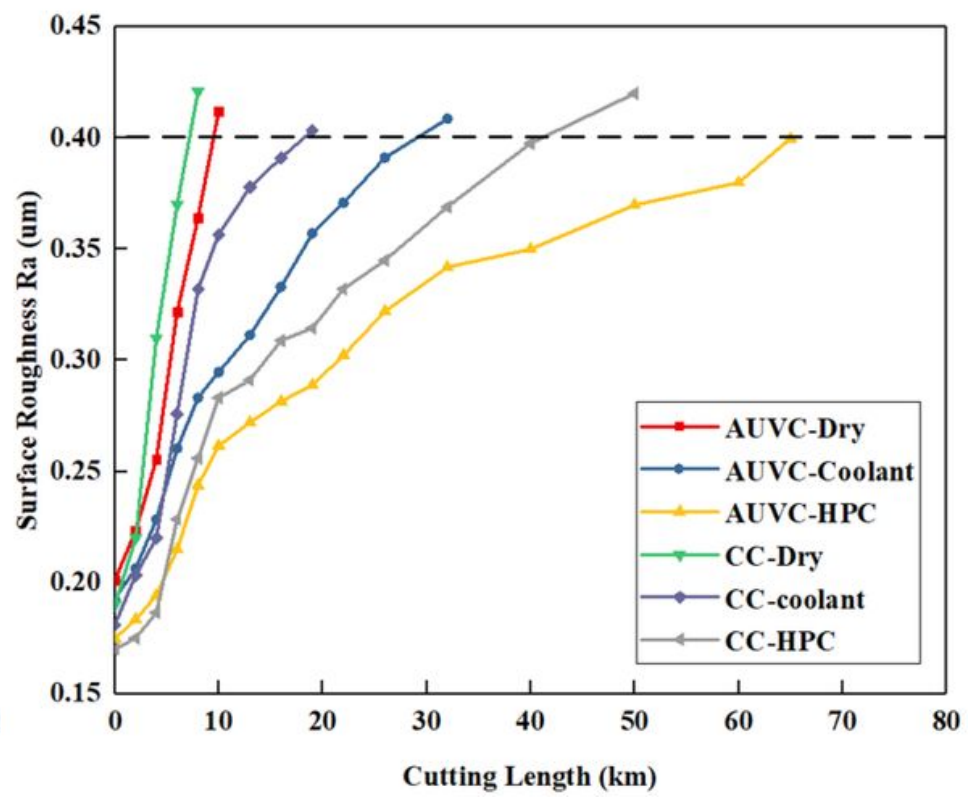

Figure 21

Machined surface roughness with respect to cutting distance $(\mathrm{n}=1200 \mathrm{r} / \mathrm{min}$, ap $=0.025 \mathrm{~mm} / \mathrm{r}$, $f=0.005 \mathrm{~mm} / \mathrm{r}, A=9 \mu \mathrm{m})$ 
(a) Before machining

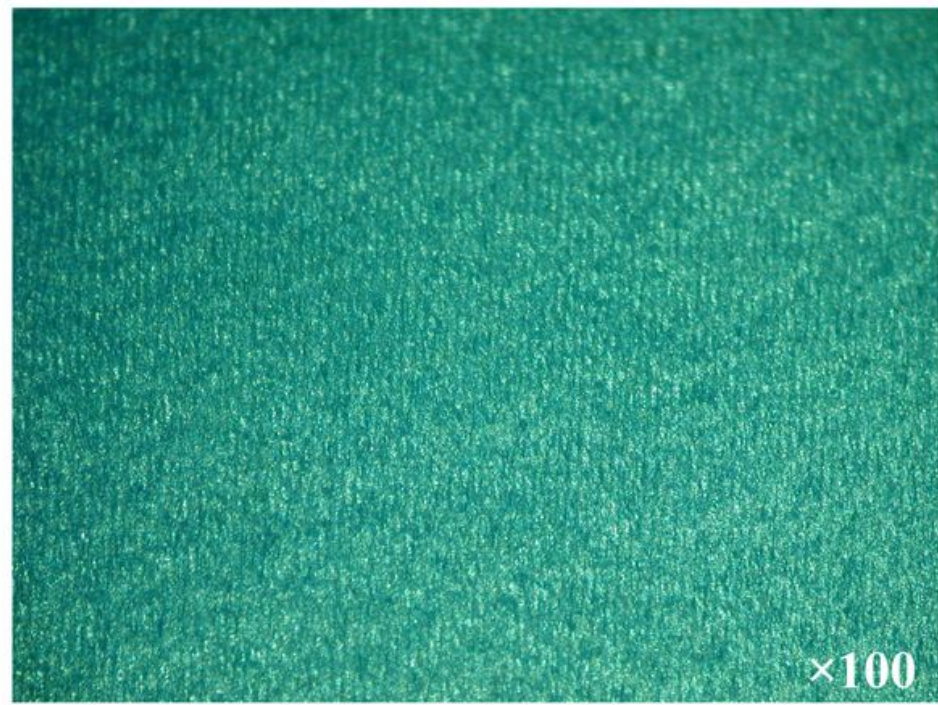

\section{(c) After $20 \mathrm{~km}$}

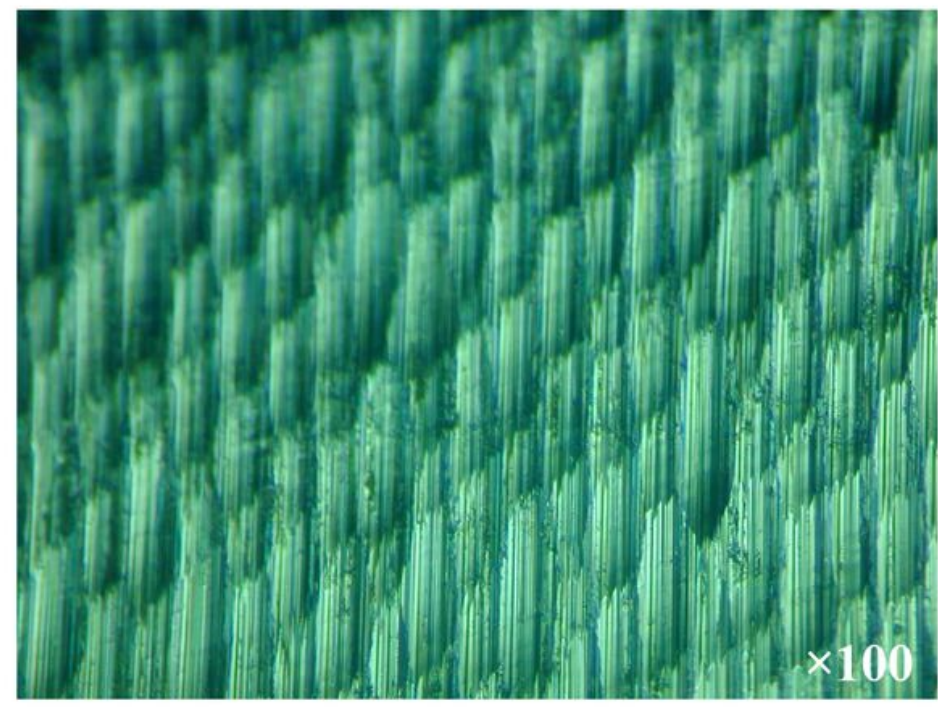

(b) After 5km

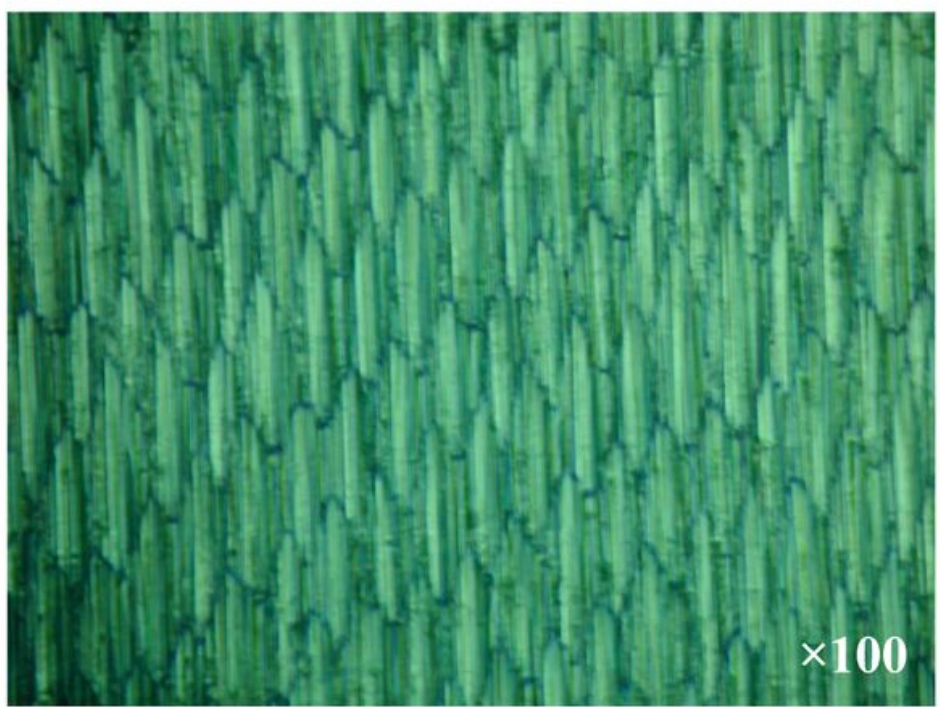

(d) After $40 \mathrm{~km}$

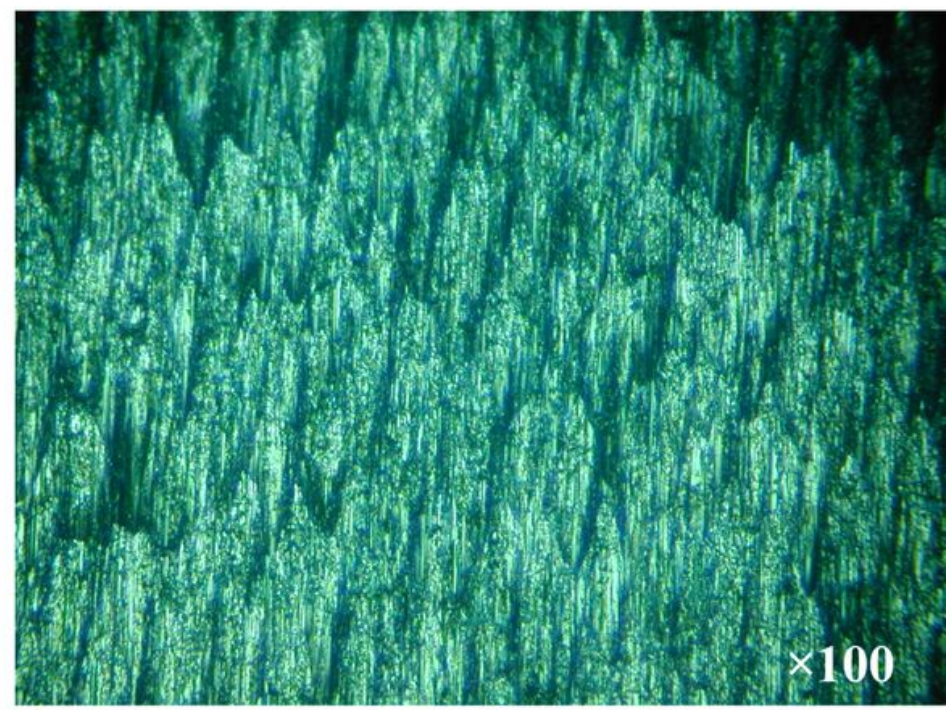

Figure 22

Machined surface roughness as the process continues $(n=1200 \mathrm{r} / \mathrm{min}$, ap $=0.025 \mathrm{~mm} / \mathrm{r}, \mathrm{f}=0.005 \mathrm{~mm} / \mathrm{r}$, $A=9 \mu \mathrm{m}, \mathrm{WC}$ tool, HPC) 
(a) Range analysis of cutting force with different parameter levels
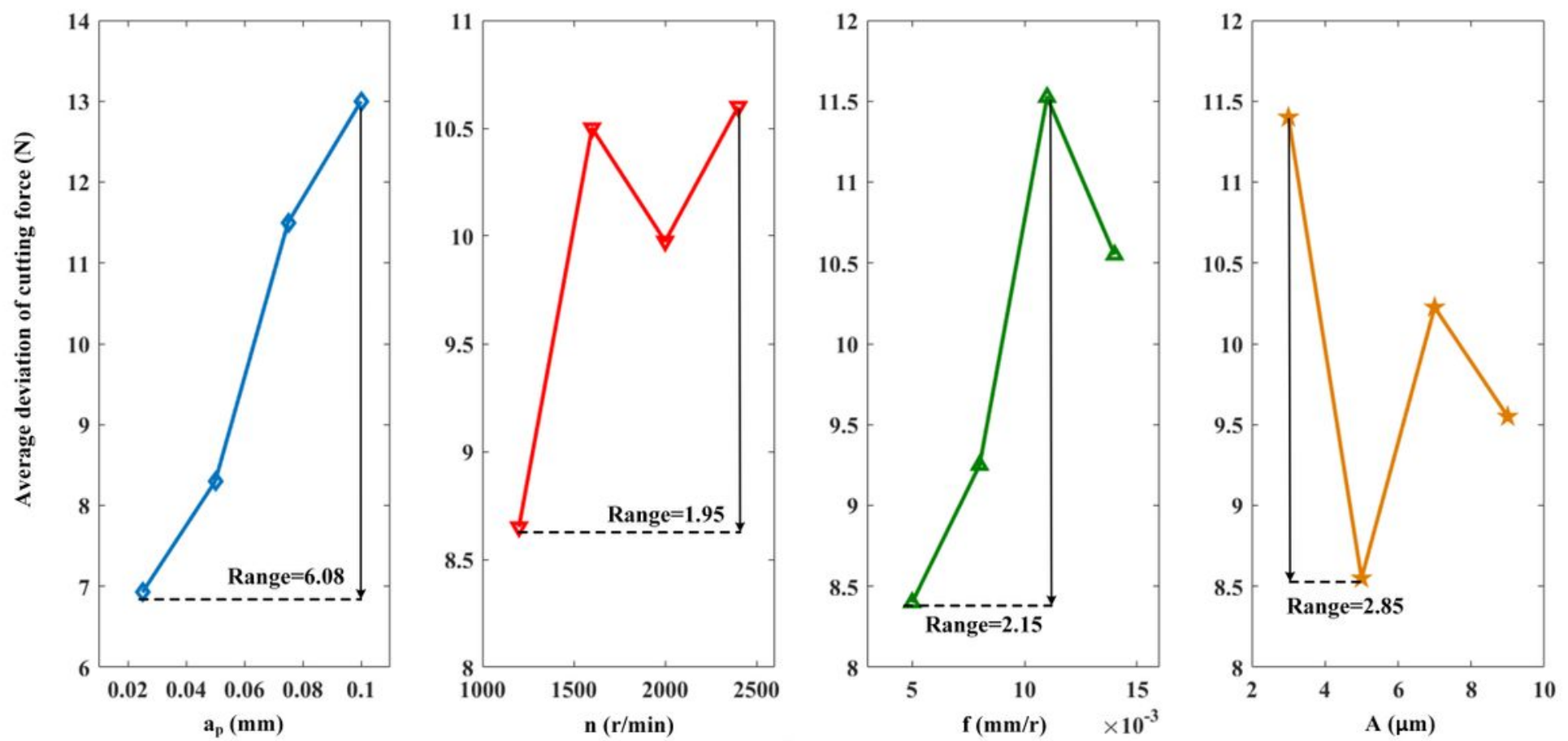

(b) Range analysis of cutting force reduction with different parameter levels
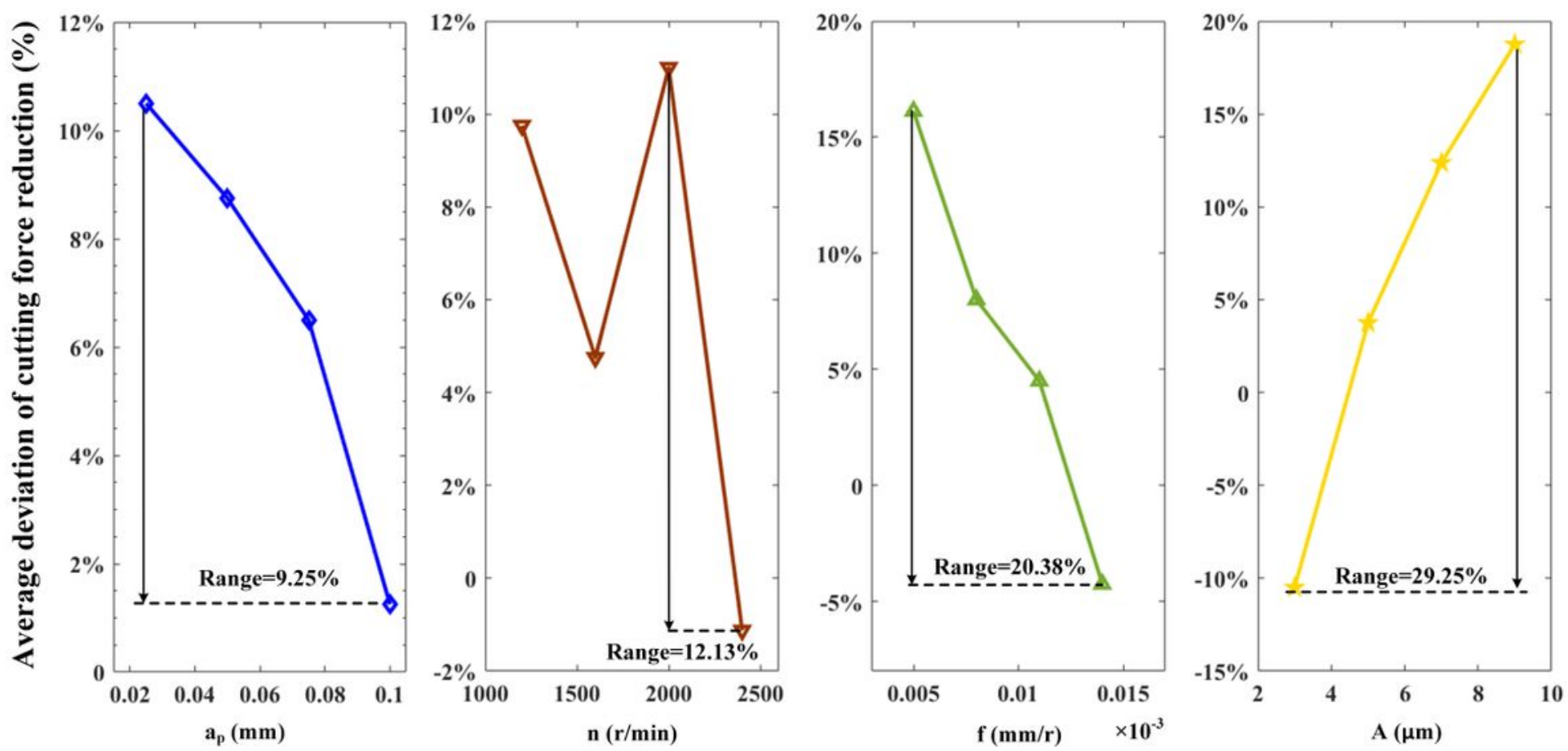

Figure 23

Range analysis of main cutting force and its reduction with different parameter levels 
(a) Range analysis of tool life with different parameter levels
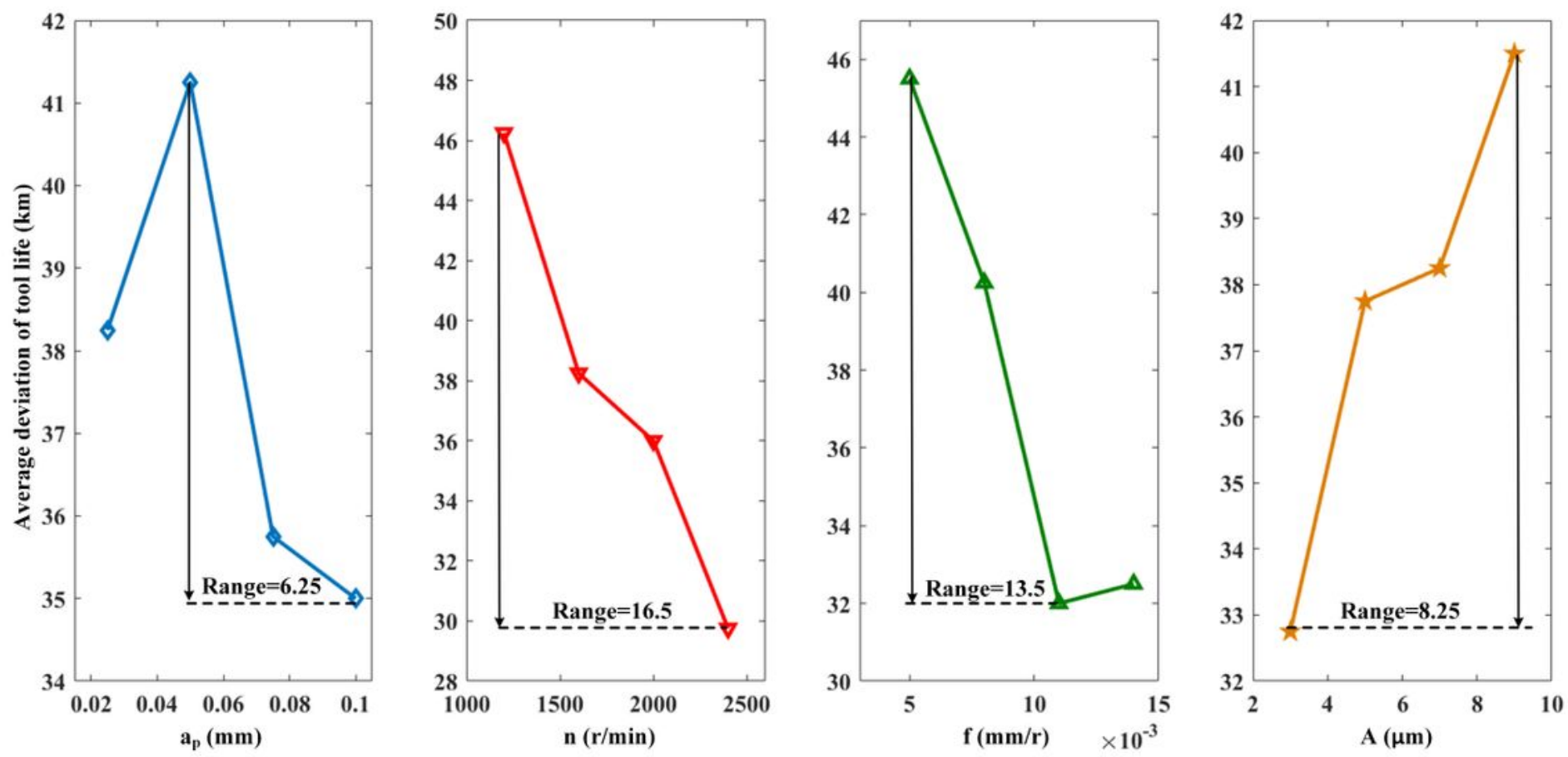

(b) Range analysis of tool life extension with different parameter levels
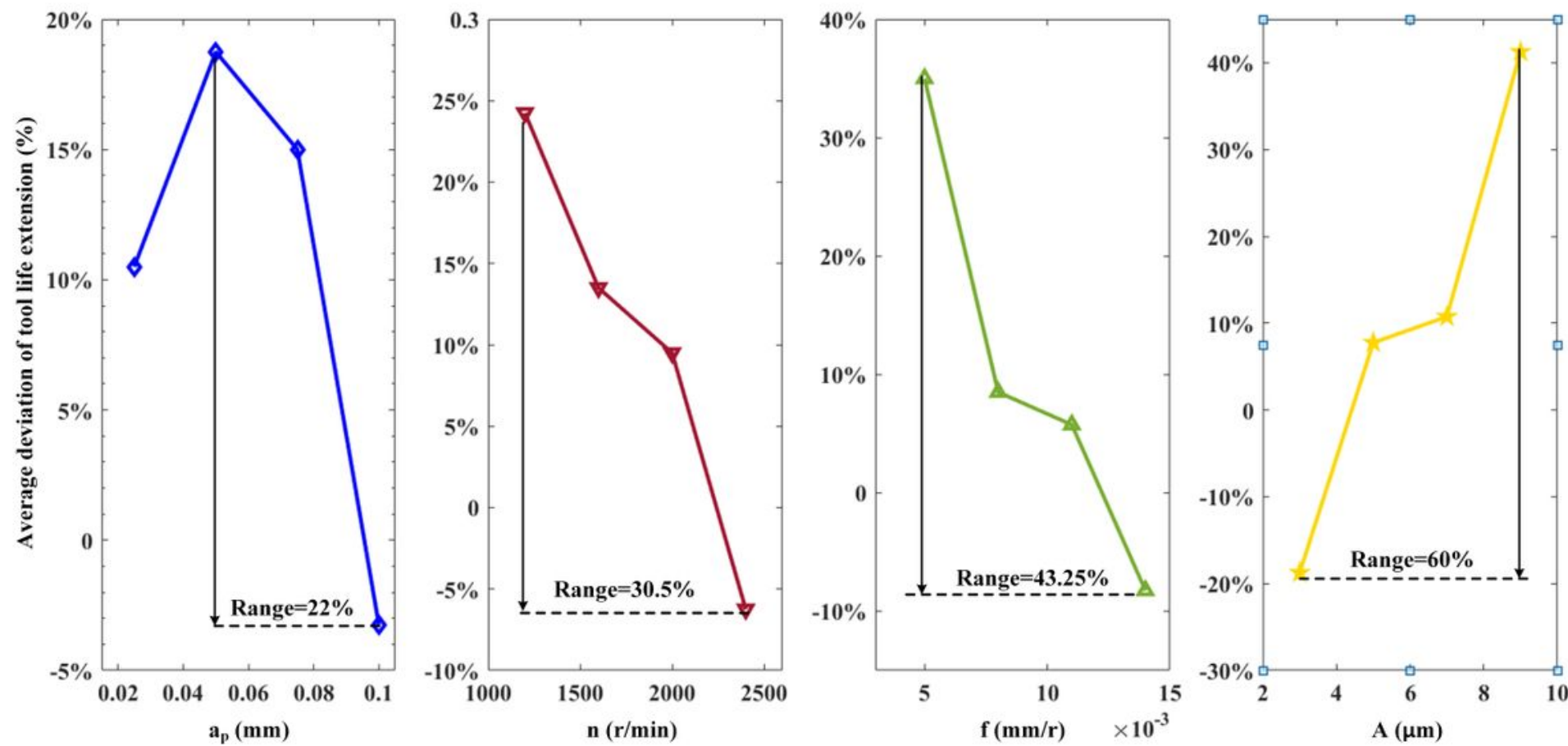

Figure 24

Range analysis of tool life and its extension with different parameter levels 
(a) Range analysis of surface roughness with different parameter levels
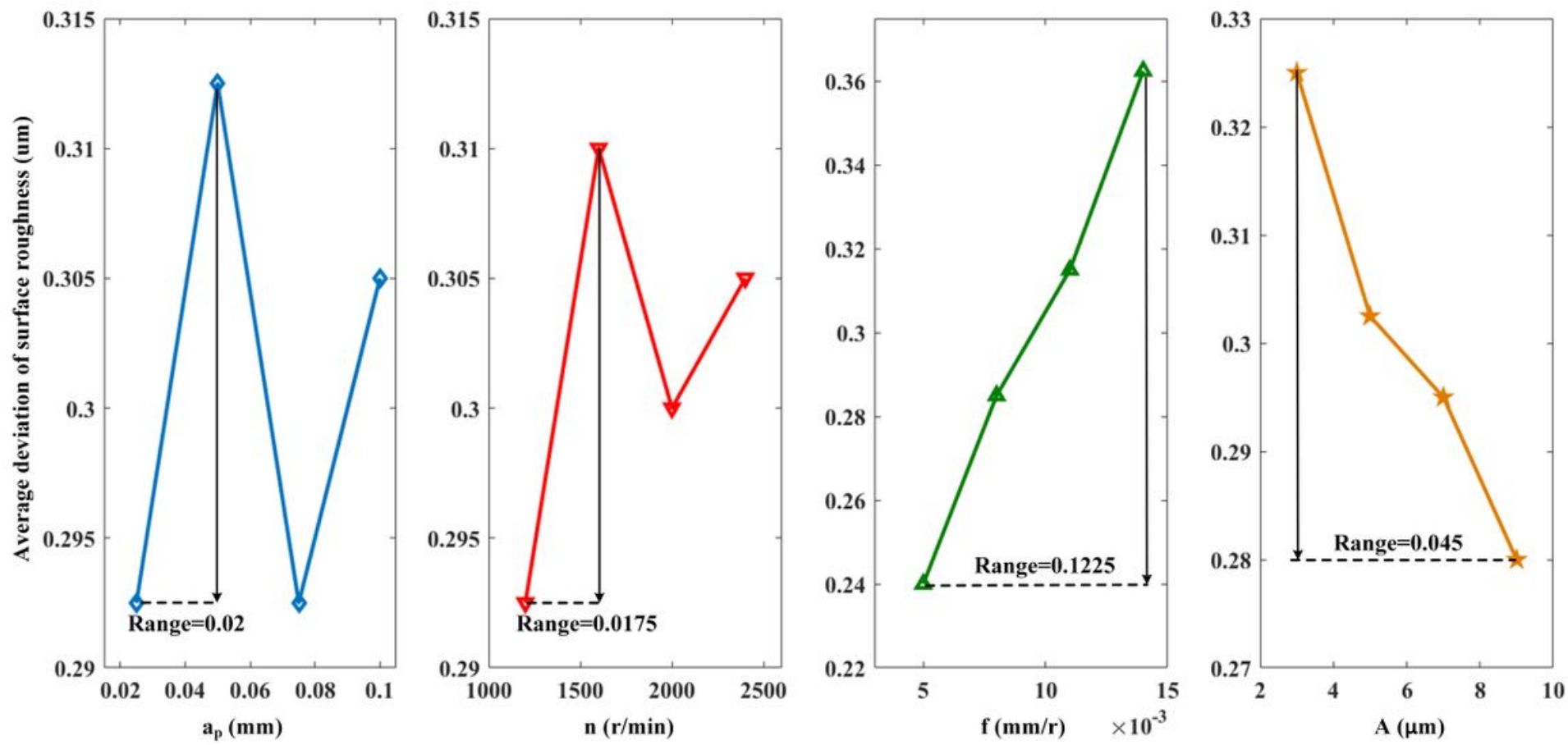

(b) Range analysis of surface roughness reduction with different parameter levels
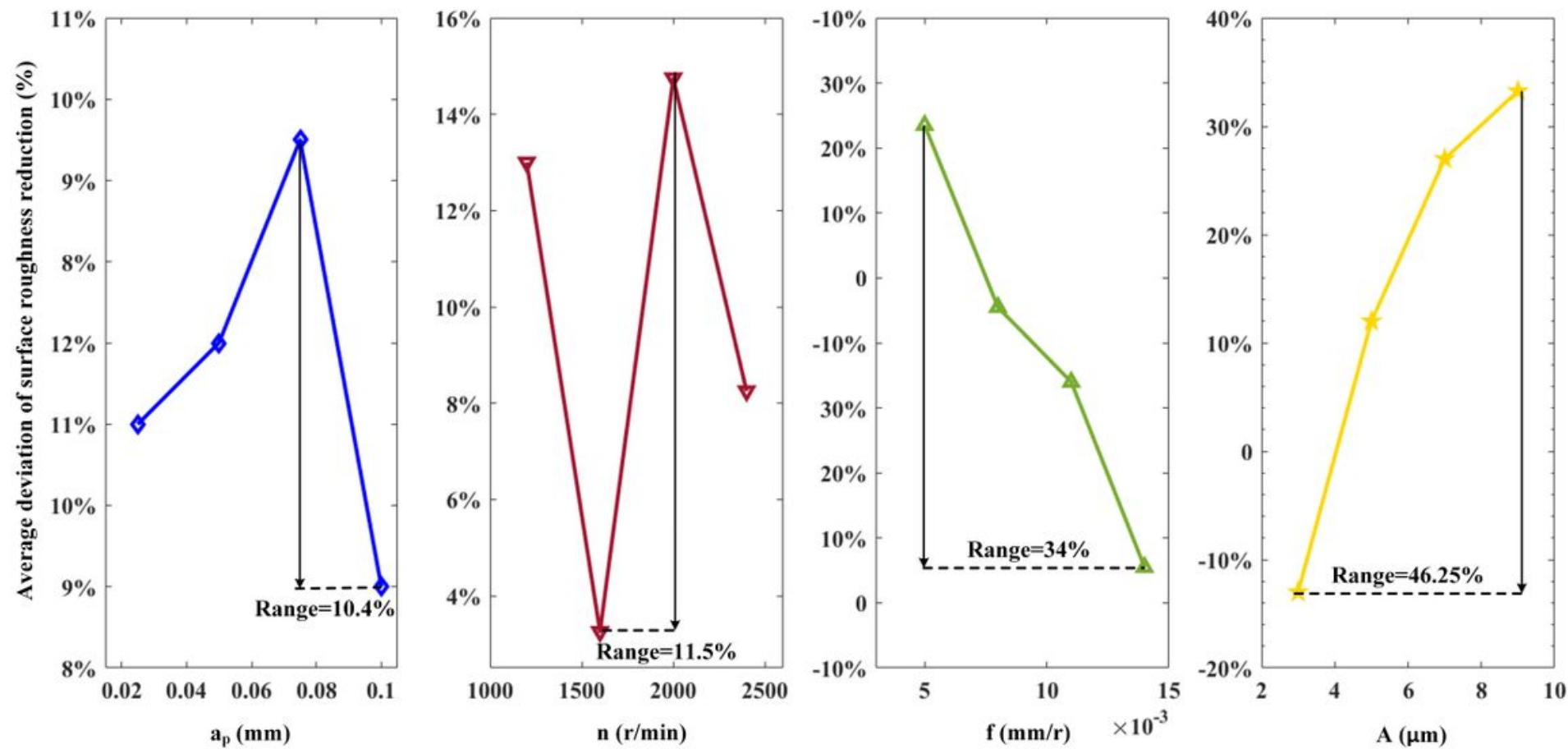

Figure 25

Range analysis of machined surface roughness and its reduction with different parameter levels 